\title{
How Significant is Energy Efficiency to Mitigate CO2 Emissions? Evidence from OECD Countries
}

DOI:

10.1016/j.eneco.2018.04.010

\section{Document Version}

Accepted author manuscript

Link to publication record in Manchester Research Explorer

\section{Citation for published version (APA):}

Tajudeen, I., Wossink, G., \& Banerjee, P. (2018). How Significant is Energy Efficiency to Mitigate CO2 Emissions? Evidence from OECD Countries. Energy Economics, 72, 200-221. https://doi.org/10.1016/j.eneco.2018.04.010

\section{Published in:}

Energy Economics

\section{Citing this paper}

Please note that where the full-text provided on Manchester Research Explorer is the Author Accepted Manuscript or Proof version this may differ from the final Published version. If citing, it is advised that you check and use the publisher's definitive version.

\section{General rights}

Copyright and moral rights for the publications made accessible in the Research Explorer are retained by the authors and/or other copyright owners and it is a condition of accessing publications that users recognise and abide by the legal requirements associated with these rights.

\section{Takedown policy}

If you believe that this document breaches copyright please refer to the University of Manchester's Takedown Procedures [http://man.ac.uk/04Y6Bo] or contact uml.scholarlycommunications@manchester.ac.uk providing relevant details, so we can investigate your claim.

\section{OPEN ACCESS}




\section{Accepted Manuscript}

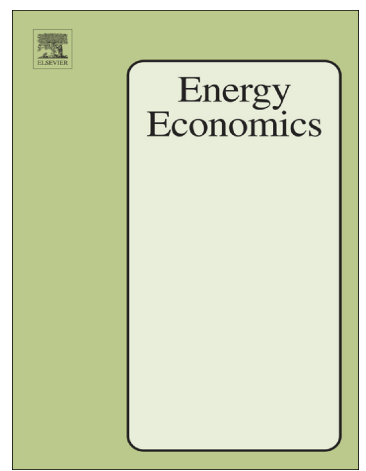

Ibrahim A. Tajudeen, Ada Wossink, Prasenjit Banerjee

PII: $\quad$ S0140-9883(18)30135-X

DOI: $\quad$ doi:10.1016/j.eneco.2018.04.010

Reference: $\quad$ ENEECO 3980

To appear in:

Received date: $\quad 2$ October 2017

Revised date: $\quad 28$ March 2018

Accepted date: $\quad 2$ April 2018

Please cite this article as: Ibrahim A. Tajudeen, Ada Wossink, Prasenjit Banerjee, How Significant is Energy Efficiency to Mitigate CO2 Emissions? Evidence from OECD Countries. The address for the corresponding author was captured as affiliation for all authors. Please check if appropriate. Eneeco(2018), doi:10.1016/j.eneco.2018.04.010

This is a PDF file of an unedited manuscript that has been accepted for publication. As a service to our customers we are providing this early version of the manuscript. The manuscript will undergo copyediting, typesetting, and review of the resulting proof before it is published in its final form. Please note that during the production process errors may be discovered which could affect the content, and all legal disclaimers that apply to the journal pertain. 


\title{
How Significant is Energy Efficiency to Mitigate $\mathrm{CO}_{2}$ Emissions? Evidence from OECD Countries
}

\author{
Ibrahim A. Tajudeen, ${ }^{*, 1}$ Ada Wossink ${ }^{*, 2}$ and Prasenjit Banerjee ${ }^{*, 3}$ \\ *Environmental and Resource Economics, \\ Department of Economics, University of Manchester, M14 5QH, UK
}

\footnotetext{
${ }^{1}$ Corresponding author: E-mail ibrahim.tajudeen@manchester.ac.uk; ibrahimdebisi@gmial.com; Tel.: +447769065096 (I. A. Tajudeen).

${ }^{2}$ Co-author: Email ada.wossink@ manchester.ac.uk ; Tel. +44 (0)161 3066916 (A. Wossink).

${ }^{3}$ Co-author: Email prasenjit.banerjee@ manchester.ac.uk; Tel. +44(0)161 2754804 (P. Banerjee).
} 


\begin{abstract}
This paper develops a two-step approach to investigate the effect of energy efficiency improvements on $\mathrm{CO}_{2}$ emissions at the macro level. We use the index decomposition analysis to derive the true energy efficiency by separating out the impact of structural shifts in economic activity on energy intensity. We then employ both STSM and LSDVC models to examine and quantify the impact of the energy efficiency on $\mathrm{CO}_{2}$ emissions accounting for non-economic factors such as consumers' lifestyle, attitudes and environmental awareness. The application for 30 OECD countries shows that at the group level, the decline in energy intensity predominately occurred due to improvements in energy efficiency while at the country level, there are mixed contributions from improvement in energy efficiency and structural shift to the decline in energy intensity. The econometric results show that income has the most significant positive impact on $\mathrm{CO}_{2}$ emissions but improving energy efficiency makes the biggest contribution to driving down $\mathrm{CO}_{2}$ emissions. The method further enables the separate assessment of non-economic behavioural effects, which are found to exert a non-trivial influence on $\mathrm{CO}_{2}$ emissions in parallel with changes in energy efficiency. We conclude that energy efficiency remains a key option but that there is also a need for additional policies aiming for behavioural and other non-economic changes.
\end{abstract}

Keywords: Energy efficiency; Index decomposition analysis; STSM, bias-corrected LSDV; $\mathrm{CO}_{2}$ emissions; $\mathrm{OECD}$

JEL codes: C22, Q41, Q43 


\section{Introduction}

Economic growth and energy consumption move in tandem with externality problems at both local and global scales. Understanding how to save energy and reduce $\mathrm{CO}_{2}$ emissions is critical for global climate change policies and for providing insights how emerging economies may develop a low emission future.

In general, a country's energy demand changes over time for a variety of reasons: growth in economic output, changes in the structure of production and consumption and in trade structure, efficiency improvements and investments in infrastructure. A key method for understanding the relative contribution of each of these factors to changes in energy demand is decomposition analysis (Boyd et al., 1987; Metcalf, 2008). Existing studies have applied different decomposition techniques to disentangle the impact of a structural shift in economic activity (economic activity index) from the reductions in energy use (energy efficiency index). The resulting energy efficiency index, generally referred to as the 'true' or 'sectoral' energy efficiency, reflects the true energy use per unit of economic output (see e.g. Boyd and Roop, 2004; Choi and Ang, 2003; Inglesi-Lotz and Pouris, 2012 and Zhao et al., 2010).

Index number decomposition studies provide a reliable measure of energy efficiency, and give clarity regarding which determinant (true efficiency index or activity index) has been more important in driving the improvement in energy intensity (see Liu and Ang, 2007 for a survey). It is also safe to conclude from this literature that in the last three decades of the $20^{\text {th }}$ century trends in aggregate energy intensity have been influenced more by energy efficiency change than by changes in the production structure despite differences in data, specific method, scope and sector in the numerous decomposition studies (Mulder, 2015).

While decomposition studies are useful for understanding trends in energy use, they provide limited insight into the effects of energy efficiency and structural shifts in economic activity on a country's level of $\mathrm{CO}_{2}$ emissions. The analysis of macro-economic determinants of pollutant emissions has developed separately, usually with reference to the Environmental Kuznets Curve (EKC) hypothesis and the environment, economy and energy (3E) nexus (Ang, 2007; Grossman and Krueger, 1991; Soytas et al., 2007). The application to $\mathrm{CO}_{2}$ emissions spurred a considerable volume of literature (see e.g., Acaravci and Ozturk, 2010; Dinda, 2004; Pao and Tsai, 2011; Sari and Soytas, 2009; Stern 2004). These studies, however, do not explicitly consider the impact of energy efficiency on $\mathrm{CO}_{2}$ emissions. Some existing studies interpret their results within the context of income, efficiency and composition effects but they rarely provide separate estimates for the magnitudes of these effects (Antweiler et al., 2001). Consequently, there is a research void with regard to both the 
analytics and the empirics of the extent in which energy efficiency improvement can help mitigate $\mathrm{CO}_{2}$ emissions at the macro level. An improved understanding is also of practical importance. Energy efficiency improvement is one of the most cost-effective and most readily scalable options to support sustainable growth and reduce further damage to the climate system and world governments are encouraged to exploit it as a first choice in their energy strategy (e.g., EGEE, 2007).

Our paper contributes to the literature in several ways. Firstly, we integrate insight from two strands of literature; one strand on index number decomposition and another strand on energy and environmental economics on the EKC and the energy-income nexus. Based on these insights we propose a two-step empirical approach to allow for an improved empirical understanding of the impact of energy efficiency on $\mathrm{CO}_{2}$ emissions at country and group levels. In the first step, we undertake detailed energy intensity decomposition to separate the contribution of fundamental improvements in energy efficiency and structural shifts in economic activity to changes in energy intensity. To accomplish this, we employ an index decomposition analysis (IDA) based on the Fisher Ideal Index (Fisher, 1921). In the second step, we use econometric models of a modified dynamic $3 \mathrm{E}$ framework to analyse the impact of the energy efficiency and structural shifts on $\mathrm{CO}_{2}$ emissions controlling for other factors.

Secondly, in order to explore significant heterogeneity among countries, our study employs both structural time series modelling (STSM) developed by Harvey (1989) and panel data modelling, the bias-corrected least square dummy variable (LSDVC) estimator in the second step. Countries are likely to possess (substantial) peculiarity in terms of energy efficiency developments and panel data alone may not appropriately account for the possible energy efficiency heterogeneity among the countries. This may hinder proper inference with regards to the impact of energy efficiency improvement on $\mathrm{CO}_{2}$ emissions. The choice of data approach is also a major source of contention among studies that have examined the EKC hypothesis and the 3E nexus, especially studies that have focused on a group of countries. The different choices may partly account for the inconsistency of the results in the existing literature. Therefore, combining both time series and panel data methods in the same study could offer advantages over a single method, by minimising variations in results and ensuring more reliable policy recommendations.

Thirdly, our approach offers further improvement on the existing literature by clearly indicating not only the impact of key economic drivers on $\mathrm{CO}_{2}$ emissions, but also the impact of exogenous noneconomic factors (ExNEF) such as consumers' tastes, lifestyle, values and preferences, increasing desire and attitude to protect the environment factors. This follows 
from the growing call and attempt to consider the impact of noneconomic factors for a better and clearer understanding of future sustainable consumption and $\mathrm{CO}_{2}$ emissions emanating from energy consumption. Moreover, it has been underscored in a separate strand of literature that the noneconomic factors would be likely to have a significant influence on energy demand and hence, on $\mathrm{CO}_{2}$ emissions (see e.g. Chitnis and Hunt, 2012; Martiskainen, 2008). The STSM allows for the estimation of a stochastic rather that a deterministic underlying carbon emissions trend (UCET). ${ }^{4}$ The UCET is likely to be strongly affected by changes in technology and energy efficiency (if there are no proxies for them in the model) and ExNEF factors, which are not easily measured, but could be influencing $\mathrm{CO}_{2}$ emissions. To the authors' knowledge, there are no such stochastic components developed into a panel data model. Consequently, we follow Adeyemi et al. (2010), Adeyemi and Hunt (2007) and Griffin and Schulman (2005) submission to use time dummies in a panel data model such as the bias-corrected LSDV to effectively capture technical change and other ExNEF.

Lastly, the further aim of this paper is attempt to quantify the relative contributions of the drivers (including ExNEF) of annual changes in $\mathrm{CO}_{2}$ emissions using the preferred models from the econometrics analysis. Some other studies have instead applied decomposition techniques directly to $\mathrm{CO}_{2}$ emissions (or $\mathrm{CO}_{2}$ intensity) to obtain the income, technique (efficiency) and composition (structural) contributions (see e.g. Diakoulaki et al., 2006; Hatzigeorgiou et al., 2008). Although these are worthy early attempts, the approach is purely descriptive. It requires large amount of data and is restrictive concerning the quantification of the contribution of technical progress and behavioural factors (such as ExNEF) to changes in $\mathrm{CO}_{2}$ emissions. Our study, which combines both decomposition and econometric approaches, improves on these earlier attempts.

As far as we know, this study is the first to use these approaches to estimate and quantify the impacts of energy efficiency on $\mathrm{CO}_{2}$ emissions controlling for other key factors including the ExNEF. Through the empirical assessment undertaken, therefore, the three following sub-questions are addressed. What is the true level of energy efficiency across countries? Do energy efficiency and economic factors have long term effects on $\mathrm{CO}_{2}$ emissions when accounting for non-economic factors? To what extent does energy efficiency mitigate the level of $\mathrm{CO}_{2}$ emissions?

We illustrate our approach and answer the questions for the case of the Organization for Economic Co-operation and Development (OECD) and our application is for 1971-2013.

\footnotetext{
${ }^{4}$ Studies that adopt STSM for analysing energy demand models named the stochastic trend as underlying energy demand trend (UEDT) (see e.g. Adeyemi et al., 2010; Hunt et al., 2003). Accordingly, we refer to it as underlying carbon emission trend (UCET).
} 
A number of factors make OECD countries relevant for this study. Almost all OECD countries belong to Annex I parties under the Kyoto protocol with legally binding targets for $\mathrm{CO}_{2}$ emissions reduction ${ }^{5}$ and they have signed to the Paris agreement on the reduction of climate change. ${ }^{6}$ Moreover, there has been a downward trend in the OECD energy intensity index (see World Bank, 2016). Analysing the main drivers of the changes in energy intensity and the impact of these drivers on $\mathrm{CO}_{2}$ emissions will be instructive for energy policymaker aiming to improve the environmental sustainability of energy use.

We continue as follows. Sections 2 and 3 present the methodology and data sources respectively. The empirical results are in section 4 . Section 5 offers concluding remarks.

\section{Methodology}

This section gives details of a two-step estimation procedure used in this study. The first step uses an index decomposition analysis based on the Fisher Ideal index to decompose the changes in energy intensity index into structural shift index and energy efficiency index. The second step uses both time series and panel data econometric models of a modified $3 \mathrm{E}$ framework to determine and quantify the impact of energy efficiency improvement on $\mathrm{CO}_{2}$ emissions in the light of the economic and other exogenous noneconomic factors.

\subsection{Energy intensity decomposition analysis}

Several decomposition methods have served as useful tools for identifying the contributions from different underlying factors to changes in energy intensity. Hoekstra and Van der Berg (2003) distinguished these methods in two categories - the structural decomposition analysis (SDA) and the index decomposition analysis (IDA). The SDA makes use of the input-output method to decompose improvements in energy intensity, whereas IDA (also known as the disaggregation technique) can be applied to data available at any level of aggregation or/and available in time series format. In other words, the major difference between these two methods is the type of data that are used. Although SDA has a major advantage over IDA for distinguishing indirect effects, such as technical effects, from direct effects, it requires more disaggregated data. Owing to the lack of energy data in an input-output format, researchers often use the IDA methods (Inglesi-Lotz and Pouris, 2012).

\footnotetext{
${ }^{5}$ The Kyoto protocol targets commit developed countries (as a group) to curb domestic emissions by $5 \%$ relative to the 1990 level in the $1^{\text {st }}$ commitment period 2008 - 2012. A second commitment period, the Doha Amendment to the Kyoto protocol, was agreed on in 2012 and parties committed to reduce GHG emissions by at least $18 \%$ below 1990 levels in the 8 years period 2013-2020 but the composition of parties in the second commitment period is different from the first. (UNFCC, available at: www.unfccc.int).

${ }^{6}$ The Paris Agreement (PA), starting in the year 2020, aims to strengthen the global response to the threat of climate change by keeping a global temperature rise to well below $2^{\circ} \mathrm{C}$ above pre-industrial levels and to pursue efforts to limit the temperature increase even further to $1.5^{\circ} \mathrm{C}$. The PA went into effect on 4 November 2016 after the threshold for entry into force was achieved on 5 October 2016. As of March 2017, 194 members have signed the treaty, 143 of which have ratified it (UNFCC, available at: www.unfccc.int).
} 
Within the IDA approach, the Fisher Ideal Index (Fisher, 1921) and Logarithmic Average Divisia Index (LMDI) are usually preferred for their desirable properties such as the ability to give perfect decomposition without unexplained residuals, consistency in aggregation and satisfying the basic index theory properties such as the time reversal and proportionality (Boyd and Roop, 2004). Following Metcalf (2008), this study decomposes energy intensity using IDA that is based on the Fisher Ideal Index (FII) as follows.

Denoting $E_{t}$ as the total energy consumption; $Y_{t}$ as the total output; $E_{i t}$ and $Y_{i t}$ are the total energy consumption and measure of economic activity (e.g. value added to output) for sector $i$ in year $t$ repectively. Aggregate energy intensity $\left(e_{t}\right)$ can be written as the weighted average of sectoral energy intensity, where weights are output share of the sectors. Explicitly,

$$
e_{t}=\frac{E_{t}}{Y_{t}}=\sum_{i}\left(\frac{E_{i t}}{Y_{i t}}\right)\left(\frac{Y_{i t}}{Y_{t}}\right)=\sum_{i} e_{i t} s_{i t}
$$

Eq. (1) shows that aggregate energy intensity is equal to the sum of the products of energy intensity within a given sector $\left(e_{i t}\right)$ and changes in the structure of the economy $\left(s_{i t}\right)$ across sectors. The energy intensity index $\left(I_{t}\right)$ is then constructed by dividing the energy intensity in year $t\left(e_{t}\right)$ by the energy intensity in a base year $\left(e_{0}\right)$ as $I_{t}=e_{t} / e_{0}=\sum_{j} e_{i t} s_{i t} / \sum_{j} e_{0} s_{i 0}$.

Following Diewert (2001), if we can distinguish sectors that account for all of the energy use in the economy (without overlap) and there exists a set of economic activities measures $\left(Y_{i t}\right)$ with which to create a measure of sectoral energy intensity $\left(e_{i t}\right)$, then we can decompose the energy intensity index $\left(I_{t}\right)$ into an efficiency index $\left(D_{t}^{E F F}\right)$ and an activity index $\left(D_{t}^{A C T}\right)$. The efficiency index therefore attributes energy intensity to efficiency change holding the economic activity constant, and the activity index attributes energy intensity to structural changes in economic activities holding efficiency within a sector constant (Moshiri and Duah, 2016). Specifically,

$$
I_{t}=\frac{e_{t}}{e_{0}}=D_{t}^{E F F} \times D_{t}^{A C T}
$$

To arrive at the decomposed intensity index (Eq. 2), the below Laspeyres and Paasche indices that use a base period fixed weight and an end period fixed weight respectively can be used.

$$
\text { Laspeyres: } L_{t}^{E F F}=\frac{\sum_{i} e_{i t} s_{i 0}}{\sum_{i} e_{i 0} S_{i 0}} ; L_{t}^{A C T}=\frac{\sum_{i} e_{i 0} S_{i t}}{\sum_{i} e_{i 0} S_{i 0}} ; \text { Paasche: } P_{t}^{E F F}=\frac{\sum_{i} e_{i t} S_{i t}}{\sum_{i} e_{i 0} S_{i t}} ; P_{t}^{A C T}=\frac{\sum_{i} e_{i t} s_{i t}}{\sum_{i} e_{i t} S_{i 0}}
$$

The two indices however might give different decompositions as they use different base year (Moshiri and Duah, 2016) and/or give residual terms which could account for a considerable degree of the variability in the underlying index of energy intensity change (Metcalf, 2008). 
The Fisher Ideal Index (Fisher, 1921) and Log Mean Divisia index (Ang, 2004) are developed to overcome the underlined setbacks by decomposing the energy intensity perfectly into an efficiency index and activity index with no unexplained residuals. Specifically, the Fisher Ideal Index uses the weighted average of the Laspeyres and Paasche indices to derive the efficiency index $F_{t}^{E F F}$ and activity index $F_{t}^{A C T}$ as follows:

$$
F_{t}^{E F F}=\left(L_{t}^{E F F} \times P_{t}^{E F F}\right)^{1 / 2} ; \quad F_{t}^{A C T}=\left(L_{t}^{A C T} \times P_{t}^{A C T}\right)^{1 / 2}
$$

As in Eq. (2), the energy intensity index is then given as the product of the two indices as: ${ }^{7}$

$$
I_{t}=\frac{e_{t}}{e_{0}}=F_{t}^{E F F} \times F_{t}^{A C T}
$$

Using Eq. (3) and denoting energy savings $\left(\Delta E S_{t}\right)$ in year $t$ due to an improvement in energy intensity as $\Delta E S_{t}=E_{t}-\widehat{E}_{t}$, we can also separate changes in energy savings resulting from improvements in energy efficiency and structural shifts in the economy as:

$$
\Delta E S_{t}=\Delta E S_{t}\left(\frac{\ln \left(F_{t}^{E F F}\right)}{\ln \left(I_{t}\right)}\right)+\Delta E S_{t}\left(\frac{\ln \left(F_{t}^{A C T}\right)}{\ln \left(I_{t}\right)}\right)=\Delta E S_{t}^{E F F}+\Delta E S_{t}^{A C T}
$$

where $E_{t}$ is the actual energy use and $\hat{E}_{t}$ is the energy that would have been used had energy intensity remained at a base-year level.

Using more disaggregated data that accounts for all of the likely changes in economic activities helps to improve the reliability of the decomposition analysis. Many studies that have applied this method, however, are constrained by data limitations. ${ }^{8}$ This study will decompose along 7 key sectors - mining, manufacturing, construction, transport, agriculture, commercial, and residential that account for all of the energy use in the OECD countries with average shares of $11.5 \%, 30.5 \%, 0.7 \%, 23.7,3 \%, 9.9 \%$ and $20.8 \%$ respectively.

\subsection{Determinants of the changes in $\mathrm{CO}_{2}$ emissions}

The decomposition analysis above is purely a descriptive exercise. Although it shows how energy intensity has changed over time and the share of the changes attributed to energy efficiency improvements, it does not show the impact of the efficiency improvement on $\mathrm{CO}_{2}$ emissions. To study this impact, we next present an analysis of the impact of the decomposed indexes on $\mathrm{CO}_{2}$ emissions, exploring the link between (energy demand and efficiency) and (energy demand and emissions) in a time series and panel data framework.

\footnotetext{
${ }^{7}$ Similarly, the Log Mean Divisia Index uses a log mean weight function to derive the efficiency $L_{t}^{E F}$ and activity $L_{t}^{A C T}$ indices as $L_{t}^{E F}=\exp \left[\sum_{i}\left\langle L\left(\frac{E_{i t}}{Y_{t}}, \frac{E_{i t}}{Y_{0}}\right) / L\left(e_{t}, e_{0}\right)\right\rangle \ln \left(\frac{e_{i t}}{e_{i 0}}\right)\right] \quad$ and $L_{t}^{A C T}=\exp \left[\sum_{i}\left\langle L\left(\frac{E_{i t}}{Y_{t}}, \frac{E_{i t}}{Y_{0}}\right) / L\left(e_{t}, e_{0}\right)\right\rangle \ln \left(\frac{s_{i t}}{s_{i 0}}\right)\right]$ respectively, where function $L(a, b)$ is the logarithmic average of two positive numbers $a$ and $b$ given by the expression: $L(a, b)=\left\{\begin{array}{l}a-b /(\ln a-\ln b), \text { if } a \neq b \\ \text {. }\end{array}\right.$

${ }^{8}$ E.g., Metcalf (2008) and Oseni (2011) decomposed along 4 sectors for 46 US states and 16 OECD countries respectively; Moshiri and Duah (2016) decomposed along 7 sectors for 10 Canadian provinces.
} 


\subsubsection{Time series model}

The link between energy efficiency and energy consumption can be established directly but the link between energy efficiency and $\mathrm{CO}_{2}$ emissions can only be mediated through changes in energy consumption. Thus, we derive the framework for analysing the impact of energy efficiency improvements on $\mathrm{CO}_{2}$ emissions by combining the two following links.

First, following Adetutu et al. (2016) and Broadstock and Hunt (2010) energy use is presented as a direct dependant on energy efficiency controlling for other variables as:

$$
E_{t}=\pi_{0}+\pi_{1} E F F_{t}+\pi_{2} Y_{t}+\boldsymbol{\tau}^{\prime} Z_{t}+\varepsilon_{t}
$$

where $E_{t}$ is energy use per capita; $E F F_{t}$ is the measure of energy efficiency; $Y_{t}$ is income per capita, $\boldsymbol{Z}_{t}$ is a vector consisting of other relevant covariates and $\varepsilon_{t}$ is the error term.

Secondly, $\mathrm{CO}_{2}$ emissions is presented as a direct dependant on energy use following Ang (2007), which combined the EKC and energy-income hypotheses to achieve the multivariate $(3 \mathrm{E})$ framework that facilitates the study of the link between $\mathrm{CO}_{2}$ emissions, energy use and economic growth as follows: ${ }^{9}$

$$
C O 2_{t}=\vartheta_{0}+\vartheta_{1} Y_{t}+\vartheta_{2} Y_{t}^{2}+\vartheta_{3} E_{t}+\varepsilon_{t}
$$

where $\mathrm{CO}_{t}$ is $\mathrm{CO}_{2}$ emission per capita; $Y_{t}^{2}$ is the square of income per capita and other variables are as defined in Eq. (5). Extant studies use $\vartheta_{1}$ and $\vartheta_{2}$ to test for the EKC hypothesis and if the hypothesis holds, they give interpretations in terms of efficiency and composition impacts without actually providing estimates for these components. Arguably, increases in income only necessarily translate to environmental improvements if channelled to improve energy efficiency and/or when spent on more environmentally friendly energy sources. A better approach to estimating the actual impacts of income improvements on the environment would be to get a true measure of actual energy used per economic output (i.e. the measure for energy efficiency). We could then examine the effect on $\mathrm{CO}_{2}$ emissions rather than relying on the income threshold as captured by the estimate of $\vartheta_{2}$ in Eq. (6).

Based on the above and the exposition from section (2.1), we derive a model for analysing the impact of energy efficiency improvement from domestic output on $\mathrm{CO}_{2}$ emissions by substituting Eq. (5) in Eq. (6) to arrive at the following:

$$
C O 2_{t}=\phi_{0}+\alpha_{0} Y_{t}+\beta_{0} E F F_{t}+\gamma_{0} E F F_{t}^{2}+\varphi_{0} A C T_{t}+\Phi_{0} A C T_{t}^{2}+\psi_{0} C E S_{t}+\omega_{0} T O_{t}+\varepsilon_{t}
$$

where $E F F_{t}$ is proxied by the energy efficiency index derived from IDA in subsection 2.1.

\footnotetext{
${ }^{9}$ Some of the extant studies that have empirically estimated the 3E framework include: Acaravci and Ozturk (2010) for 19 European countries; Apergis and Payne (2010) for 11 Commonwealth Independent States; Hatzigeorgiou et al. (2011) for Greece; Iwata et al. (2010) for 11 OECD countries; Saboori and Sulaiman (2013) for 5 Association of Southeast Asian Nations; Soytas et al. (2007) for U.S.
} 
Consistent with some of existing studies on the $3 \mathrm{E}$ nexus, we control for the impact of changes in structural composition of the economy, cleaner energy substitution and openness of the economy to trade captured by $A C T_{t}, C E S_{t}$ and $T O_{t}$ respectively to avoid omission bias. ${ }^{10}$ Moreover, the relationship between $\mathrm{CO}_{2}$ emissions and energy efficiency may be nonlinear. Countries that are energy inefficient may improve over time and become more efficient. There could also be a declining return to improving energy efficiency (in terms of smaller marginal reductions in $\mathrm{CO}_{2}$ emissions over time), which would mean a nonlinear effect. Thus, we hypothesized that the nonlinear effect is a-priori ambiguous and can be determined empirically by adding the squared term of the energy efficiency index $E F F_{t}^{2}$ in the model. ${ }^{11}$ We use a similar analogy to include the squared term of the activity index $A C T_{t}^{2}$.

Eq. (7) is a static model and as such, it assumes the response of $\mathrm{CO}_{2}$ emissions to changes in any of the explanatory variables to be immediate. In reality, $\mathrm{CO}_{2}$ emissions may require some time to adjust to improvements in energy efficiency or shifts in the composition of the economy. Similarly, the previous level of $\mathrm{CO}_{2}$ emissions may instigate stringent policy to mitigate future $\mathrm{CO}_{2}$ emissions and the erstwhile energy efficiency achieved may have spill over effects on subsequent $\mathrm{CO}_{2}$ emissions. In this context, we adopt a dynamic model, starting with two-lagged dependent and independent variables, i.e. $\operatorname{ARDL}(2,2) .^{12}$

Lastly, we introduce an underlying carbon emissions trend (UCET) $\mu_{t}$ into the model. Also note that in Eq. (7) we separate out the effect of technical progress and energy efficiency from the UCET by incorporating an appropriate proxy variable for energy efficiency. Arguably, the estimated UCET, which could be stochastic or deterministic, should thus only pick up the effects of other noneconomic factors; hence, it is assumed to capture the effect of exogenous changes in such factors as societal preferences, lifestyle, values, attitudes and peoples' environmental awareness (see Broadstock and Hunt, 2010; Chitnis and Hunt, 2012). Considering all these factors together, we therefore restate Eq. (7) as follows:

$$
\begin{gathered}
c o 2_{t}=\mu_{t}+\sum_{j=0}^{2} \alpha_{j} y_{t-j}+\sum_{j=0}^{2} \beta_{j} e f f_{t-j}+\sum_{j=0}^{2} \gamma_{j} e f f_{t-j}^{2}+\sum_{j=0}^{2} \varphi_{j} a c t_{t-j}+\sum_{j=0}^{2} \Phi_{j} a c t_{t-j}^{2} \\
+\sum_{j=0}^{2} \psi_{i} C E S_{t-j}+\sum_{j=0}^{2} \omega_{j} T O_{t-j}+\sum_{j=1}^{2} \lambda_{j} c o 2_{t-j}+\varepsilon_{t}
\end{gathered}
$$

\footnotetext{
${ }^{10}$ We proxy changes in the structural composition of the economy by activity index derived from Eq. (3), cleaner energy substitution by alternative and nuclear energy as \% of total energy use (see also footnote 22) and trade openness by trade (export + import) as \% of GDP. ${ }^{11}$ If follows that, if a country is having a declining energy efficiency index and we found $\beta_{0}>0$ and $\gamma_{0}<0$ in Eq. (7), then energy efficiency index forms a $U$-shape relationship with $\mathrm{CO}_{2}$ emissions after a given minimum. In contrast, if the country is having an increasing energy efficiency index and we found $\beta_{0}>0$ and $\gamma_{0}<0$, then the non-linear effect forms an inverted U-shape after a given threshold.

${ }^{12}$ Given the length of our data, the lags are limited to two to avoid losing many degrees of freedom.
} 
All the variables are in natural log, with the exception of the cleaner energy substitution and trade openness, which are in percentages.

With Eq. (8), the short- and long- run elasticities of the regressors with respect to $\mathrm{CO}_{2}$ emissions can be estimated together. ${ }^{13}$ However, with the introduction of the unobservable component $\mu_{t}$, if it is found to be stochastic, it will render common estimators such as OLS biased and inconsistent. The structural time series model (STSM) developed by Harvey (1989) helps to overcome this problem. The STSM combined with ARDL is simple to comprehend. The order of integration of the variables is not very crucial for STSM and allows the trend component $\mu_{t}$ in the model to vary stochastically over time (Amarawickrama and Hunt, 2008).

With the STSM, the trend $\mu_{t}$ is assumed to have the following stochastic process:

$$
\begin{array}{ll}
\mu_{t}=\mu_{t-1}+\varrho_{t-1}+\eta_{t} \bigcirc \eta_{t} \sim \operatorname{NID}\left(0, \sigma_{\eta}^{2}\right) \\
\varrho_{t}=\varrho_{t-1}+\xi_{t} & \xi_{t} \sim N I D\left(0, \sigma_{\xi}^{2}\right)
\end{array}
$$

The trend includes a level (Eq. 9), defined as the trend in past period plus a growth term; a slope (Eq. 10) generated by a random walk; $\eta_{t}$ and $\xi_{t}$ are white noise disturbance term. ${ }^{14}$ The hyperparameters (i.e., $\sigma_{\eta}^{2}$ and $\sigma_{\xi}^{2}$ ) values determine the nature of the stochastic trend. Thus, this gives a number of alternative forms of the stochastic trend and in the limiting case $\sigma_{\eta}^{2}=$ $\sigma_{\xi}^{2}=0$, the model collapses to a conventional deterministic time trend regression. ${ }^{15}$ The likelihood ratio $(L R)$ test can be used to determine whether the hyperparameters are actually equal to zero. ${ }^{16}$ Also the inclusion of irregular, level and slope interventions in $\mu_{t}$ gives information about possible structural breaks at certain periods of the estimation (Harvey and Koopman, 1992; Hunt et al., 2003, Broadstock and Hunt, 2010). ${ }^{17}$

The Maximum Likelihood procedure in conjunction with the Kalman filter is used to estimate the general STSM-ARDL $(2,2)$ function, consisting of Eqs (8) - (10) in STAMP 8.2 software (Koopman et al., 2009). The general model is considered initially and the preferred parsimonious specification of the model found by testing down and eliminating insignificant variables while ensuring that the model passes a range of diagnostic tests.

\footnotetext{
${ }^{13}$ E.g., the short- and long-run income elasticities are given as $\alpha_{0}$ and $\sum_{j=0}^{2} \alpha_{j} /\left(1-\sum_{j=1}^{2} \lambda_{j}\right)$ respectively

${ }^{14}$ An important assumption for these models is that the three error terms $\varepsilon_{t}, \eta_{t}$ and $\xi_{t}$ are independent and uncorrelated.

${ }^{15}$ I.e., the UCET component in Eq. (8) collapses to $\mu_{t}=\phi_{0}+b t$; where $\phi_{0}$ is the constant in Eq. (7) and $t$ is a linear time trend

${ }^{16}$ Given that the restriction is on the hyper-parameters, an $L R$ test expressed as $L R_{(r)}=-2\left(L L_{R}-L L_{U}\right) \sim \chi_{r}^{2}$ is suitable to test the validity of the restriction. Where $L L_{U}$, is the log-likelihood value for the unrestricted model; $L L_{R}$ is the log-likelihood value for the restricted model and $r$ is the number of restrictions imposed on the hyper-parameters.

${ }^{17}$ The UCET in this case is given as UCET $=\mu_{t}+$ level interventions + slope interventions + irregular interventions. If none of the interventions are significant then $U C E T=\mu_{t}$.
} 


\subsubsection{Panel data model}

Using exposition similar to that for deriving the time series model Eq. (7), we present the panel data model as follows:

$$
\begin{aligned}
c o 2_{n t}=\phi_{0}+ & \alpha_{0} y_{n t}+\beta_{0} e f f_{n t}+\gamma_{0} e f f_{n t}^{2}+\varphi_{0} a c t_{n t}+\Phi_{0} a c t_{n t}^{2}+\psi_{0} C E S_{n t}+\omega_{0} T O_{n t} \\
& +\theta_{t} D_{t}+u_{n t}
\end{aligned}
$$

where $n=1,2, \ldots, N$ is each country in the panel; $t=1,2, \ldots, T$ refers to the period; the composite error $u_{n t}=v_{n}+\Omega_{n t}$ where $v_{n}$ is the unobservable country-specific effects; $\Omega_{n t}$ is the idiosyncratic error term and the definitions of other variables are as above.

Several facts are noteworthy of Eq. (11). First, as mentioned in Section 1, we include time dummies $D_{t}$ to capture the impact of ExNEF in line with Adeyemi et al. (2010), Adeyemi and Hunt (2007) and Griffin and Schulman (2005) that time dummies are a good proxy for ExNEF in a panel model. Secondly, since $c o 2_{i t}$ is a function of $v_{n}$, which is time invariant, it follows that the inclusion of $c o 2_{n t-1}$ as one of the regressors in Eq. (11) will correlate with $u_{n t}$ which contains $v_{n}$ rendering an ordinary least square (OLS) biased and inconsistent. The fixed effect or least square dummy variable (LSDV) estimator which eliminates $v_{n}$ through within transformation does not completely solve the problem. ${ }^{18}$

A common method to solve this problem is to take the first difference of Eq. (11) to eliminate $v_{n}$ via either an instrumental variable approach (e.g., Anderson and Hsiao, 1982) or a generalized method of moments (GMM) estimator (e.g., Arellano and Bond, 1991; Arellano and Bover, 1995; Blundell and Bover, 1998). However, the basic properties of GMM estimators hold for small $T$, large $N$ panels. The number of instruments in GMM tends to explode with $T$ and biases the estimates towards those of the OLS (Roodman, 2009). Consequently, the application of the GMM estimators to a small cross-section or large $T$, as in the present study, may bias the estimated parameters and standard errors.

Kiviet (1995) proposes an alternative approach that directly corrects the bias of LSDV. The study uses dynamic panel data with $T \leq 20$ and $N \leq 50$ in a Monte Carlo analysis to show that the Anderson-Hsiao and the Kiviet - corrected LSDV estimator (LSDVC) are better than the GMM estimator in this circumstance. Judson and Owen (1999) use a similar method to Kiviet (1995) to simulate data with qualities normally encountered by macroeconomists, a large time dimension. Their results show that in a balanced long panel, the LSDVC is the best option, and Anderson and Hsiao's approach performs well too.

\footnotetext{
${ }^{18}$ For details of this discussion, see e.g., Baltagi (2008), Filippini (2011), Nickell (1981) and Roodman (2009).
} 
Following the exposition from these studies and the nature of our panel data (i.e. large $\mathrm{T}$ and small $\mathrm{N}$ ), our preferred estimator for the determinants of $\mathrm{CO}_{2}$ emissions in a dynamic panel model is the LSDVC estimator. Prior to this estimation, we estimate the static model (Eq. 11) using either LSDV or RE as a benchmark for the dynamic model. Besides, since the LSDVC is designed for a dynamic panel model with one lagged-dependent variable, the dynamic version of Eq. (11) to be estimated is stated as follows:

$$
\begin{aligned}
c o 2_{n t}=\phi_{0}+ & \alpha_{0} y_{n t}+\beta_{0} e f f_{n t}+\gamma_{0} e f f_{n t}^{2}+\varphi_{0} a c t_{n t}+\Phi_{0} a c t_{n t}^{2}+\psi_{0} C E S_{n t}+\omega_{0} T O_{n t} \\
& +\theta_{t} D_{t}+\lambda_{0} c o 2_{n t-1}+u_{n t}
\end{aligned}
$$

where $\mathrm{co}_{n t-1}$ is the first lag of $\mathrm{CO}_{2}$ emissions, and the definitions of other variables are as in Eq. (11). The panel models specified in Eqs (11) and (12) may be prone to other econometric issues (such as endogeneity and cross-section dependence), we discuss and test for these issues in subsection 4.3. The estimations are conducted in STATA 14 software.

\subsubsection{Contributions of the drivers to annual changes in $\mathrm{CO}_{2}$ emissions}

As mentioned in section 1, we aim to examine not only the link between the regressors (including energy efficiency improvements) and $\mathrm{CO}_{2}$ emissions, but to quantify their relative contributions to the annual change in $\mathrm{CO}_{2}$ emissions. The first aim is achieved by estimating the coefficients of Eqs (8) and (12) for the time series and panel data respectively. For the second aim, if the preferred parsimonious model does not include any lags, the relative contributions are easily calculated using the procedure in Broadstock and Hunt (2010) as:

$$
\Delta \widehat{c o 2}_{t}=\Delta \hat{\mu}_{t}+\hat{\alpha}_{0} \Delta y_{t}+\hat{\beta}_{0}^{*} \Delta e f f_{t}+\hat{\varphi}_{0}^{*} \Delta a c t_{t}+\widehat{\psi}_{0} \Delta C E S_{t}+\widehat{\omega}_{0} \Delta T O_{t}
$$

where $\hat{\alpha}_{0}, \hat{\beta}_{0}^{*}, \hat{\varphi}_{0}^{*}, \hat{\varphi}_{0}$, and $\widehat{\omega}_{0}$ are the estimated impacts from income, efficiency, structural shift, cleaner energy substitution and openness respectively, and $\hat{\mu}_{t}$ is the estimated UCET. ${ }^{19}$ Thus, $\hat{\alpha}_{0} \Delta y_{t}, \hat{\beta}_{0}^{*} \Delta e f f_{t}, \hat{\varphi}_{0}^{*} \Delta a c t_{t}, \hat{\varphi}_{0} \Delta C E S_{t}, \widehat{\omega}_{0} \Delta T O_{t}$ and $\Delta \hat{\mu}_{t}$ represent the estimated relative contributions to changes in $\mathrm{CO}_{2}$ emissions from the corresponding variables respectively. ${ }^{20}$

However, if the lagged terms in Eqs 8 and 12 are significant, it is tedious to calculate the relative contributions of the regressors to changes in $\mathrm{CO}_{2}$ emissions $\Delta \widehat{C O}_{t}$. In this case, Chitnis and Hunt (2012) suggested that the estimated lagged-dependent variable (e.g., $\hat{A}^{\prime}(L) \operatorname{co}_{t}$ for the time series; where the polynomial lag operator $\left.\hat{A}^{\prime}(L)=\hat{\lambda}_{1} L+\hat{\lambda}_{2} L^{2}\right)$ should be continually substituted by a lagged estimated version of Eq. (8) until $\hat{A}^{\prime}(L)$ is sufficiently close to zero, and hence ignorable. This may not be easy to follow through in the case on

\footnotetext{
${ }^{19}$ Given that energy efficiency and structural shift indices are hypothesized to have nonlinear effects, the marginal impacts are calculated $\hat{\beta}_{0}^{*}=\left(\hat{\beta}_{0}+2 \hat{\gamma}_{0} \overline{e f f_{t}}\right)$ and $\hat{\varphi}_{0}^{*}=\left(\hat{\varphi}_{0}+2 \widehat{\Phi}_{0} \overline{a c t} t_{t}\right)$ respectively.

${ }^{20}$ Given the model is in logs the change approximates the percentage change
} 
hand. As an alternative, we estimate the long-run elasticities of the variables, which incorporate the lags in the estimated model, and use it alongside changes in the corresponding variables to arrive at their relative contributions to the changes in $\mathrm{CO}_{2}$ emissions $\Delta \widehat{\mathrm{CO}} 2_{t}$. For the time series model, this is stated as follows:

$$
\Delta \widehat{c o 2}_{t}=\Delta \hat{\mu}_{t}+\widehat{\alpha}^{*} \Delta y_{t}+\hat{\beta}^{*} \Delta e f f_{t}+\widehat{\varphi}^{*} \Delta a c t_{t}+\widehat{\psi}^{*} \Delta C E S_{t}+\widehat{\omega}^{*} \Delta T O_{t}
$$

where $\hat{\alpha}^{*}, \hat{\beta}^{*}, \hat{\varphi}^{*}, \hat{\psi}^{*}$, and $\widehat{\omega}^{*}$ are the long-run elasticities of the explanatory variables. ${ }^{21}$ Thus, $\hat{\alpha}^{*} \Delta y_{t}, \hat{\beta}^{*} \Delta e f f_{t}, \hat{\varphi}^{*} \Delta a c t_{t}, \hat{\psi}^{*} \Delta C E S_{t}, \widehat{\omega}^{*} \Delta T O_{t}$ and $\Delta \hat{\mu}_{t}$ are the estimated relative contributions of income, efficiency, structural shift, cleaner energy substitution, trade openness and ExNEF respectively to the annual change in $\mathrm{CO}_{2}$ emissions.

For the panel data model, we adopt a similar method as in Eq. (14) and focus on changes in $\mathrm{CO}_{2}$ emissions for the aggregate countries $\left(\Delta \widehat{c o 2}_{t}^{a}\right)$. We use $y_{t}^{a}$, eff $f_{t}^{a}$, act $t_{t}^{a}, C E S_{t}^{a}$ $\mathrm{TO}_{t}^{a}$ for the aggregate countries ${ }^{22}$ to replace the country level variables $y_{t}$, eff $f_{t}$, act $_{t}, C E S_{t}$, $T O_{t}$ respectively. We also use the panel long run elasticities and derive the contribution for ExNEF using $\Delta\left(\hat{\theta}_{t} / 1-\hat{\lambda}_{0}\right)$, where $\left(\hat{\theta}_{t} / 1-\hat{\lambda}_{0}\right)$ denotes the long run UCET; ${ }^{23} \hat{\theta}_{t}$ and $\hat{\lambda}_{0}$ are the coefficients of the time dummies and $c o 2_{n t-1}$ respectively in the panel model Eq. (12).

\section{Data}

For the estimations, we use annual data over the period 1971-2015 for 30 OECD countries. ${ }^{24}$ The period and countries are selected based on data availability. For the energy intensity decomposition analysis, data on the whole economy output $(Y)$ and energy consumption $(E)$, and the sectoral output $\left(Y_{i}\right)$ and energy consumption $\left(E_{i}\right)$ are used. $E$ and $E_{i}$ are proxied by aggregate and sectoral energy use (in kilo tonne of oil equivalent) respectively sourced from the International Energy Agency (IEA) database. Y is represented by real GDP (at constant 2005 prices in US\$) taken from the United Nations Statistical Division (UNSD) database. For the 7 energy-consuming sectors - mining, manufacturing, construction, transport, agriculture, commercial and residential, $Y_{i}$ is represented by the measure of economic output related to the underlying energy use for each sector. E.g. personal consumption expenditure (at constant 2005 prices in US\$) sourced from UNSD is considered as a key driver of residential energy

\footnotetext{
${ }^{21}$ The covariates LR elasticities for the time series model are $\hat{\alpha}^{*}=\left(\sum_{i=0}^{2} \hat{\alpha}_{i} / 1-\sum_{i=1}^{2} \hat{\lambda}_{i}\right), \hat{\beta}^{*}=\left(\sum_{i=0}^{2} \hat{\beta}_{i}+2\left[\sum_{i=0}^{2} \hat{\gamma}_{i}\right] \overline{e f f} f_{t} / 1-\sum_{i=1}^{2} \hat{\lambda}_{i}\right)$, $\hat{\varphi}^{*}=\left(\sum_{i=0}^{2} \hat{\varphi}_{i}+2\left[\sum_{i=0}^{2} \widehat{\Phi}_{i}\right] \overline{a c t}_{t} / 1-\sum_{i=1}^{2} \hat{\lambda}_{i}\right), \hat{\psi}^{*}=\left(\sum_{i=0}^{2} \hat{\psi}_{i} / 1-\sum_{i=1}^{2} \hat{\lambda}_{i}\right), \widehat{\omega}^{*}=\left(\sum_{i=0}^{2} \widehat{\omega}_{i} / 1-\sum_{i=1}^{2} \hat{\lambda}_{i}\right)$

${ }^{22}$ Since $c 02_{t}, y_{t}$, eff $_{t}$ and $a c t_{t}$ are in log, we derive $\widehat{c o 2}_{t}^{a}$ and $y_{t}^{a}$ by aggregating the variables across the countries, divide by the combined population and then take the log; ef $f_{t}^{a}$ and $a c t_{t}^{a}$ are the log of the resulting efficiency and activity indices from the decomposed energy intensity for the aggregated countries; $E S_{t}^{a}$ and $T O_{t}^{a}$ are the cleaner energy share and trade openness (both in \%) for the combined countries. ${ }^{23}$ Griffin and Schulman (2005) use this method to calculate the long run UEDT in a panel data model.

${ }^{24}$ The list of the 30 OECD countries are Australia (ASL), Austria (AST), Belgium (BEL), Canada (CAN), Chile (CHI), Denmark (DEN), Finland (FIN), France (FRA), Germany (GER), Greece (GRE), Hungary (HUN), Iceland (ICE), Ireland (IRE), Israel (ISR), Italy (ITA), Japan (JAP), Korea (KOR), Luxembourg (LUX), Mexico (MEX), Netherlands (NTL), New Zealand (NZD), Norway (NOR), Poland (POL), Portugal (POR), Spain (SPA), Sweden (SWE), Switzerland (SWZ), Turkey (TUR), United Kingdom (UK), United States (US).
} 
demand and we prefer this measure to personal income as part of the latter goes to savings, which may not have a major impact on residential energy consumption. We use the contribution of a given sector to final production, i.e. sectoral value added (at constant 2005 prices in US\$) taken from UNSD as a proxy for economic output for the remaining 6 sectors.

For the analysis of the determinants of $\mathrm{CO}_{2}$ emissions, in addition to the energy efficiency and structural shift indices obtained from the energy intensity decomposition, we use data on $\mathrm{CO}_{2}$ emissions in tonne per capita (CO2) sourced from IEA. Trade openness (TO) is proxied by trade (import + export) as \% of GDP sourced from UNSD. Cleaner energy substitution $(C E S)$ is proxied by alternative and nuclear energy ${ }^{25}$ (\% of total energy use) sourced alongside population data for deriving income per capita from the World Bank database - world development indicators. The descriptive statistics of the data for the first and second step estimations are in Tables A.1 and A.2 of the Appendix respectively.

\section{Empirical results}

\subsection{Empirical results of energy intensity decomposition}

We first use the Fisher Ideal index presented by Eq. (3) to decompose the energy intensity index into efficiency and activity indices for the period of 1971-2015. The decomposition results for OECD as a group illustrated in the line graph in Fig. 1 show interesting findings. By construction in subsection 2.1, a declining energy intensity or energy efficiency or activity index from its base value is regarded as an improvement. ${ }^{26}$ Intuitively we expect positive relationships between the three variables since efficiency (or activity) index attributes improvement in energy intensity index to an improving efficiency (or structural shift away from energy-intensive sectors) holding economic activity (or energy efficiency) constant.

Taking 1971 as the base year, the total energy intensity index in 2015 is $47 \%$ of its 1971 level (energy intensity index decreases by 53\% between 1971 and 2015). The efficiency index and activity index are $46 \%$ and $102.3 \%$ of their 1971 levels, respectively. Energy efficiency index is the major driver of the declining energy intensity index for OECD as a group, it accounts for $104.5 \%$ of the decline in energy intensity index while change in economic activity is found driving up energy intensity index in recent time. That is, if the composition of OECD's economic activities had remained unchanged between 1971 and 2015 , energy intensity would have been $46 \%$. Likewise, if energy efficiency had remained constant at its 1971 level, energy intensity would have increased by $2.3 \%$ of its 1971 level.

\footnotetext{
${ }^{25}$ Alternative energy is non-carbohydrate energy produced without the undesirable consequences of the burning of fossil fuels, such as high carbon dioxide emissions, which is considered to be the major contributing factor of global warming. It includes hydropower, geothermal, wind and solar power, among other renewable energy (World Bank, 2015).

${ }^{26}$ Thus, improvements are used interchangeably for declining indices while deterioration is used for increasing indices.
} 
Fig. 1: Energy indices and energy savings relative to 1971 for OECD group-level

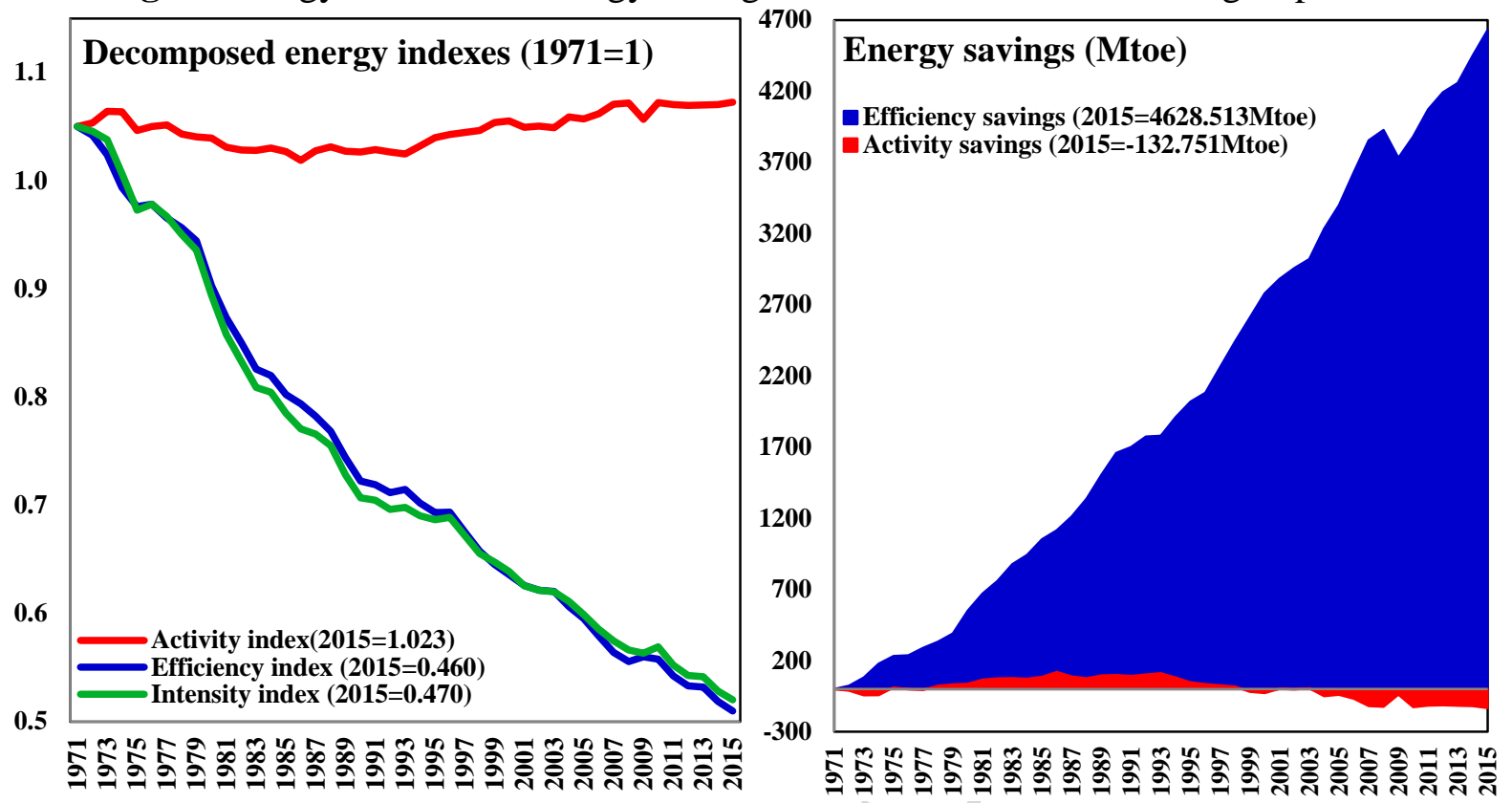

Using Eq. (4), we allocate the total energy (dis)saved (relative to the amount that would have been consumed had energy intensity remained at its 1971 level) between energy efficiency and structural shift. Based on this approach, in 2015, roughly $112.7 \%$ of total energy use (about 4496 Mtoe) has been saved due to the decrease in OECD energy intensity. The findings attribute $103 \%$ of the $4496 \mathrm{Mtoe}$ of energy saved to improvements in energy efficiency while structural changes in favour of energy-intensive sectors amount to $3 \%$ energy dissaving. The area graph in Fig. 1 shows the trend of the energy saving due to improvements in energy efficiency and compositional changes over the entire period. Throughout the period under consideration, energy saving can be attributed almost entirely to improvements in energy efficiency. Structural shift contributes only a small portion of energy savings and after 2003, it starts moving in a negative direction, with energy dissaving.

The results in Fig. 1 are at group level; improving (or deteriorating) energy efficiency at a group level does not mean that all countries within the group are efficient (or inefficient). A brief description of the decomposition results at the country level shows significant variations for the three energy indices across countries and across time. Table 1 provides summary results for the three energy indices across the 30 OECD countries for various intervals between 1971 and 2015. Several facts are noteworthy.

First, energy intensity and efficiency indices have been declining at $0.829 \%$ and $0.906 \%$ average annual rate respectively but were slow in 1982-92. Activity index has been increasing at a $0.118 \%$ average annual rate across OECD countries with a decline achieved in 2004-13. Second, variations in the indices across countries are rising. 
Table 1: Summary statistics of energy indices for OECD country-level

\begin{tabular}{lllllcccc}
\hline Indexes & Year & Mean & S.D. & Min & Max & $\begin{array}{c}\text { Coefficient } \\
\text { of } \\
\text { variation }\end{array}$ & $\begin{array}{c}\text { Average } \\
\text { annual } \\
\text { change }\end{array}$ & $\begin{array}{c}\text { Average } \\
\text { annual change } \\
\text { (cumulative) }\end{array}$ \\
\hline Intensity & $1971-1982$ & 0.972 & 0.092 & 0.709 & 1.182 & 0.094 & $-0.881 \%$ & $-0.881 \%$ \\
& $1983-1993$ & 0.874 & 0.196 & 0.517 & 1.435 & 0.224 & $-0.379 \%$ & $-0.630 \%$ \\
& $1994-2004$ & 0.803 & 0.258 & 0.359 & 1.496 & 0.322 & $-0.977 \%$ & $-0.746 \%$ \\
& $2005-2015$ & 0.684 & 0.251 & 0.266 & 1.407 & 0.367 & $-1.079 \%$ & $-0.829 \%$ \\
Efficiency & Total & 0.837 & 0.233 & 0.266 & 1.496 & 0.279 & $-0.829 \%$ & \\
\cline { 2 - 8 } & $1971-1982$ & 0.959 & 0.079 & 0.712 & 1.142 & 0.083 & $-0.997 \%$ & $-0.997 \%$ \\
& $1983-1993$ & 0.851 & 0.165 & 0.529 & 1.311 & 0.193 & $-0.555 \%$ & $-0.776 \%$ \\
& $1994-2004$ & 0.757 & 0.226 & 0.345 & 1.306 & 0.299 & $-1.137 \%$ & $-0.896 \%$ \\
& $2005-2015$ & 0.648 & 0.217 & 0.286 & 1.304 & 0.335 & $-0.935 \%$ & $-0.906 \%$ \\
& Total & 0.807 & 0.214 & 0.286 & 1.311 & 0.265 & $-0.906 \%$ & \\
\cline { 2 - 8 } & $1971-1982$ & 1.014 & 0.049 & 0.837 & 1.211 & 0.049 & $0.118 \%$ & $0.118 \%$ \\
& $1983-1993$ & 1.025 & 0.088 & 0.794 & 1.350 & 0.086 & $0.220 \%$ & $0.169 \%$ \\
& $1994-2004$ & 1.062 & 0.120 & 0.776 & 1.475 & 0.113 & $0.324 \%$ & $0.221 \%$ \\
& $2005-2015$ & 1.055 & 0.149 & 0.773 & 1.532 & 0.141 & $-0.191 \%$ & $0.118 \%$ \\
\hline
\end{tabular}

The coefficients of variation for intensity, efficiency and activity indices increased more than triple across OECD countries between 1971 and 2015, and the increases were more rapid when moving from 1971-82 to 1983-93. This indicates that some countries may have decreased their energy intensity by improvement in energy efficiency while others may not have been able to achieve this. These variations, thus, buttress the need to further analyse the three indices at the individual country level.

\section{2. $\quad$ Country level results of decomposed energy indices}

Table 2 shows the decomposition results for the individual country level between 1971 and 2015. The results indicate wide variations in the three indices by country. There are notable disparities in the relative importance of a shift in economic activity and the improvement in energy efficiency across the countries. Between 1971 and 2015, based on the average energy intensity index, 24 of the 30 OECD countries have energy intensities that declined from its respective 1971 levels. For some of the 24 countries, the decline in their energy intensity is due to both improvements in the energy efficiency and shift in economic activity towards less energy intensive activity. That is, energy efficiency and structural shift contributed positively (though at different scale) to the decline in energy intensity. There are 9 countries (Canada, Germany, Iceland, Ireland, Japan, Luxembourg, Netherlands, UK and US) in this category. E.g., the UK's average energy intensity index is $65 \%$ of its 1971 level; structural activity and energy efficiency indices are $97 \%$ and 67\% respectively of their 1971 levels. Consequently, had the composition of economic activity remained constant between 1971 and 2015, energy intensity would have been $67 \%$ of its 1971 level. Consequently, $92 \%$ of the decline in energy intensity is due to a decline in energy efficiency while the remaining $8 \%$ is due to structural shifts. 
Table 2: Energy intensity index and decomposition results for OECD country-level

\begin{tabular}{|c|c|c|c|c|c|c|c|c|c|c|c|c|}
\hline & \multicolumn{3}{|c|}{$\begin{array}{l}\text { Indexes values } \\
\text { in } 2015 \\
(1971=1.00)\end{array}$} & \multicolumn{3}{|c|}{$\begin{array}{c}\text { Indexes average } \\
\text { values } \\
(1971-2015)\end{array}$} & \multicolumn{3}{|c|}{$\begin{array}{c}\text { Indexes average } \\
\text { annual change }(\%) \\
(1971-2015)\end{array}$} & \multicolumn{3}{|c|}{$\begin{array}{c}\text { Indexes average energy } \\
\text { savings in Mtoe }(\Delta \mathrm{ES}) \\
(1971-2015)\end{array}$} \\
\hline & EI & EFF & ACT & EI & $\mathrm{EFF}$ & ACT & EI & EFF & ACT & EI & EFF & $\mathrm{ACT}$ \\
\hline Australia & 0.68 & 0.67 & 1.01 & 0.91 & 0.86 & 1.05 & -0.73 & -0.75 & 0.03 & 11.44 & 15.26 & -3.82 \\
\hline Austria & 0.70 & 0.67 & 1.04 & 0.84 & 0.79 & 1.06 & -0.68 & -0.75 & 0.10 & 5.63 & 7.14 & -1.51 \\
\hline Belgium & 0.58 & 0.56 & 1.04 & 0.75 & 0.72 & 1.05 & -0.95 & -1.00 & 0.08 & 15.17 & 17.63 & -2.47 \\
\hline Canada & 0.58 & 0.64 & 0.92 & 0.77 & 0.79 & 0.97 & -0.95 & -0.83 & -0.19 & 75.17 & 65.53 & 9.64 \\
\hline Chile & 0.65 & 0.62 & 1.06 & 0.93 & 0.90 & 1.04 & -0.79 & -0.86 & 0.13 & 2.51 & 3.24 & -0.73 \\
\hline Denmark & 0.46 & 0.43 & 1.07 & 0.69 & 0.67 & 1.04 & -1.22 & -1.29 & 0.16 & 8.54 & 9.45 & -0.90 \\
\hline Finland & 0.54 & 0.49 & 1.10 & 0.73 & 0.70 & 1.06 & -1.04 & -1.16 & 0.23 & 10.88 & 12.75 & -1.88 \\
\hline France & 0.47 & 0.41 & 1.14 & 0.69 & 0.65 & 1.08 & -1.22 & -1.35 & 0.32 & 87.75 & 104.53 & -16.78 \\
\hline Germany & 0.42 & 0.42 & 0.99 & 0.67 & 0.69 & 0.97 & -1.32 & -1.31 & -0.03 & 157.52 & 145.94 & 11.58 \\
\hline Greece & 1.36 & 0.95 & 1.43 & 1.28 & 0.98 & 1.31 & 0.81 & -0.11 & 0.97 & -3.84 & 0.38 & -4.23 \\
\hline Hungary & 0.56 & 0.53 & 1.07 & 0.80 & 0.77 & 1.04 & -1.00 & -1.08 & 0.15 & 6.14 & 7.15 & -1.02 \\
\hline Iceland & 0.86 & 0.99 & 0.87 & 0.88 & 0.96 & 0.91 & -0.31 & -0.03 & -0.28 & 0.33 & 0.10 & 0.23 \\
\hline Ireland & 0.27 & 0.29 & 0.93 & 0.63 & 0.67 & 0.93 & -1.67 & -1.62 & -0.15 & 8.39 & 7.40 & 0.99 \\
\hline Israel & 0.68 & 0.78 & 0.87 & 0.91 & 1.05 & 0.87 & -0.73 & -0.50 & -0.30 & 1.32 & -0.18 & 1.50 \\
\hline Italy & 0.65 & 0.58 & 1.12 & 0.77 & 0.71 & 1.10 & -0.80 & -0.96 & 0.26 & 43.02 & 57.50 & -14.48 \\
\hline Japan & 0.50 & 0.50 & 0.99 & 0.68 & 0.71 & 0.97 & -1.14 & -1.13 & -0.02 & 171.36 & 159.26 & 12.10 \\
\hline Korea & 0.67 & 0.47 & 1.44 & 0.86 & 0.72 & 1.23 & -0.74 & -1.21 & 1.01 & 25.74 & 54.44 & -28.71 \\
\hline Luxembourg & 0.27 & 0.32 & 0.84 & 0.56 & 0.59 & 0.96 & -1.66 & -1.54 & -0.37 & 3.80 & 3.53 & 0.27 \\
\hline Mexico & 0.88 & 0.64 & 1.37 & 1.06 & 0.87 & 1.23 & -0.27 & -0.82 & 0.85 & -4.59 & 19.07 & -23.66 \\
\hline Netherlands & 0.55 & 0.60 & 0.92 & 0.84 & 0.85 & 0.98 & -1.02 & -0.91 & -0.17 & 17.17 & 15.44 & 1.73 \\
\hline New Zealand & 0.99 & 1.00 & 0.99 & 1.18 & 1.11 & 1.06 & -0.03 & 0.00 & -0.02 & -1.54 & -0.96 & -0.58 \\
\hline Norway & 0.59 & 0.59 & 1.01 & 0.78 & 0.76 & 1.03 & -0.93 & -0.94 & 0.02 & 7.91 & 8.79 & -0.88 \\
\hline Poland & 0.34 & 0.30 & 1.14 & 0.72 & 0.68 & 1.10 & -1.50 & -1.60 & 0.32 & 44.16 & 53.47 & -9.31 \\
\hline Portugal & 1.18 & 1.05 & 1.12 & 1.21 & 1.15 & 1.05 & 0.40 & 0.12 & 0.27 & -2.90 & -2.12 & -0.79 \\
\hline Spain & 0.87 & 0.94 & 0.93 & 1.02 & 1.04 & 0.98 & -0.30 & -0.14 & -0.16 & -1.40 & -3.80 & 2.40 \\
\hline Sweden & 0.41 & 0.39 & 1.06 & 0.71 & 0.69 & 1.03 & -1.34 & -1.39 & 0.14 & 19.26 & 20.87 & -1.61 \\
\hline Switzerland & 0.63 & 0.65 & 0.98 & 0.89 & 0.88 & 1.01 & -0.83 & -0.80 & -0.05 & 3.01 & 3.13 & -0.12 \\
\hline Turkey & 1.00 & 0.84 & 1.20 & 1.08 & 0.98 & 1.11 & 0.01 & -0.37 & 0.46 & -3.20 & 2.99 & -6.19 \\
\hline UK & 0.36 & 0.40 & 0.89 & 0.65 & 0.67 & 0.97 & -1.46 & -1.36 & -0.25 & 106.82 & 99.29 & 7.53 \\
\hline US & 0.36 & 0.36 & 1.01 & 0.60 & 0.62 & 0.98 & -1.45 & -1.46 & 0.03 & 1349.6 & 1300.6 & 49.02 \\
\hline
\end{tabular}

For some other countries, the decline in their energy intensity index is predominantly due to a decline in energy efficiency index. The size of the decline in efficiency index dominates the increase in structural shift index such that the net impact decreased the intensity index. 14 countries (Australia, Austria, Belgium, Chile, Denmark, Finland, France, Hungary, Italy, Korea, Norway, Poland, Sweden and Switzerland) are in this set. For Israel only, the decline in its average energy intensity is solely due to structural shifts to less energy-intensive activities while energy efficiency deteriorated.

For the remaining 6 OECD countries, their average energy intensity index increased relative to its 1970 level. Two of these countries (New Zealand and Portugal) have an increased energy intensity index due to deteriorations in their energy efficiency and a structural shift leading to energy dissaving. E.g., the average intensity, efficiency and activity indices for New Zealand were 118\%, 111\% and 106\% respectively of their 1971 levels. Thus, $65 \%$ of the increase in energy intensity index was due to shifts toward energy intensive activity while the remaining $35 \%$ increase was due to energy inefficiency. Spain achieved favourable shifts in economic activity but failed to improve on its energy efficiency, which eventually led to an increase in its energy intensity index. Finally, Greece, Mexico and Turkey, achieved improvements in their energy efficiency but the dominance of their adverse structural shifts led to an increase in their energy intensity index. 
Overall, the decomposition results indicate that many of the OECD countries improved in energy efficiency. Specifically, only 4 of the 30 OECD considered (Israel, New Zealand, Portugal and Spain) became less energy efficient while the remaining 26 countries improved their energy efficiency with a large amount of energy saved. These results are generally consistent with the findings of Oseni (2011) for 16 OECD countries.

As with the aggregate OECD, we use Eq. (4) to measure the total energy (dis)saved (relative to the amount that would have been consumed had energy intensity remained unchanged and the relative amount attributed to improved efficiency and structural change. The last three columns of Table 2 show that 24 OECD countries saved energy - the largest saving of 1349.6 Mtoe is from US. Mexico, followed by Greece, has the largest energy dissaving of 4.6 Mtoe and 3.8 Mtoe respectively.

Further energy decomposition analysis at the individual country was conducted by estimating the average and change in the energy indices, energy savings and share attributed to energy efficiency and structural shift at different time intervals. The results in Table A.3 of the Appendix show significant variation in the indices across time at the country level. For robustness checks, we redo the analysis using LMDI method (stated in footnote 4) and use the spearman rank correlation to compare the results. Correlation coefficients of 0.998 for efficiency index (between FII and LMDI) and 0.977 for structural shift index (between FII and LMDI) shows that the results from LMDI are not different from the abovementioned.

In conclusion, there are considerable variations across time and across countries in the energy efficiency index. Arguably, these variations would have impacted on $\mathrm{CO}_{2}$ emissions across the countries, yet little is known about the relative extent of the impact. To help examine and quantify the magnitude of the impact, we present the econometric analysis of the impact of changes in energy efficiency on $\mathrm{CO}_{2}$ emissions controlling for other factors.

\subsection{Empirical results of the determinants of $\mathrm{CO}_{2}$ emissions}

As discussed in section 2.2, the variables for the econometric analysis include $\mathrm{CO}_{2}$ emissions per capita, GDP per capita, energy efficiency and structural activity indices (derived from intensity decomposition) and their squared terms to account for a possible non-linear response of $\mathrm{CO}_{2}$ emissions. We control for cleaner energy substitution and trade openness. All of the variables are in natural log, with the exception of the two control variables, which are in percentages. The summary statistics are in Table A.2 of the Appendix.

We estimate both time series and panel data models as specified in Eqs (8) and (12) respectively. Moreover, since we found Israel, New Zealand, Portugal and Spain to have 
become more energy inefficient from the index decomposition analysis, to ensure that the impact of energy efficiency improvements on $\mathrm{CO}_{2}$ emissions is well estimated in the panel model, we conduct the panel data analysis with (and without) those four countries.

\subsubsection{Time series results}

The general STSM model combining Eqs (8) - (10) is estimated for each of the 30 OECD countries for the period 1971-2012 (42 observations) saving 2013-2015 (3 observations) for a post-sample prediction test. With the general-to-specific principle adopted, the preferred models given in Table 3 were found by testing down from the general model and eliminating statistically insignificant variables but ensuring a range of diagnostics tests are passed.

The results show that, in general, almost all models fit the data well, free of misspecification and instability (as indicated by the results of the predictive failure test) and passing almost all diagnostic tests. The exceptions being Chile, Germany, Korea, UK (where there is a slight problem of heteroscedasticity) and Germany, Korea, Mexico and Spain (where the Box-Ljung test suggests there might be a problem with serial correlation, but the correlation coefficients up to three lags do not suggest there is problem). The reported $R^{2} \mathrm{~s}$ are satisfactorily high, implying strong evidence that the final regressors in the preferred models explain a larger part of the changes in $\mathrm{CO}_{2}$ emissions. In what follows, we discuss the estimated coefficients with some relevant policy and research implications.

Table 3 shows that the dynamic structures of the preferred model vary across the 30 OECD countries. 26 of the countries displayed immediate adjustment (i.e. no dynamics) despite starting with lags of 2 years, while the lagged dependent variable for the remaining 4 countries is statistically significant in the preferred model. The expected sign of the lagged $\mathrm{CO}_{2}$ emissions varies and the interpretation is open to discussion. A negative sign may imply that the previous magnitude of $\mathrm{CO}_{2}$ emissions led to more stringent environmental policy, which makes current $\mathrm{CO}_{2}$ emissions decline. A positive sign may point to a lack of effective policies (or incentives) in the past to abate $\mathrm{CO}_{2}$ emissions, leading to a spill over effect that increased current $\mathrm{CO}_{2}$ emissions. 3 of the 4 countries with a dynamic term indicate a negative effect on $\mathrm{CO}_{2}$ emissions, while just one country shows positive effect.

Consistent with the results in the existing literature, income generally has a positive significant impact on $\mathrm{CO}_{2}$ emissions, with some variations in the magnitude - ranging from 0.346 (for Austria) to 1.397 (for Sweden). That is, a 1\% increase in income will increase $\mathrm{CO}_{2}$ emissions by $0.35 \%$ and $1.40 \%$ for Austria and Sweden respectively. Structural shifts in economic activity likewise have a significant positive impact on $\mathrm{CO}_{2}$ emissions. ${ }^{27}$

\footnotetext{
${ }^{27}$ We drop the squared term of the structural shift from the model because it was always found to be insignificant.
} 
Table 3: Preferred STSMs for OECD country-level $\mathrm{CO}_{2}$ emissions, 1971-2015

Dependent variable: co2 (carbon emission in logs)

\begin{tabular}{|c|c|c|c|c|c|c|c|c|}
\hline \multirow[b]{2}{*}{ Regressors: } & \multicolumn{8}{|l|}{ Countries } \\
\hline & AUS & AUST & BEL & CAN & $\mathrm{CHI}$ & $\overline{\mathrm{DEN}}$ & FIN & FRA \\
\hline \multirow{2}{*}{$\alpha_{0}(y)$} & $0.924 * * *$ & $0.346 * * *$ & $1.357 * * *$ & $0.950 * * *$ & $1.273 * * *$ & $1.380 * * *$ & $0.955 * * *$ & $0.871 * * *$ \\
\hline & $(0.143)$ & $(0.110)$ & $(0.126)$ & $(0.095)$ & $(0.116)$ & $(0.228)$ & $(0.294)$ & $(0.156)$ \\
\hline \multirow{2}{*}{$\beta_{0}(e f f)$} & $1.145 * * *$ & $0.778 * * *$ & $0.784 * * *$ & $0.703 * * *$ & $1.144 * * *$ & $0.735 * *$ & $0.869 * * *$ & $0.826 * * *$ \\
\hline & $(0.112)$ & $(0.105)$ & (0.059) & $(0.086)$ & $(0.151)$ & $(0.273)$ & $(0.282)$ & (0.059) \\
\hline \multirow[t]{2}{*}{$\gamma_{0}\left(e f f^{2}\right)$} & $1.813 * * *$ & - & - & - & - & $-1.010 * *$ & - & - \\
\hline & $(0.342)$ & & & & & $(0.468)$ & & \\
\hline \multirow[t]{2}{*}{$\varphi_{0}(a c t)$} & $0.610 * * *$ & $2.077 * * *$ & $1.485 * * *$ & $0.887 * * *$ & $1.376 * * *$ & $1.440 * *$ & $2.895 * * *$ & $0.871 * * *$ \\
\hline & $(0.211)$ & $(0.255)$ & $(0.201)$ & $(0.135)$ & $(0.424)$ & $(0.568)$ & $(0.924)$ & $(0.320)$ \\
\hline \multirow[t]{2}{*}{$\omega_{0}(T O)$} & $-0.007 * *$ & $0.002 *$ & $-0.003 * * *$ & - & - & - & $-0.011 * * *$ & $0.004 * *$ \\
\hline & $(0.003)$ & $(0.001)$ & $(0.001)$ & & & & $(0.004)$ & $(0.002)$ \\
\hline$\omega_{1}\left(T O_{-1}\right)$ & - & - & - & - & $0.004 * *$ & - & - & - \\
\hline \multirow{2}{*}{$\psi_{0}(C E S)$} & $-0.043 * *$ & $-0.016 * * *$ & $-0.008 * * *$ & $-0.012 * * *$ & $\begin{array}{l}(0.002) \\
-0.032 * * *\end{array}$ & $-0.080 * * *$ & $-0.023 * * *$ & $-0.011 * * *$ \\
\hline & $(0.016)$ & $(0.004)$ & $(0.001)$ & $(0.002)$ & $(0.004)$ & $(0.028)$ & $(0.004)$ & $(0.001)$ \\
\hline$\psi_{2}\left(C E S_{-2}\right)$ & - & - & - & - & $\begin{array}{l}0.015 * * * \\
(0.004)\end{array}$ & $\begin{array}{c}0.044 * \\
(0.032)\end{array}$ & - & - \\
\hline$\lambda_{1}\left(\operatorname{co}_{-1}\right)$ & - & - & $\begin{array}{l}-0.082 * \\
(0.041)\end{array}$ & - & - & & - & - \\
\hline дсо2/дeff & 0.573 & 0.778 & 0.784 & 0.703 & 1.144 & 1.615 & 0.869 & 0.826 \\
\hline \multicolumn{9}{|c|}{ Long run elasticities } \\
\hline$\alpha^{*}(y)$ & 0.924 & 0.346 & 1.254 & 0.950 & 1.273 & 1.380 & 0.955 & 0.871 \\
\hline$\beta^{*}(e f f)$ & 0.573 & 0.778 & 0.725 & 0.703 & 1.144 & 1.615 & 0.869 & 0.826 \\
\hline$\varphi^{*}(a c t)$ & 0.610 & 2.077 & 1.372 & 0.887 & 1.376 & 1.440 & 2.895 & 0.871 \\
\hline$\omega^{*}(T I)$ & -0.219 & 0.139 & -0.311 & - & 0.205 & - & -0.615 & 0.156 \\
\hline$\psi^{*}(C E S)$ & -0.071 & -0.176 & -0.123 & -0.236 & -0.123 & -0.056 & -0.417 & -0.365 \\
\hline \multicolumn{9}{|c|}{ Variance of hyperparameters } \\
\hline \multirow{6}{*}{$\begin{array}{l}\text { Irregular }\left(10^{-4}\right) \\
\text { Level }\left(10^{-4}\right) \\
\text { Slope }\left(10^{-4}\right) \\
\text { Trend: } \\
\text { Nature of trend } \\
\text { Interventions }\end{array}$} & 0.736 & 1.093 & 0.000 & 1.057 & 1.105 & 0.129 & 2.743 & 0.628 \\
\hline & 0.389 & 0.578 & 1.382 & 0.000 & 0.000 & 2.606 & 0.152 & 0.000 \\
\hline & 0.055 & - & 0.000 & 0.017 & 1.563 & - & 2.331 & 0.036 \\
\hline & & & & & & & & \\
\hline & LT & LLT & LLTD & ST & ST & LLT & LT & ST \\
\hline & - & Lvl.1990 & Lvl.1975 & $->$ & - & Irr.1982 & - & $\begin{array}{l}\text { Irr.2001 } \\
\text { Lvl.1989 }\end{array}$ \\
\hline \multicolumn{9}{|c|}{ Diagnostics: } \\
\hline \multicolumn{9}{|c|}{ Equation residuals } \\
\hline Standard error & 0.013 & 0.014 & 0.010 & 0.012 & 0.021 & 0.040 & 0.044 & 0.010 \\
\hline Normality & 0.600 & 10.527 & 0.716 & 15.653 & 1.732 & 3.595 & 1.207 & 2.281 \\
\hline$h_{(n)}$ & $1.340_{(11)}$ & $2.450_{(11)}$ & $1.337_{(10)}$ & $1.124_{(12)}$ & $3.502^{\pi \pi}(10)$ & $1.233_{(10)}$ & $1.410_{(11)}$ & $0.820_{(11)}$ \\
\hline$r_{(1)}$ & 0.150 & -0.030 & 0.073 & -0.025 & 0.020 & -0.101 & -0.141 & 0.023 \\
\hline$r_{(2)}$ & -0.067 & -0.129 & -0.066 & -0.260 & -0.052 & -0.137 & -0.227 & -0.033 \\
\hline$r_{(3)}$ & -0.209 & -0.101 & -0.042 & -0.105 & -0.235 & 0.127 & 0.203 & -0.211 \\
\hline$D W$ & 1.602 & 2.058 & 1.793 & 1.973 & 1.947 & 2.171 & 2.126 & 1.717 \\
\hline$Q_{(q, d)}$ & $3.754_{(6,4)}$ & $2.826_{(5,4)}$ & $3.581_{(6,4)}$ & $3.924_{(7,5)}$ & $4.139_{(6,4)}$ & $2.209_{(5,4)}$ & $5.705_{(6,4)}$ & $3.536_{(6,4)}$ \\
\hline$\widetilde{R}$-squares & 0.804 & 0.925 & 0.960 & 0.867 & 0.932 & 0.831 & 0.781 & 0.957 \\
\hline \multicolumn{9}{|c|}{ Predictive failure tests (2013-2015): } \\
\hline Failure $\chi_{(3)}^{2}$ & 1.698 & 0.190 & 3.858 & 0.206 & 5.692 & 5.120 & 1.271 & 1.498 \\
\hline & -1.237 & -0.403 & -0.034 & -0.47 & -1.154 & 0.820 & -1.054 & -0.454 \\
\hline \multicolumn{9}{|c|}{$\begin{array}{l}\text { Cusum }_{(3)} \\
\text { Likelihood ratio test: }\end{array}$} \\
\hline$L R \chi_{,(2)}^{2}$ & $25.04 * * *$ & - & - & - & - & - & $29.20 * * *$ & - \\
\hline $\operatorname{LR} \chi_{(1)}^{2(2)}$ & - & $8.42 * * *$ & $25.42 * * *$ & $9.24 * * *$ & $28.32 * * *$ & $11.99 * * *$ & - & $6.13 * *$ \\
\hline
\end{tabular}

1. $* * * * *$ and $*$ indicate $99 \%, 95 \%$ and $90 \%$ significance levels respectively; standard errors are in parenthesis; the marginal effect of energy efficiency $\partial c 02 / \partial e f f$ is evaluated at the mean; we derive the long run elasticities using the formula stated in footnote 18 ; the SR elasticities are the coefficients of the variables at levels and the marginal effect of energy efficiency;

2. Nature of trend: the local trend (LT) model is where the trend is stochastic both in the level and slope, i.e., $\sigma_{\eta}^{2} \neq 0$; $\sigma_{\xi}^{2} \neq 0$; local level trend with drift (LLTD) model is where the trend is stochastic in the level but fixed in the slope, i.e. $\sigma_{\eta}^{2} \neq 0$; $\sigma_{\xi}^{2}=0$; local level trend (LLT) model is where the trend is stochastic in the level but no slope, $\sigma_{\eta}^{2} \neq 0$; and smooth trend (ST) model is where the trend is fixed in the level but stochastic in the slope, i.e. $\sigma_{\eta}^{2}=0 ; \sigma_{\xi}^{2} \neq 0$.

3. $L v l$. and Irr. represent level break and irregular intervention dummies respectively, included where necessary for outliers and breaks;

4. Normality is the Bowman-Shenton test distributed approximately as $\chi_{(2)}^{2}$;

5. $H_{(h)}$ is the test for heteroscedasticity distributed approximately as $F_{(h, h)}$;

6. $r_{(n)}$ are the residual autocorrelation coefficients at lag $n$ distributed approximately as $N(0,1 / T) ; D W$ is the Durbin-Watson statistic;

7. $Q_{(p, d)}$ is the Box-Ljung Q-statistic based on the first $p$ residuals autocorrelations and distributed approximately as $\chi_{(d)}^{2}$;

8. Failure is the post-sample predictive failure test for 2013-2015 distributed approximately as $\chi_{(3)}^{2}$;

9. Cusum is the test of parameters consistency distributed approximately as the $t$-distribution;

10. $L R$ test, where applicable, is for the restriction that both $\sigma_{\eta}^{2}$ and $\sigma_{\xi}^{2}$ are equal to zero, distributed as $\chi_{(2)}^{2}$ or either $\sigma_{\eta}^{2}$ or $\sigma_{\xi}^{2}$, is equal to zero, distributed as $\chi_{(1)}^{2}$ 


\begin{tabular}{|c|c|c|c|c|c|c|c|c|}
\hline \multicolumn{9}{|c|}{ Dependent variable: co2 (carbon emission in logs) } \\
\hline \multirow[b]{2}{*}{ Regressors: } & \multicolumn{8}{|c|}{ Countries: } \\
\hline & GER & GRE & HUN & ICE & IRE & ISRL & ITA & JAP \\
\hline \multirow[t]{2}{*}{$\alpha_{0}(y)$} & $0.967 * * *$ & $0.929 * * *$ & $0.883 * * *$ & $0.741 * * *$ & $0.816^{* * *}$ & $0.670 * * *$ & $1.138 * * *$ & $0.888 * * *$ \\
\hline & $(0.084)$ & $(0.160)$ & $(0.059)$ & $(0.163)$ & $(0.076)$ & $(0.167)$ & $(0.145)$ & $(0.061)$ \\
\hline \multirow[t]{2}{*}{$\beta_{0}(e f f)$} & $0.934 * * *$ & $0.809 * * *$ & $0.987 * * *$ & $0.576^{* *}$ & $0.865 * * *$ & $0.633 * * *$ & $0.759 * * *$ & $0.771 * * *$ \\
\hline & $(0.062)$ & $(0.198)$ & $(0.122)$ & $(0.163)$ & $(0.094)$ & $(0.133)$ & $(0.108)$ & $(0.087)$ \\
\hline$\gamma_{0}\left(e f f^{2}\right)$ & - & - & $\begin{array}{l}0.297 * \\
(0.157)\end{array}$ & - & - & - & - & $\begin{array}{l}-0.276 * * \\
(0.130)\end{array}$ \\
\hline$\varphi_{0}(a c t)$ & $\begin{array}{l}0.948 * * * \\
(0.208)\end{array}$ & $\begin{array}{l}1.213 * * * \\
(0.374)\end{array}$ & $\begin{array}{l}1.598 * * * \\
(0.264)\end{array}$ & - & $\begin{array}{l}0.886 * * * \\
(0.152)\end{array}$ & $\begin{array}{l}0.779 * * * \\
(0.196)\end{array}$ & $\begin{array}{l}0.640 * * * \\
(0.225)\end{array}$ & $\begin{array}{l}1.045^{* * * *} \\
(0.162)\end{array}$ \\
\hline$\omega_{0}(T O)$ & - & - & $\begin{array}{l}-0.001 * \\
(0.001)\end{array}$ & $\begin{array}{l}0.006 * * \\
(0.003)\end{array}$ & $\begin{array}{l}0.001 * \\
(0.001)\end{array}$ & $-\quad-1$ & $\begin{array}{l}0.002 * \\
(0.001)\end{array}$ & $\begin{array}{l}0.005^{* *} \\
(0.002)\end{array}$ \\
\hline$\psi_{0}(E S)$ & $\begin{array}{l}-0.005^{*} \\
(0.003)\end{array}$ & $\begin{array}{l}-0.032 * * \\
(0.013)\end{array}$ & $\begin{array}{l}-0.006 * * * \\
(0.002)\end{array}$ & $\begin{array}{l}-0.012 * * * \\
(0.003)\end{array}$ & $\begin{array}{l}-0.029 * \\
(0.016)\end{array}$ & $\begin{array}{l}-0.048 * \\
(0.024)\end{array}$ & $\begin{array}{l}-0.010 * \\
(0.005)\end{array}$ & $\begin{array}{l}-0.008^{* * *} \\
(0.001)\end{array}$ \\
\hline 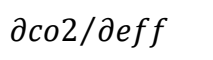 & 0.934 & 0.809 & 0.821 & 0.576 & 0.865 & 0.633 & 0.759 & 0.975 \\
\hline \multicolumn{9}{|c|}{ Long run elasticities: } \\
\hline$\alpha^{*}(y)$ & 0.967 & 0.929 & 0.883 & 0.741 & 0.816 & 0.670 & 1.138 & 0.888 \\
\hline$\beta^{*}(e f f)$ & 0.934 & 0.809 & 0.821 & 0.576 & 0.865 & 0.633 & 0.759 & 0.975 \\
\hline$\varphi^{*}(a c t)$ & 0.948 & 1.213 & 1.598 & - & 0.886 & 0.779 & 0.640 & 1.045 \\
\hline$\omega^{*}(T O)$ & - & - & -0.077 & 0.375 & 0.105 & - & 0.076 & 0.100 \\
\hline$\psi^{*}(C E S)$ & -0.049 & -0.068 & -0.059 & -0.853 & -0.035 & -0.122 & -0.054 & -0.096 \\
\hline \multicolumn{9}{|c|}{ Variance of hyperparameters } \\
\hline Irregular $\left(10^{-4}\right)$ & 0.557 & 0.000 & 1.269 & 8.658 & 2.490 & 0.000 & 0.000 & 0.404 \\
\hline Level $\left(10^{-4}\right)$ & 0.000 & 8.697 & 0.000 & 0.000 & 0.150 & 9.238 & 1.417 & 0.356 \\
\hline \multicolumn{9}{|l|}{ Trend: } \\
\hline Nature of trend & $\mathrm{ST}$ & $\mathrm{LT}$ & $\mathrm{ST}$ & ST & $\mathrm{LT}$ & LLT & LLT & LLT \\
\hline Interventions & - & - & $\begin{array}{l}\text { Irr1990 } \\
\text { Irr2008 }\end{array}$ & $\begin{array}{l}\text { Lvl1988 } \\
\text { Lvl1990 }\end{array}$ & - & - & - & Lv11990 \\
\hline \multicolumn{9}{|c|}{ Diagnostics: } \\
\hline Standard error & 0.010 & 0.031 & 0.014 & 0.035 & 0.019 & 0.028 & 0.011 & 0.009 \\
\hline Normality & 1.167 & 0.360 & 10.660 & 2.305 & 0.319 & 5.040 & 1.525 & 2.500 \\
\hline$h(n)$ & $2.972^{* * *}(12)$ & $1.227_{(12)}$ & $2.821_{(11)}$ & $1.618_{(11)}$ & $1.199_{(11)}$ & $1.659_{(12)}$ & $1.556_{(11)}$ & $0.913_{(11)}$ \\
\hline$r(1)$ & 0.229 & 0.017 & -0.096 & -0.173 & 0.276 & 0.017 & 0.050 & -0.009 \\
\hline$r(2)$ & -0.211 & -0.091 & 0.043 & -0.044 & -0.043 & -0.064 & -0.055 & -0.211 \\
\hline$r(3)$ & -0.117 & 0.103 & -0.216 & 0.045 & -0.221 & -0.256 & -0.263 & -0.035 \\
\hline$D W$ & 1.459 & 1.794 & 2.054 & 2.186 & 1.287 & 1.396 & 1.887 & 1.935 \\
\hline$Q(q, p)$ & $14.87_{(7,5)}^{* * *}$ & $2.247_{(7,5)}$ & $5.715_{(6,4)}$ & $2.411_{(6,4)}$ & $5.719_{(6,4)}$ & $5.052_{(6,5)}$ & $6.163_{(6,4)}$ & $2.103_{(5,4)}$ \\
\hline$R$-squares & 0.903 & 0.679 & 0.915 & 0.826 & 0.868 & 0.493 & 0.917 & 0.954 \\
\hline \multicolumn{9}{|c|}{ Predictive failure tests (2013-2015): } \\
\hline Failure $\chi_{(3)}^{2}$ & 3.949 & 1.857 & 0.971 & 3.337 & 5.125 & 0.689 & 2.168 & 3.010 \\
\hline Cusum t(3) $_{(3)}$ & -0.381 & 1.261 & -0.266 & -0.496 & 0.030 & 0.677 & 0.583 & -1.392 \\
\hline \multicolumn{9}{|c|}{ Likelihood ratio tests: } \\
\hline$L R \chi_{(2)}^{2}$ & - & $19.60 * * *$ & - & - & $3.17 *$ & - & - & - \\
\hline$L R \chi_{(1)}^{2}$ & $23.68 * * *$ & - & $7.85 * * *$ & $16.31 * * *$ & - & $14.52 * * *$ & $23.40 * * *$ & $3.19 *$ \\
\hline
\end{tabular}




\begin{tabular}{|c|c|c|c|c|c|c|c|}
\hline \multicolumn{8}{|c|}{ Dependent variable: co2 (carbon emission in logs) } \\
\hline \multirow[b]{2}{*}{ Regressors: } & \multicolumn{7}{|c|}{ Countries: } \\
\hline & KOR & LUX & MEX & NTL & NZD & NOR & POL \\
\hline \multirow{2}{*}{$\alpha_{0}(y)$} & $0.926 * * *$ & $1.213 * * *$ & $0.928 * * *$ & $0.401 * *$ & $-0.449 *$ & $0.768 * * *$ & $0.865 * * *$ \\
\hline & $(0.090)$ & $(0.168)$ & $(0.081)$ & $(0.152)$ & $(0.226)$ & $(0.095)$ & $(0.043)$ \\
\hline \multirow[t]{2}{*}{$\beta_{0}(e f f)$} & $0.573 * * *$ & $0.940 * * *$ & $0.869 * * *$ & $0.468 * * *$ & 0.106 & $1.942 * * *$ & $0.834 * * *$ \\
\hline & $(0.099)$ & $(0.193)$ & $(0.100)$ & $(0.081)$ & $(0.141)$ & $(0.342)$ & $(0.044)$ \\
\hline$\gamma_{0}\left(e f f^{2}\right)$ & - & $\begin{array}{l}-0.247^{*} \\
(0.132)\end{array}$ & - & - & - & $\begin{array}{l}1.309 * * * \\
(0.477)\end{array}$ & - \\
\hline$\varphi_{0}(a c t)$ & $\begin{array}{l}0.948 * * * \\
(0.221)\end{array}$ & $\begin{array}{l}1.412 * * * \\
(0.232)\end{array}$ & $\begin{array}{l}1.143 * * * \\
(0.277)\end{array}$ & $\begin{array}{l}1.120 * * * \\
(0.322)\end{array}$ & $\begin{array}{l}0.670 * * \\
(0.288)\end{array}$ & $\begin{array}{l}1.456 \text { *** } \\
(0.228)\end{array}$ & $\begin{array}{l}0.828 * * * \\
(0.046)\end{array}$ \\
\hline$\omega_{0}(T O)$ & - & - & - & - & - & $\begin{array}{l}0.005 * * \\
(0.001)\end{array}$ & - \\
\hline$\omega_{1}\left(T O_{-1}\right)$ & - & - & - & - & $\begin{array}{l}0.007 * \\
(0.004)\end{array}$ & - & - \\
\hline$\omega_{2}\left(T O_{-2}\right)$ & - & - & - & - & & - & $\begin{array}{l}-0.002 * * \\
(0.001)\end{array}$ \\
\hline$\psi_{0}(C E S)$ & $\begin{array}{l}-0.012 * * * \\
(0.002)\end{array}$ & $\begin{array}{l}-0.243 * * \\
(0.097)\end{array}$ & $\begin{array}{l}-0.012 * * \\
(0.001)\end{array}$ & $\begin{array}{l}-0.043 * * * \\
(0.015)\end{array}$ & $\begin{array}{l}-0.019 * * \\
(0.002)\end{array}$ & $\begin{array}{l}-0.004 * * \\
(0.001)\end{array}$ & $\begin{array}{l}-0.107 * \\
(0.053)\end{array}$ \\
\hline$\psi_{1}\left(C E S_{-1}\right)$ & - & - & - & - & & $\begin{array}{l}-0.002 * \\
(0.001)\end{array}$ & - \\
\hline$\lambda_{1}\left(\operatorname{co} 2_{-1}\right)$ & - & - & - & & $\begin{array}{l}-0.149 * \\
(0.082)\end{array}$ & - & - \\
\hline$\partial c o 2 / \partial e f f$ & 0.573 & 1.241 & 0.869 & & 0.106 & 1.179 & 0.834 \\
\hline \multicolumn{8}{|c|}{ Long run elasticities: } \\
\hline$\alpha^{*}(y)$ & 0.926 & 1.213 & 0.928 & 0.401 & -0.391 & 0.768 & 0.865 \\
\hline$\beta^{*}(e f f)$ & 0.573 & 1.241 & 0.869 & 0.468 & 0.092 & 1.179 & 0.834 \\
\hline$\varphi^{*}(a c t)$ & 0.948 & 1.412 & 1.143 & 1.120 & 0.583 & 1.456 & 0.828 \\
\hline$\omega^{*}(T O)$ & - & - & - & - & 0.274 & 0.319 & -0.090 \\
\hline$\psi^{*}(C E S)$ & -0.131 & -0.071 & -0.058 & -0.066 & -0.449 & -0.249 & -0.026 \\
\hline \multicolumn{8}{|c|}{ Variance of hyperparameters: } \\
\hline \multirow{5}{*}{$\begin{array}{l}\text { Irregular }\left(10^{-4}\right) \\
\text { Level }\left(10^{-4}\right) \\
\text { Slope }\left(10^{-4}\right) \\
\text { Trend: } \\
\text { Nature of trend } \\
\text { Interventions }\end{array}$} & 2.668 & 1.198 & 0.000 & 3.054 & 0.000 & 4.122 & 0.051 \\
\hline & 0.000 & 4.847 & 2.054 & 0.000 & 4.122 & 0.858 & 0.988 \\
\hline & 2.668 & 1.829 & 0.000 & 0.062 & 1.093 & - & 0.018 \\
\hline & ST & LT & LLTD & ST & LT & & \\
\hline & - & Lvl1973 & - & Lvl.1983 & $\begin{array}{l}\text { Li } \\
\text { Lvl.1991 }\end{array}$ & $\begin{array}{l}\text { LL1 } \\
-\end{array}$ & $\begin{array}{l}\text { L1 } \\
\text { Lvl.1993 }\end{array}$ \\
\hline \multicolumn{8}{|c|}{ Diagnostics: } \\
\hline Standard error & 0.021 & 0.031 & 0.013 & 0.021 & 0.023 & 0.023 & 0.010 \\
\hline Normality & 0.075 & 0.367 & 2.330 & 1.444 & 0.123 & 6.621 & 8.674 \\
\hline$h(n)$ & $4.254^{* *}(12)$ & $2.163_{(11)}$ & $0.755_{(11)}$ & $1.610_{(11)}$ & $0.511_{(9)}$ & $0.900_{(10)}$ & $0.177_{(10)}$ \\
\hline$r(1)$ & 0.278 & -0.007 & 0.013 & 0.238 & 0.159 & -0.136 & -0.083 \\
\hline$r(2)$ & -0.423 & -0.091 & 0.219 & -0.022 & -0.015 & 0.005 & -0.051 \\
\hline$r(3)$ & -0.329 & 0.165 & 0.002 & -0.177 & -0.298 & -0.160 & -0.170 \\
\hline$D W$ & 1.430 & 1.904 & 1.863 & 1.423 & 1.614 & 2.227 & 1.711 \\
\hline$Q(q, p)$ & $26.26^{* * * *}(6,4)$ & $2.266_{(6,4)}$ & $9.617_{(6,4)}^{* *}$ & $6.153_{(6,4)}$ & $4.694_{(6,4)}$ & $4.751_{(5,4)}$ & $4 \cdot 144_{(6,4)}$ \\
\hline$R$-squares & 0.880 & 0.900 & 0.887 & 0.772 & 0.822 & 0.849 & 0.958 \\
\hline \multicolumn{8}{|c|}{ Predictive failure tests (2013-2015): } \\
\hline Failure $\chi_{(3)}^{2}$ & 4.178 & 6.774 & 1.470 & 4.254 & 2.298 & 1.494 & 1.311 \\
\hline Cusum $t_{(3)}$ & 1.146 & -0.053 & -0.446 & -1.470 & -0.106 & -0.455 & 0.634 \\
\hline \multicolumn{8}{|c|}{ Likelihood ratio tests: } \\
\hline$L R \chi_{(2)}^{2}$ & - & $34.44 * * *$ & - & - & $27.08 * *$ & - & $22.53 * * *$ \\
\hline$L R \chi_{(1)}^{2}$ & $35.84 * * *$ & - & $21.12 * * *$ & $7.96 * *$ & - & $12.18 * * *$ & - \\
\hline
\end{tabular}




\begin{tabular}{|c|c|c|c|c|c|c|c|}
\hline \multicolumn{8}{|c|}{ Dependent variable: co2 (carbon emission in logs) } \\
\hline \multirow[b]{2}{*}{ Regressors: } & \multicolumn{7}{|c|}{ Countries: } \\
\hline & POR & SPA & SWE & SWZ & TUR & UK & US \\
\hline \multirow[t]{2}{*}{$\alpha_{0}(y)$} & $0.968 * * *$ & $0.784 * * *$ & $1.397 * * *$ & $0.986 * * *$ & $1.126^{* * *}$ & $1.099 * * *$ & $0.967 * * *$ \\
\hline & $(0.077)$ & $(0.160)$ & $(0.219)$ & $(0.056)$ & $(0.056)$ & $(0.082)$ & $(0.077)$ \\
\hline \multirow[t]{2}{*}{$\beta_{0}(e f f)$} & $0.924 * * *$ & $0.525 * * *$ & $1.542 * * *$ & $1.475^{* * *}$ & $0.854 * * *$ & $1.192 * * *$ & $0.479 * *$ \\
\hline & $(0.125)$ & $(0.161)$ & $(0.136)$ & $(0.070)$ & $(0.079)$ & $(0.168)$ & $(0.175)$ \\
\hline \multirow[t]{2}{*}{$\gamma_{0}\left(e f f^{2}\right)$} & - & - & - & $0.591 * * *$ & $-1.120^{*}$ & $0.367 * *$ & $-0.460 * *$ \\
\hline & & & & $(0.165)$ & $(0.555)$ & $(0.172)$ & $(0.134)$ \\
\hline \multirow[t]{2}{*}{$\varphi_{0}(a c t)$} & $0.705 * * *$ & $0.623 *$ & $1.772 * * *$ & $1.216 * * *$ & $0.844 * * *$ & - & $0.940 * * *$ \\
\hline & $(0.247)$ & $(0.366)$ & $(0.389)$ & $(0.199)$ & $(0.128)$ & & $(0.159)$ \\
\hline \multirow[t]{2}{*}{$\omega_{0}(T O)$} & - & $0.005 * *$ & $-0.004 * *$ & - & - & $0.003 *$ & - \\
\hline & & $(0.002)$ & $(0.002)$ & & & $(0.001)$ & \\
\hline$\omega_{1}\left(T O_{-1}\right)$ & - & - & - & - & - & - & $\begin{array}{l}0.009 * * * \\
(0.003)\end{array}$ \\
\hline \multirow[t]{2}{*}{$\psi_{0}(E S)$} & $-0.023 * * *$ & $-0.019 * * *$ & $-0.006 * * *$ & $-0.002 * * *$ & $-0.033 * * *$ & $-0.008 * * *$ & $-0.013^{* *}$ \\
\hline & $(0.002)$ & $(0.002)$ & $(0.001)$ & $(0.001)$ & $(0.003)$ & $(0.002)$ & $(0.005)$ \\
\hline$\lambda_{1}\left(\operatorname{co}_{-1}\right)$ & - & - & $\begin{array}{l}0.211 * * * \\
(0.075)\end{array}$ & - & - & $\begin{array}{l}-0.042 * * * \\
(0.052)\end{array}$ & - \\
\hline 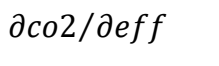 & 0.924 & 0.525 & 1.542 & 1.319 & 0.904 & 0.872 & 0.968 \\
\hline \multicolumn{8}{|c|}{ Long run elasticities: } \\
\hline$\alpha^{*}(y)$ & 0.968 & 0.784 & 1.771 & 0.986 & 1.126 & 1.055 & 0.967 \\
\hline$\beta^{*}(e f f)$ & 0.924 & 0.525 & 1.954 & 1.319 & 0.904 & 0.837 & 0.968 \\
\hline$\varphi^{*}(a c t)$ & 0.705 & 0.623 & 2.246 & 1.216 & 0.844 & - & 0.940 \\
\hline$\omega^{*}(\mathrm{TO})$ & - & 0.179 & -0.321 & - & - & 0.114 & 0.168 \\
\hline$\psi^{*}(E S)$ & -0.151 & -0.271 & -0.309 & -0.071 & -0.154 & -0.065 & -0.115 \\
\hline \multicolumn{8}{|c|}{ Variance of hyperparameters: } \\
\hline Irregular $\left(10^{-4}\right)$ & 2.624 & 0.000 & 4.097 & 0.554 & 1.113 & 0.436 & 0.185 \\
\hline Level $\left(10^{-4}\right)$ & 2.248 & 6.128 & 0.766 & 0.117 & 0.000 & 0.319 & 0.567 \\
\hline Slope $\left(10^{-4}\right)$ & - & - & - & - & 0.180 & 0.020 & 0.000 \\
\hline \multicolumn{8}{|l|}{ Trend: } \\
\hline \multirow{4}{*}{$\begin{array}{l}\text { Nature of trend } \\
\text { Interventions }\end{array}$} & LLT & & LLT & LLT & ST & $\mathrm{LT}$ & LLTD \\
\hline & - & & - & Lvl.1978 & - & Irr.1984, & Lvl.1989 \\
\hline & & & & & & Irr.2001 & Irr.2010 \\
\hline & & & & & & Lvl.2001 & \\
\hline \multicolumn{8}{|c|}{ Diagnostics: } \\
\hline Equation residu & & & & & & & \\
\hline Standard error & 0.024 & 0.023 & 0.023 & 0.009 & 0.015 & .010 & 0.008 \\
\hline Normality & 1.026 & 7.811 & 3.667 & 1.361 & 1.268 & 14.960 & 1.007 \\
\hline$H_{(h)}$ & $1.135_{(12)}$ & $0.412_{(12)}$ & $1.584_{(11)}$ & $1.149_{(11)}$ & $0.401_{(11)}$ & $4.108_{(10)}^{* * *}$ & $1.551_{(10)}$ \\
\hline$r_{(1)}$ & -0.007 & -0.059 & -0.173 & -0.089 & 0.028 & -0.138 & -0.286 \\
\hline$r_{(2)}$ & -0.149 & 0.206 & -0.019 & 0.046 & 0.039 & -0.012 & -0.138 \\
\hline$r_{(3)}$ & 0.178 & 0.115 & -0.013 & -0.432 & -0.202 & 0.022 & 0.283 \\
\hline$D W$ & 1.969 & 1.976 & 2.306 & 2.068 & 1.908 & 1.755 & 2.515 \\
\hline$Q_{(q, d)}$ & $6.270_{(6,5)}$ & $10.489^{* *}(6,5)$ & $7.245_{(5,4)}$ & $8.152_{(5,4)}$ & $6.663_{(6,4)}$ & $6.289_{(6,4)}$ & $6.849_{(6,4)}$ \\
\hline$R$-squares & 0.888 & 0.826 & 0.861 & 0.982 & $0.929^{(0,4)}$ & $0.948^{(0,4)}$ & $0.935^{(0,4)}$ \\
\hline Predictive Failu & ts $(2013-20$ & 5): & & & & & \\
\hline Failure $\chi_{(3)}$ & 1.702 & 2.367 & 1.934 & 5.494 & 2.896 & 7.400 & 0.733 \\
\hline Cusum $t_{(3)}$ & 0.708 & 0.320 & -0.220 & -1.896 & 1.498 & 1.619 & -0.402 \\
\hline Likelihood rati & & & & & & & \\
\hline$L R \chi_{(2)}$ & - & - & - & - & - & $9.25 * * *$ & - \\
\hline$L R \chi_{(1)}$ & $12.65 * * *$ & $46.71 * * *$ & $12.64 * * *$ & $10.82 * * *$ & $26.01 * * *$ & - & $4.82 * *$ \\
\hline
\end{tabular}


This means for the OECD countries whose economy compositions were found shifting towards less energy-intensive sectors (i.e. declining activity index), their $\mathrm{CO}_{2}$ emissions decrease and vice versa. The coefficients vary from 0.610 (Australia) to 2.895 (for Finland).

Similarly, the energy efficiency index generally has a significant positive impact on $\mathrm{CO}_{2}$ emissions. A positive relationship with $\mathrm{CO}_{2}$ emissions implies that as the energy efficiency index decreases (i.e. energy efficiency improvement) $\mathrm{CO}_{2}$ emissions decreases. The coefficients vary from 0.468 (Netherlands) to 1.942 (Norway). Also, the squared term of the efficiency index for 10 OECD countries was also found to be significant and 5 of the square-terms (for Denmark, Japan, Luxembourg, Turkey and US) have a negative sign. Since these 5 countries have declining energy efficiency index from the start, the nonlinear effect of energy efficiency on $\mathrm{CO}_{2}$ emission forms a U-shape, i.e., the declining energy efficiency index decreases $\mathrm{CO}_{2}$ emissions to a certain minimum after which it starts to increase $\mathrm{CO}_{2}$ emissions. Thus, there is a declining return to energy efficiency (in terms of marginal reduction in $\mathrm{CO}_{2}$ emission over time). In contrast, the other 5 countries (Australia, Hungary, Norway, Switzerland and UK) with positive sign indicate an increasing return to their energy efficiency in terms of reduction in $\mathrm{CO}_{2}$ emission over time. For the remaining 20 countries, the energy efficiency index has precisely a linear positive impact of $\mathrm{CO}_{2}$ emissions.

Lastly, the control variables (cleaner energy substitution and trade openness) included in the model also have significant impacts on $\mathrm{CO}_{2}$ emissions. As expected, cleaner energy substitution has a negative impact on $\mathrm{CO}_{2}$ emissions. Also, for Chile, Denmark and Norway the lagged terms of cleaner energy substitution have significant impacts on $\mathrm{CO}_{2}$ emissions. Thus, cleaner energy substitution is an important factor that has to be accounted for in a model of this nature. The impacts of trade openness on $\mathrm{CO}_{2}$ emissions confirm the mixed evidence in the literature on whether trade openness is good for the environment.

With some dynamics in the preferred models, we are able to separate the short run (SR) from the long run (LR) elasticities (also reported in Table 3). ${ }^{28}$ There are variations in the LR income-, efficiency-, structural shift-, cleaner energy substitution-, and trade openness -elasticities of $\mathrm{CO}_{2}$ emissions. Structural shift in the composition of the economy has the highest LR elasticities ranging from 0.610 (Australia) to 2.895 (Finland). Next is energy efficiency with LR elasticities varying from 0.092 (Netherlands) to 1.954 (Sweden). Trade openness and cleaner energy substitution have the least absolute LR elasticities ranging from 0.076 (Italy) to 0.615 (Finland), and 0.026 (Poland) to 0.853 (Iceland) respectively.

\footnotetext{
${ }^{28}$ We derive LR elasticities using the formula stated in footnote 18; SR elasticities are the coefficients of the variables at levels and the marginal effect of energy efficiency.
} 
Of interest also is the difference between the SR and LR energy efficiency elasticities. Of the 4 countries that we separated their SR from LR energy efficiency effects (due to the significance of the dynamic terms), 3 have a SR > LR and 1 has a SR < LR. Perhaps it is reflecting the time-lag taken for $\mathrm{CO}_{2}$ emissions to fully respond to improvement in energy efficiency. It may also be linked to possible impacts of (indirect) rebound effects of energy efficiency on $\mathrm{CO}_{2}$ emissions. Energy efficiency improvement may lead to rebound effects that could potentially results in the total or partial erosion of energy savings, thereby reducing $\mathrm{CO}_{2}$ emissions with a lesser proportion. As such, for Belgium, New Zealand and UK with a SR > LR, the improvement in their energy efficiency, which is very significant in reducing $\mathrm{CO}_{2}$ emissions in the $\mathrm{SR}$, may have resulted in rebound effects that reduce energy savings in the $\mathrm{LR}$, thereby reducing $\mathrm{CO}_{2}$ emissions with a lesser proportion. For Sweden with a $\mathrm{SR}<$ LR suggests that its energy efficiency gains in the SR may have, through learning, continuous awareness and policy, resulted in more energy savings in the LR, thereby reducing $\mathrm{CO}_{2}$ emissions with a higher proportion. In all, taking into account the possible (indirect) rebound effects, energy efficiency improvement is still very important for protecting the environment.

Apart from the heterogeneity in the estimated elasticities, it is pertinent to emphasize the various estimated UCETs given in Fig. 2. Notably, the $L R$ test for all the preferred models shows that setting the hyperparameters to zero for a deterministic trend is rejected so that the UCETs have different stochastic trend. Four different trend specifications, which are clearly non-linear, are observed across the 30 models, i.e. local, local level, local level with drift and smooth trend where the trends are stochastic both in level and slope $\sigma_{\eta}^{2} \neq 0 ; \sigma_{\xi}^{2} \neq 0$, stochastic in the level but no slope, i.e. $\sigma_{\eta}^{2} \neq 0$, stochastic in the level but fixed in the slope, i.e. $\sigma_{\eta}^{2} \neq$ $0 ; \sigma_{\xi}^{2}=0$, and fixed in the level but stochastic in the slope, i.e. $\sigma_{\eta}^{2}=0 ; \sigma_{\xi}^{2} \neq 0$ respectively.

In general, the estimated UCETs show that after controlling for energy efficiency as well as a structural shift in economic activities, income, cleaner energy substitution and trade openness effects, there are still other important exogenous influences. As discussed above, we associate these with noneconomic effects such as lifestyles and tastes, values, awareness and attitudes towards the environment. The exogenous influences as observed in the UCETs vary from one country to another, reflecting country specific effect. Specifically, the general trends of the estimated UCETs for Australia, Finland, Greece, Israel, Mexico, Netherlands, New Zealand, Portugal, Sweden and Turkey are upward sloping over the estimation period, suggesting increasing 'carbon emitting' behaviour and lifestyle. 
Fig. 2: Estimated UCETs $\hat{\mu}$ (in logs) for preferred OECD country-level STSMs, 1971-2015
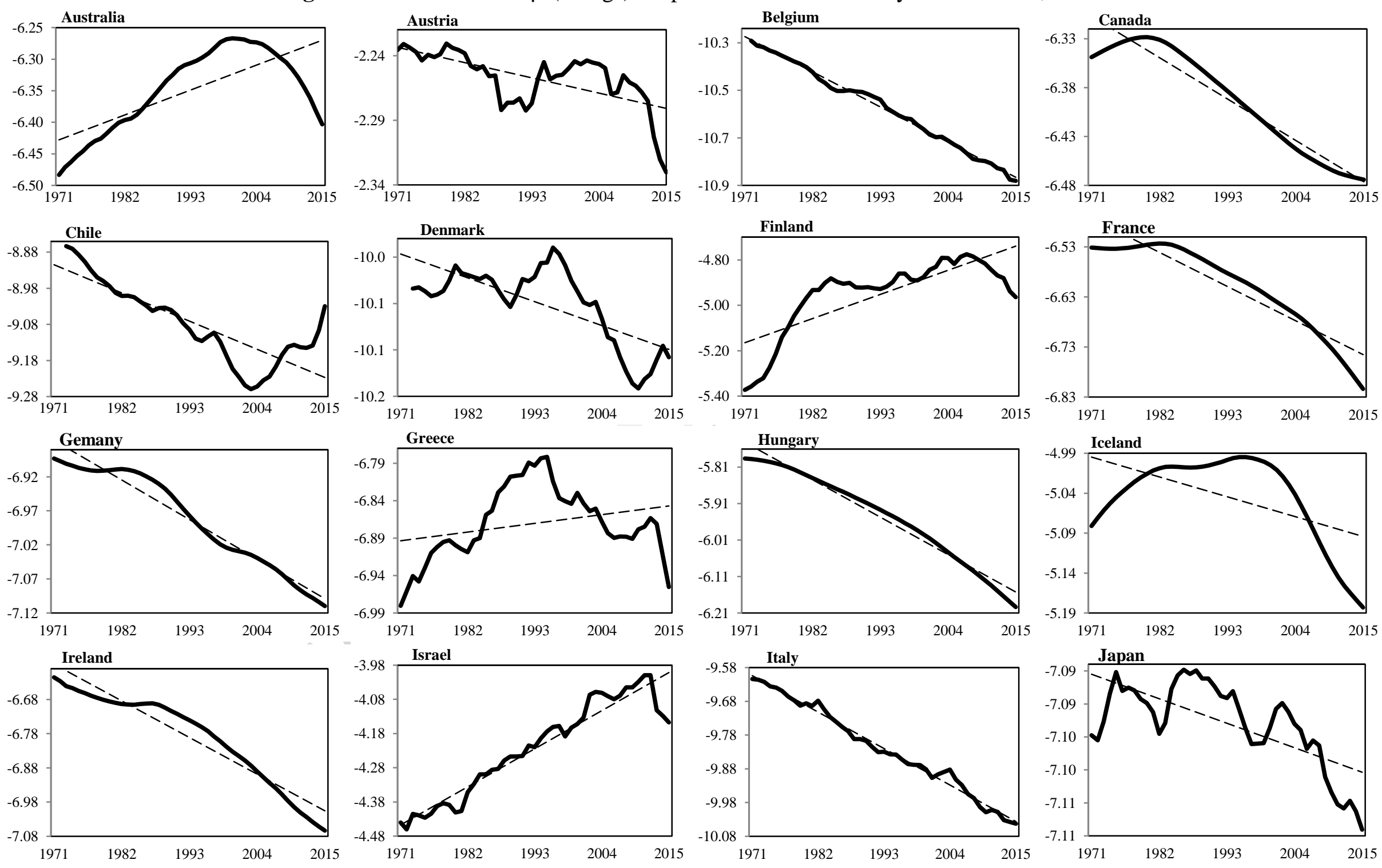


\section{ACCEPTED MANUSCRIPT}
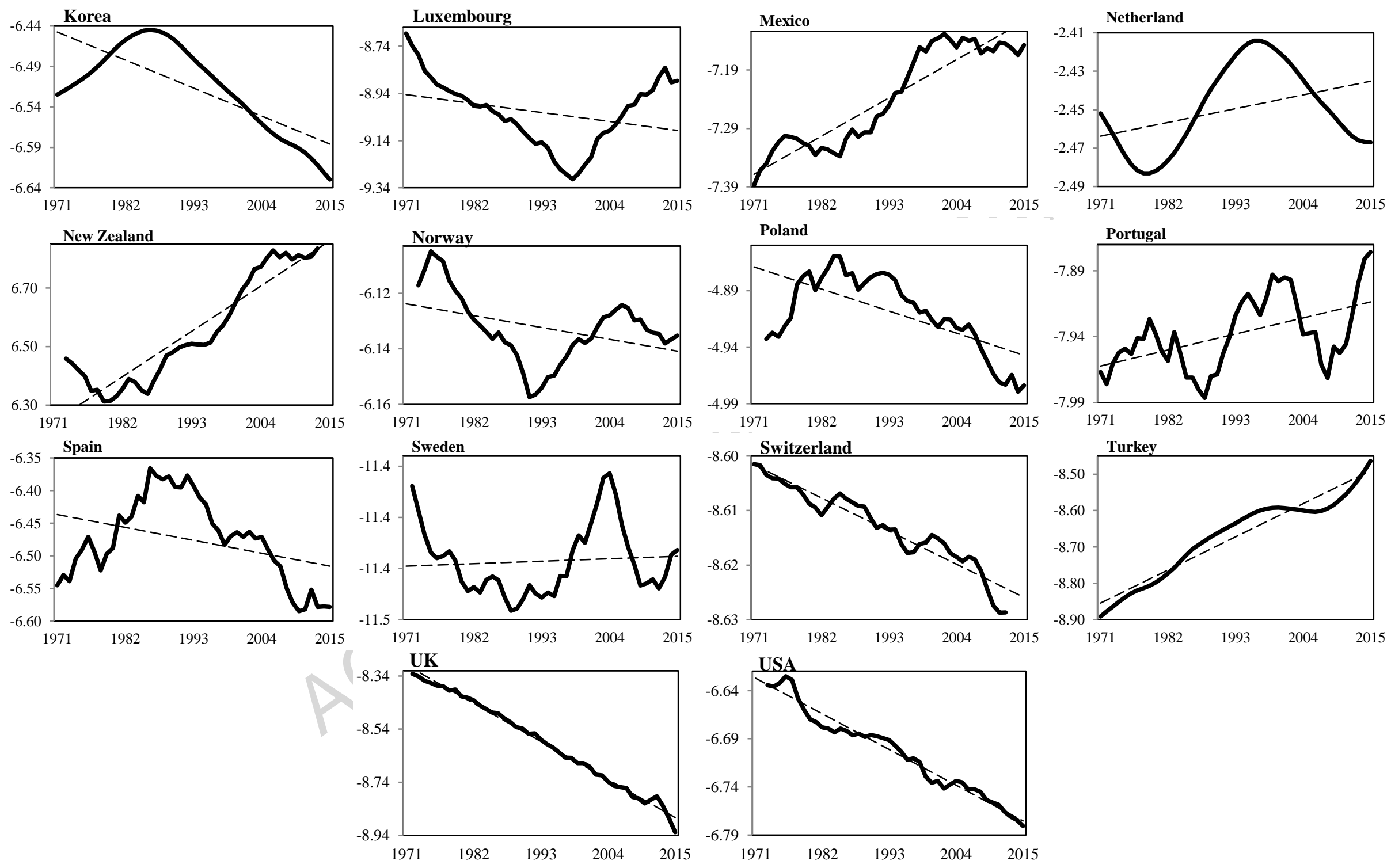

Note: solid lines are the estimated UCETs; dotted lines are trends of the estimated UCETs 
Table 4: Contribution to the average per annum change in $\mathrm{OECD} \mathrm{CO}_{2}$ emissions (in logs)

\begin{tabular}{|c|c|c|c|c|c|c|c|c|c|}
\hline & & Avera & e percent & age (197 & $-2013) c$ & ntributi & ns from: & Fitted & Actual \\
\hline & & $\mathrm{y}$ & eff & act & TO & CES & ExNEF & $\Delta \widehat{\operatorname{co} 2}$ & $\Delta \operatorname{co} 2$ \\
\hline & Australia & 1.573 & -0.502 & 0.027 & -0.166 & 0.000 & 0.388 & 1.320 & 1.064 \\
\hline & Austria & 0.720 & -0.732 & 0.196 & 0.221 & -0.023 & -0.011 & 0.371 & 0.391 \\
\hline & Belgium & 2.304 & -1.034 & 0.119 & -0.710 & -0.061 & -1.523 & -0.905 & -0.926 \\
\hline & Canada & 1.522 & -0.674 & -0.198 & 0.000 & -0.064 & -0.332 & 0.253 & 0.005 \\
\hline & Chile & 3.148 & -1.087 & 0.145 & 0.268 & 0.000 & -0.926 & 1.548 & 1.736 \\
\hline & Denmark & 2.111 & -3.026 & 0.246 & 0.000 & -0.007 & -0.079 & -0.755 & -1.274 \\
\hline & Finland & 2.100 & -1.430 & 0.612 & -0.315 & -0.173 & 1.077 & 1.872 & 0.111 \\
\hline & France & 1.434 & -1.690 & 0.273 & 0.147 & -0.379 & -0.626 & -0.840 & -1.280 \\
\hline & Germany & 1.850 & -1.856 & -0.043 & 0.000 & -0.012 & -0.561 & -0.622 & -0.729 \\
\hline & Greece & 1.047 & -0.143 & 1.112 & 0.000 & -0.002 & 0.308 & 2.321 & 2.217 \\
\hline & Hungary & 1.705 & -1.232 & 0.251 & -0.301 & -0.027 & -1.110 & -0.713 & -0.722 \\
\hline & Iceland & 1.556 & 0.027 & 0.000 & 0.123 & -0.889 & -0.871 & -0.054 & -0.244 \\
\hline & Ireland & 2.649 & -1.982 & -0.178 & 0.360 & -0.002 & -0.519 & 0.327 & 0.183 \\
\hline & Israel & 1.313 & -0.196 & -0.311 & 0.000 & -0.014 & 0.868 & 1.660 & 1.725 \\
\hline OECD & Italy & 1.854 & -0.934 & 0.180 & 0.057 & -0.001 & -0.941 & 0.214 & 0.313 \\
\hline & Japan & 1.874 & -1.504 & 0.022 & 0.042 & 0.001 & 0.054 & 0.489 & 0.686 \\
\hline & Korea & 5.567 & -1.020 & 0.837 & 0.000 & -0.046 & -0.131 & 5.207 & 4.800 \\
\hline & Luxembourg & 3.227 & -2.701 & -0.795 & 0.000 & -0.001 & -2.084 & -2.354 & -2.395 \\
\hline & Mexico & 1.302 & -0.745 & 0.865 & 0.000 & -0.002 & 0.584 & 2.004 & 1.962 \\
\hline & Netherlands & 0.692 & -0.501 & -0.147 & 0.000 & -0.003 & -0.134 & -0.094 & -0.098 \\
\hline & New Zealand & 0.268 & 0.037 & -0.120 & -0.205 & -0.294 & 0.889 & 0.576 & 1.026 \\
\hline & Norway & 1.801 & -1.491 & 0.039 & 0.140 & -0.005 & -0.034 & 0.450 & 0.459 \\
\hline & Poland & 2.153 & -2.301 & 0.318 & -0.141 & 0.000 & -0.136 & -0.107 & -0.313 \\
\hline & Portugal & 1.939 & 0.100 & 0.208 & 0.000 & 0.004 & 0.037 & 2.288 & 2.358 \\
\hline & Spain & 1.419 & 0.014 & -0.118 & 0.180 & -0.076 & -0.086 & 1.333 & 1.173 \\
\hline & Sweden & 2.949 & -4.116 & 0.414 & -0.427 & -0.268 & -0.036 & -1.485 & -2.189 \\
\hline & Switzerland & 0.922 & -1.123 & -0.028 & 0.000 & -0.042 & -0.179 & -0.450 & -0.472 \\
\hline & Turkey & 2.639 & -0.244 & 0.308 & 0.000 & -0.022 & 0.839 & 3.520 & 3.062 \\
\hline & UK & 1.944 & -1.693 & 0.000 & 0.086 & -0.011 & -1.393 & -1.067 & -1.038 \\
\hline & US & 1.732 & -2.313 & 0.000 & 0.080 & -0.027 & -0.018 & -0.546 & -0.622 \\
\hline
\end{tabular}

For the remaining 20 countries, the general trends are downward sloping over time, showing exogenous 'carbon mitigating' behaviour and lifestyle. That is, there are improving behaviours, values and lifestyle to conserve the environment in these countries. This confirms the findings in Broadstock and Hunt (2010) and Chitnis and Hunt (2012), and underscore the need to also consider exogenous noneconomic factors such as tastes and lifestyles in energy and environmental models. This is particularly important as there are growing needs for potentially effective regulations or policies to mitigate $\mathrm{CO}_{2}$ emissions.

To shed more light on the importance of energy efficiency improvement and the noneconomic factors, we estimate Eq. (14) to derive the relative contributions of the drivers to the annual change in $\mathrm{CO}_{2}$ emissions. The estimated relative contributions of income, efficiency, structural shift, cleaner energy substitution, trade openness and ExNEF over the period 1971-2013 are summarised in Table 4. For most of the OECD countries considered, income has the largest positive contribution driving up the average per annum change in $\mathrm{CO}_{2}$ emissions. Improving energy efficiency has the biggest contribution in driving down the changes in $\mathrm{CO}_{2}$ emissions during this period so that despite the relatively strong positive contribution from income, the growth in $\mathrm{CO}_{2}$ emissions is slowed down considerably. 
Although structural shift contributes to the reduction in growth of $\mathrm{CO}_{2}$ emissions for some countries, its contribution to increasing $\mathrm{CO}_{2}$ emissions for others is relatively greater. For 21 OECD countries, ExNEF contributes considerably to the decline in growth of $\mathrm{CO}_{2}$ emissions relative to trade openness and cleaner energy substitution. This implies that the effect of ExNEF, in particular, on $\mathrm{CO}_{2}$ emissions should not be ignored. Moreover, the fitted average annual change in $\mathrm{CO}_{2}$ emissions is positive (i.e. increasing) for $17 \mathrm{OECD}$ countries, while the remaining 13 OECD countries have negative change (i.e. decreasing).

Finally, for a robustness check, we compare the fitted average annual change in $\mathrm{CO}_{2}$ emissions $(\widehat{\triangle C O 2})$ to the actual average annual change in $\mathrm{CO}_{2}$ emissions $(\Delta c o 2)$. The last two columns of Table 4 show that the two estimates are very close in value and identical in sign. Also, the fitted changes are in line with the actual changes over the long periods (the graphs are available upon request from authors) indicating strong evidence that our estimates of relative contributions to annual change in $\mathrm{CO}_{2}$ emissions are reliable for policy formulation.

\subsubsection{Panel data results}

To complement the time series results, we estimate the panel data model of the impact of energy efficiency improvements on $\mathrm{CO}_{2}$ emissions for the OECD countries as a group over the period 1971-2015. We report the static panel regression Eq. (11) estimated by the fixed effects in columns I (panel of all OECD) and II (panel of OECD but excluding energy inefficient countries) of Table 5. The dynamic panel regression Eq. (12) estimated by the LSDVC is reported in columns III (panel of all OECD) and IV (panel of OECD excluding energy inefficient country) of Table 5 . We start by discussing the diagnostic tests addressing the econometric issues that may arise in the panel model.

The panel data model Eq. (11) may be prone to some econometric issues including unobserved heterogeneity, endogeneity and cross-section dependence. The Hausman test for correlated fixed effects $\chi^{2}=16.95$ ( vvalue $=0.01$ ) for panel I and $\chi^{2}=25.13$ ( pvalue $=0.00$ ) for panel II rejected the null of exogeneity in favour of fixed effects method. We used the Durbin-Wu-Hausman technique to test for endogeneity of energy efficiency, structural shift, and trade openness using their first and second lags as instruments. For panel I, the test failed to reject the null hypothesis of exogeneity for the three variables with $\chi^{2}=3.73$ (pvalue=0.05) and 0.17 (pvalue $=0.69$ ) and 0.12 (pvalue $=0.73$ ) respectively. Similarly, for panel II, the test failed to reject the null for exogeneity for the three variables with $\chi^{2}=1.60$ (pvalue $=0.21$ ), 0.37 (pvalue $=0.54$ ), and 0.12 (pvalue $=0.73$ ) respectively and the overall results using IV also remain unchanged from the FE results, thus, endogeneity is not an issue in this model. 
Table 5: Estimated panel data of the drivers of OECD CO $\mathrm{CO}_{2}$ emissions, 1971-2015 Dependent variable: co2 (carbon emissions in logs)

\begin{tabular}{|c|c|c|c|c|}
\hline Estimation method: & $\mathrm{FE}$ & FE & LSDVC & LSDVC \\
\hline Independent variables & I & II & III & IV \\
\hline$\phi_{0}($ Constant $)$ & $\begin{array}{l}-7.803 * * * \\
(0.264)\end{array}$ & $\begin{array}{l}-7.572 * * * \\
(0.282)\end{array}$ & - & - \\
\hline$\alpha_{0}(y)$ & $\begin{array}{l}1.034 * * * \\
(0.028)\end{array}$ & $\begin{array}{l}1.017 * * * \\
(0.030)\end{array}$ & $\begin{array}{l}0.285 * * * \\
(0.023)\end{array}$ & $\begin{array}{l}0.266 * * * \\
(0.025)\end{array}$ \\
\hline$\beta_{0}(e f f)$ & $\begin{array}{l}0.898 * * * \\
(0.046)\end{array}$ & $\begin{array}{l}0.819 * * * \\
(0.069)\end{array}$ & $\begin{array}{l}0.228 * * * \\
(0.032)\end{array}$ & $\begin{array}{l}0.201 * * * \\
(0.047)\end{array}$ \\
\hline$\gamma_{0}\left(e f f^{2}\right)$ & $\begin{array}{l}-0.273 * * * \\
(0.033)\end{array}$ & $\begin{array}{l}-0.326^{* * *} \\
(0.049)\end{array}$ & $\begin{array}{l}-0.071 * * * \\
(0.026)\end{array}$ & $\begin{array}{l}-0.080 * * * \\
(0.037)\end{array}$ \\
\hline$\varphi_{0}(a c t)$ & $\begin{array}{l}1.331 * * * \\
(0.073)\end{array}$ & $\begin{array}{l}1.438 * * * \\
(0.089)\end{array}$ & $\begin{array}{l}0.302 * * * \\
(0.049)\end{array}$ & $\begin{array}{l}0.306 * * * \\
(0.052)\end{array}$ \\
\hline$\omega_{0}(T O)$ & $\begin{array}{l}-0.002 * * * \\
(0.000)\end{array}$ & $\begin{array}{l}-0.002^{* * *} \\
(0.000)\end{array}$ & $\begin{array}{l}-0.0004 * * * \\
(0.0002)\end{array}$ & $\begin{array}{l}-0.0004 * * * \\
(0.0002)\end{array}$ \\
\hline$\psi_{0}(C E S)$ & $\begin{array}{l}-0.011 * * * \\
(0.001)\end{array}$ & $\begin{array}{l}-0.011^{* * * *} \\
(0.001)\end{array}$ & $\begin{array}{l}-0.004 * * * \\
(0.001)\end{array}$ & $\begin{array}{l}-0.003 * * * \\
(0.001)\end{array}$ \\
\hline$\lambda_{1}\left(\operatorname{co2}_{-1}\right)$ & - & - & $\begin{array}{l}0.729 * * * \\
(0.018)\end{array}$ & $\begin{array}{l}0.744 * * * \\
(0.020)\end{array}$ \\
\hline Marginal effect: $\partial c o 2 / \partial e f f$ & $\begin{array}{l}1.037 * * * \\
(0.035)\end{array}$ & $\begin{array}{l}1.018 * * * \\
(0.047)\end{array}$ & $\begin{array}{l}0.265^{* * *} \\
(0.026)\end{array}$ & $\begin{array}{l}0.251 * * * \\
(0.033)\end{array}$ \\
\hline $\begin{array}{l}\text { Time dummies included } \\
\text { Observations }\end{array}$ & $\begin{array}{l}\text { Yes } \\
1350\end{array}$ & $\begin{array}{l}\text { Yes } \\
1170\end{array}$ & $\begin{array}{l}\text { Yes } \\
1320\end{array}$ & $\begin{array}{l}\text { Yes } \\
1144\end{array}$ \\
\hline $\begin{array}{l}\text { No. of countries } \\
\text { Diagnostics: }\end{array}$ & 30 & 26 & 30 & 26 \\
\hline$R^{2}$ & 0.892 & 0.883 & - & - \\
\hline$F-t e s t$ & $4914.50 * * *$ & $7444.57 * * *$ & - & - \\
\hline $\operatorname{Hausman}\left(\chi^{2}\right)$ & $16.95 * *$ & $25.13 * * *$ & - & - \\
\hline Restriction test I: & $158.98 * * *$ & $728.32 * * *$ & $85.57 * * *$ & $81.72 * * *$ \\
\hline Elasticities & SR (III) & SR (IV) & LR (III) & LR (IV) \\
\hline$\alpha^{*}(y)$ & $0.285 * * *$ & $0.266 * * *$ & $1.054 * * *$ & $1.038 * * *$ \\
\hline$\beta^{*}(e f f)$ & $0.265 * * *$ & $0.251 * * *$ & $0.981 * * *$ & $0.978 * * *$ \\
\hline$\varphi^{*}(a c t)$ & $0.303 * * *$ & $0.306^{* * *}$ & $1.117 * * *$ & $1.196 * * *$ \\
\hline$\omega^{*}(T O)$ & $-0.026 * * *$ & $-0.025 * *$ & $-0.098 * * *$ & $-0.099 * *$ \\
\hline$\psi^{*}(C E S)$ & $-0.053 * * *$ & $-0.051 * * *$ & $-0.196 * * *$ & $-0.198 * * *$ \\
\hline Relative co & SR (III) & SR (IV) & LR (III) & LR (IV) \\
\hline$Y$ & $0.494 \%$ & $0.460 \%$ & $1.826 \%$ & $1.795 \%$ \\
\hline Eff & $-0.469 \%$ & $-0.454 \%$ & $-1.731 \%$ & $-1.772 \%$ \\
\hline Act & $0.015 \%$ & $0.018 \%$ & $0.057 \%$ & $0.069 \%$ \\
\hline TO & $-0.022 \%$ & $-0.021 \%$ & $-0.083 \%$ & $-0.083 \%$ \\
\hline CES & $-0.013 \%$ & $-0.012 \%$ & $-0.048 \%$ & $-0.048 \%$ \\
\hline ExNEF & $-0.085 \%$ & $-0.090 \%$ & $-0.315 \%$ & $-0.353 \%$ \\
\hline$\widehat{\Delta C O 2}$ & $-0.080 \%$ & $-0.100 \%$ & $-0.295 \%$ & $-0.392 \%$ \\
\hline$\Delta c o 2$ & $-0.190 \%$ & $-0.223 \%$ & $-0.190 \%$ & $-0.223 \%$ \\
\hline
\end{tabular}

Notes of the table:

1. All estimations are undertaken in STATA; ***, ** and * denote $99 \%, 95 \%$ and $90 \%$ significance levels respectively;

2. Driscoll-Kraay standard errors and bootstrapped standard errors are in parenthesis for FE and LSDVC respectively;

3. All variables in small letters are in log form and variables in capital letters are in levels;

4. Models I \& III correspond to Eqs (11) \& (12) respectively and both models are estimated using panel data of 30 OECD countries.

5. Models II \& IV also correspond to Eqs (11) \& (12) respectively but the data exclude the 4 OECD countries (Israel, New Zealand,

Portugal and Spain) that we found to be energy inefficient;

6. F-test is test for the joint significant of the parameters;

7. Hausman $\chi^{2}$ is a specification test for correlated fixed effects;

8. Restriction test $I$ is the $F$-statistic from the $F$-test of no fixed time effects restriction;

9. The long run $(L R)$ elasticities for models III and IV are estimated as $\hat{\Gamma}_{i} /\left(1-\hat{\lambda}_{1}\right)$ where $\hat{\Gamma}_{i}$ and $\hat{\lambda}_{1}$ are the estimated parameter for variable $i$ and the lagged $\mathrm{CO}_{2}$ emissions respectively;

10. The relative contributions of the variables to changes in $\mathrm{CO}_{2}$ emission is based on the panel data version of Eq. (14). 
However, FE results may be biased in the presence of cross-sectional correlation. Although OECD is made up sovereign countries with each country having a great deal of autonomy, it is still likely that the countries respond similarly to common shocks implying that their economic performance, energy consumption and hence energy efficiency and $\mathrm{CO}_{2}$ emissions may be correlated (Moshiri and Duah, 2016). We conduct a test for cross-sectional correlation using Pesaran (2004) test, which follows a standard normal distribution and handles balanced panel as in this case. The Pesaran test values -3.00 (pvalue $=0.00)$ and -3.46 (pvalue $=0.00$ ) for panels I and II respectively reject the null of cross-sectional independency. Consequently, for the FE, we report the Driscoll and Kraay (1998) standard error, which is robust to very general forms of cross sectional and temporal dependence. Finally, the estimates of the standard $F$-test reported in Table 5 clearly reject the null hypothesis that the time dummies are jointly equal to zero for panels I and II implying that time dummies are a significant proxy for UCETs in these panels.

Table 5 shows that the estimated coefficients of the variables are significant and have the expected signs for panel I. Energy efficiency has a nonlinear effect on $\mathrm{CO}_{2}$ emissions and the marginal effect is computed at the mean value. The degrees of the impact of structural shift and energy efficiency indices on $\mathrm{CO}_{2}$ emissions are 1.331 and 1.037 respectively. That is, a $1 \%$ decrease in efficiency index will reduce $\mathrm{CO}_{2}$ emissions by $1.037 \%$. Trade openness has the least effect and shows that trade is good for the environment, which slightly deviates from the mixed evidence from the time series model, and the effect is statistically significant. Also, the entire coefficient estimates of the dynamic panel model (panel III) including the lagged dependent variable are significant with the expected signs.

Using 26 OECD countries, which exclude the 4 countries that we found to be energy inefficient, to estimate the static model (panel II) and dynamic model (panel IV) leads to changes in the estimated parameters. The exceptions being the coefficients of trade openness and cleaner energy substitute that are unchanged. Also, the lagged $\mathrm{CO}_{2}$ emissions for both panels III and IV shows a positive impact on the current level of $\mathrm{CO}_{2}$ emissions indicating that, if the existing environmental policies have not been effective to abate $\mathrm{CO}_{2}$ emissions in the previous year, it will lead to a spillover effect that will increase current $\mathrm{CO}_{2}$ emissions.

There are variations in the elasticities obtained from the dynamic model via LSDVC (reported in Table 5). Specifically, the LR elasticities are about four times the corresponding SR elasticities for panel III, indicating that the variables are more effective in influencing $\mathrm{CO}_{2}$ emissions in the LR than they do in the SR. With more time, energy efficiency improvements become more significant in mitigating $\mathrm{CO}_{2}$ emissions. 

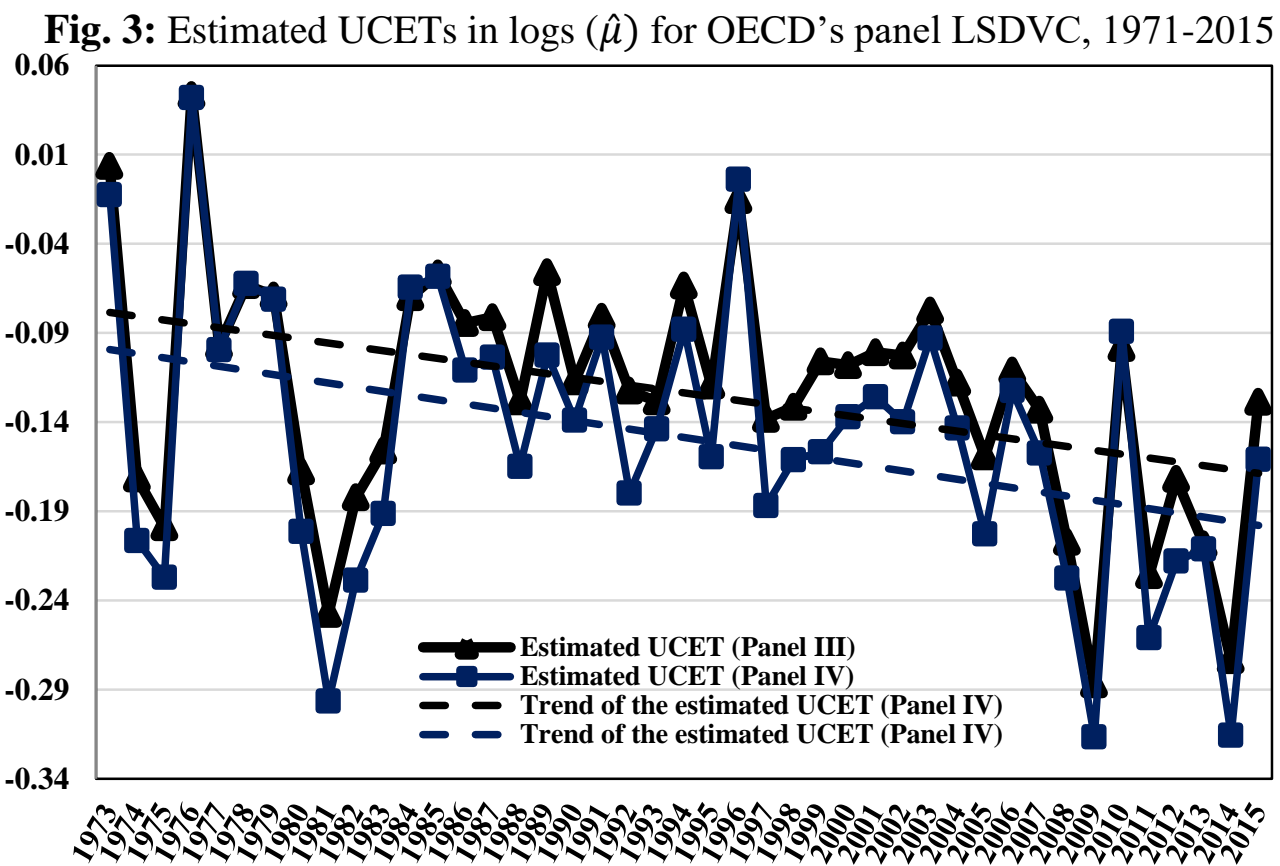

A $1 \%$ increase in energy efficiency will reduce $\mathrm{CO}_{2}$ emissions by $0.265 \%$ in the SR and with a larger size of $0.981 \%$ in the LR. This could also be seen as (an indirect) super conservation of rebound effects on $\mathrm{CO}_{2}$ emissions, in which, energy efficiency gains in the SR result in more energy savings in the LR, thereby reducing $\mathrm{CO}_{2}$ emissions with a higher proportion. Excluding the 4 energy inefficient countries from the group (i.e. panel IV) leads to just slight changes in the elasticities both in the SR and LR. Thus, the inclusion of the energy inefficient countries in the panel OECD countries has a minimal impact in driving down the net effect of energy efficiency on $\mathrm{CO}_{2}$ emissions. Notably, the estimated LR elasticities are comparable with the LR elasticities from the time series model. E.g. all the estimated LR elasticities income (1.054), efficiency (0.981), structural shift (1.117), trade (-0.098) and cleaner energy substitution (-0.196) elasticities for Panel III fall in the range of [-0.391]-[1.771], [0.092][1.954], [0.583]-[2.895], [-0.615]-[0.375] and [-0.853]-[-0.026] for the corresponding LR elasticities from the time series model in Table 3.

The trends of the panel data version of the UCETs given by the estimated coefficients of the time dummies are plotted in Fig. 3. Following Adeyemi and Hunt (2007) and Griffin and Schulman (2005), if there have been significant progressions in the ExNEF (such as positive lifestyle, taste, behaviour and attitude towards the environment) that are driving the UCET, we expect the UCET, estimated as $\left(\hat{\theta}_{t} / 1-\hat{\lambda}_{1}\right)$, to be reflected in declining values. In Fig. 3, the UCETs reflect variation from year to year, which is consistent with the estimated UCETs from the time series model. The large declines in 1974-75 and 1979-80 observed in the UCETs correspond to the period of the OPEC oil embargo and Iran-Iraq war respectively. 
Fig. 4: Contributions to annual change in OECD panel $\mathrm{CO}_{2}$ emissions, in logs $(\Delta \widehat{\mathrm{CO} 2})$

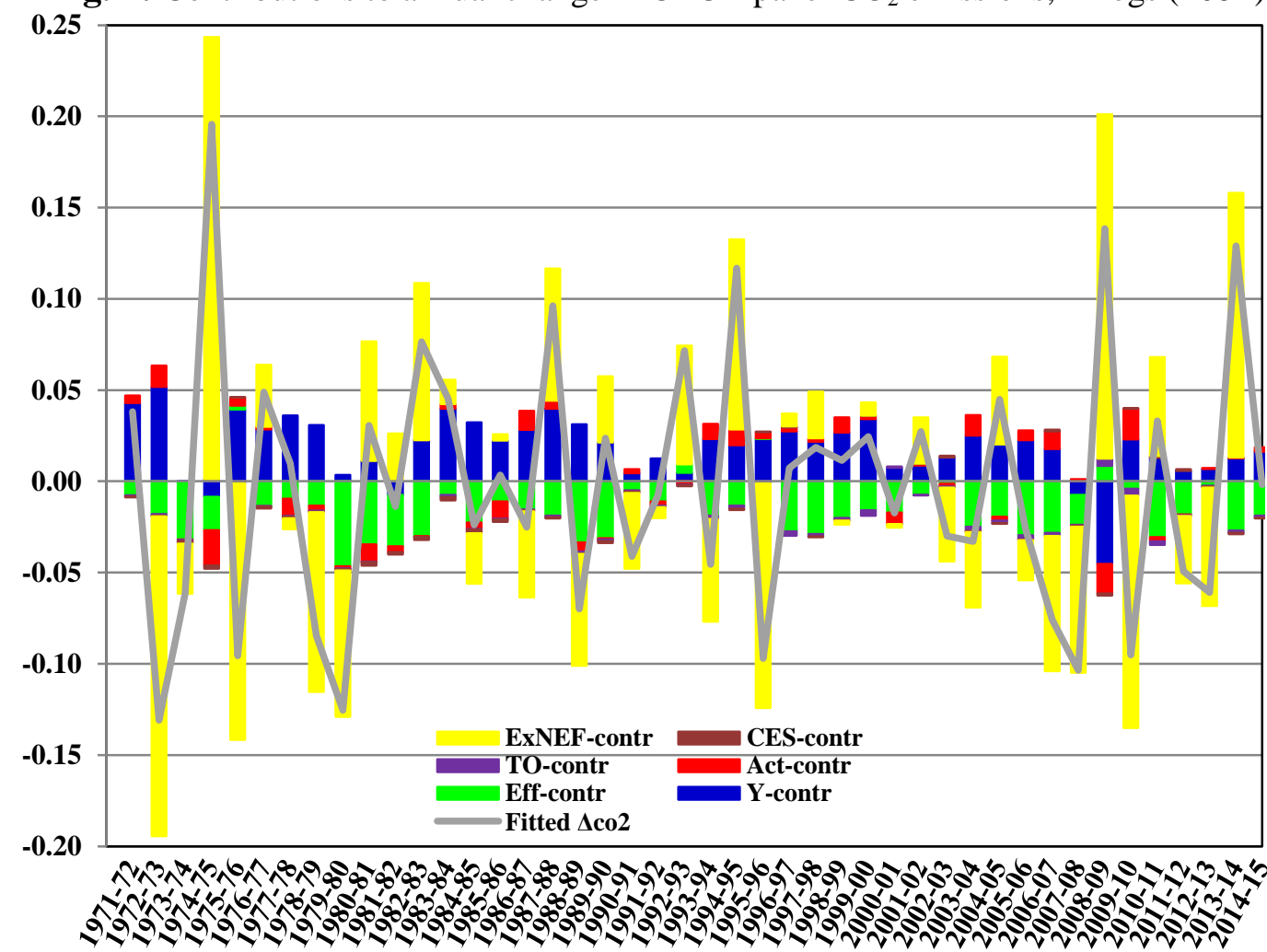

These two events arguably led to increases in the price of crude oil and consequently, energy saving and carbon mitigating behaviour. There is also a remarkable decline in 2006-10, the first commitment period of the Kyoto protocol.

The implicit trend of the long run UCET for the 30 countries as a group (panel III) is generally downward slopping - suggesting an exogenous 'carbon mitigating' behaviour, attitude, lifestyle etc. Also, excluding the 4 energy inefficient countries makes the long run UCET (panel IV) shift further downward. The observed trends of the UCET for the group of the countries are not surprising given that 20 of the 30 countries show downward sloping trend in their individual UCET in the time series model given in Fig. 2.

Lastly, using the panel data version of Eq. (14), we quantify the contributions of the drivers to the annual change in $\mathrm{CO}_{2}$ emissions. This is shown in Fig. 4 and summarised at the end of Table 5. The results further highlight the importance of the improvement in energy efficiency and ExNEF (captured by UCET) to the environment. It is clear from Fig. 4 that the relative contributions of the variables driving the annual change in $\mathrm{CO}_{2}$ emissions are relatively stable over the period. Income and structural shift towards energy-intensive industries remain significant positive drivers for most of the period. Increasing income makes the largest positive contribution, on average $1.826 \%$ per annum followed by structural shift with about $0.057 \%$ per annum as in the end of Table 5 (panel III (LR (III))). 
In contrast, improved energy efficiency, trade openness, cleaner energy substitution and ExNEF are driving down the growth in $\mathrm{CO}_{2}$ emissions. Among these drivers, energy efficiency improvement constitutes the largest share, on average $1.731 \%$ per annum. Thus, despite the relatively strong positive contributions from income and structural shift, the annual growth in $\mathrm{CO}_{2}$ emissions slowed down significantly, driven primarily by energy efficiency and the relatively small contributions from ExNEF, trade openness and cleaner energy substitution. These results are broadly consistent with the time series results reported in Table 3.

\section{Concluding remarks}

This paper develops a two-step method to examine the effect of energy efficiency improvement on $\mathrm{CO}_{2}$ emissions at the macro level for 30 OECD countries. First, an index decomposition analysis is used to derive energy efficiency from energy intensity. Secondly, we use STSM and LSDVC models in a modified dynamic 3E framework to examine and quantify the impact of energy efficiency improvement on $\mathrm{CO}_{2}$ emissions controlling for other factors including the exogenous noneconomic factors (ExNEF) such as taste, lifestyle etc.

Our findings of the first step, the decomposition results for the OECD as a group, indicate that most of the decreases (i.e. progressions) in energy intensity between 1971 and 2015 occur due to improvements in energy efficiency while structural shift was found to be driving up energy intensity in recent time. At the country level, the decomposition results shows that the average (1971-2015) share of improvements in energy efficiency in the overall decline in energy intensity ranges from $32.1 \%$ (for Iceland) to $94.5 \%$ (for US) and more than $100 \%$ for Australia, Austria, Belgium, Chile, Denmark, Finland, France, Hungary, Italy, Korea, Norway, Poland, Sweden and Switzerland (as the share of structural shift index in the decline in energy intensity in these countries are negative). Only 4 countries, Israel, New Zealand, Portugal and Spain, were found to be having deteriorating energy efficiency indices. These results are generally similar to the findings of Oseni (2011) for 16 OECD countries.

In the second step, the econometric analysis highlights some important results. For OECD as a group, improvements in energy efficiency reduce $\mathrm{CO}_{2}$ emissions and with a higher reduction in the long run. Energy efficiency improvement presents the biggest contribution to driving down $\mathrm{CO}_{2}$ emissions, on average $1.731 \%$ per annum, so that despite the relatively strong positive contribution from income, the growth in $\mathrm{CO}_{2}$ emissions slows down considerably. The impacts of trade openness on the environment are mixed for the individual countries but they are found to be good for the environment at the group level. 
Cleaner energy substitution (i.e., renewable and nuclear energy share) contributes to driving down $\mathrm{CO}_{2}$ emissions but is not as important as energy efficiency improvement.

More importantly, the UCET, which captures the non-economic factors is downward slopping for the OECD countries as a group, indicating 'carbon mitigating' lifestyle, taste or/and attitude to the environment. This stems from the fact that 20 of the 30 countries we considered, showed downward trends in their various stochastic UECTs obtained from the time series model. The quantification of the contribution of the non-economic factors to the decrease in $\mathrm{CO}_{2}$ emissions using the estimated UCET shows a significant share, on average $0.315 \%$ per annum. In all, the time series results and the panel data results are generally comparable and excluding the 4 countries that are found to becoming more energy inefficient from the panel of OECD countries slightly improves the panel data results.

Several important policy implications emerged from this study. Improving energy efficiency remains a key option for mitigating $\mathrm{CO}_{2}$ emissions and conserving energy for future use. Although we found cleaner energy substitution not to be as effective as energy efficiency to mitigate $\mathrm{CO}_{2}$ emissions for our data set, in a balanced policy package, policy makers could combine improving energy efficiency with cleaner energy substitutes. Similarly, action on factors such, attitudes, lifestyles, behaviours, etc. are essential to protect the environment given the non-trivial contribution of these exogenous non-economic factors to changes in $\mathrm{CO}_{2}$ emissions. Effective policy action would entail stimulating behavioural and other non-economic changes for a positive environmental conservation, especially for countries that exhibit carbon-emitting attitudes, lifestyles, behaviours, etc. which are harmful to the environment.

\section{Acknowledgment}

This paper is part of Dr Tajudeen PhD thesis funded by the Petroleum Technology Development Fund in Nigeria and Economic Discipline Area, University of Manchester, UK - their support is highly appreciated. We are grateful for the comments received from the participants of the $38^{\text {th }}$ International Association of Energy Economics (IAEE) conference, 25-27 May, Antalya, Turkey, where the earlier version of this was presented. The comments of the anonymous referees are gratefully acknowledged. The usual disclaimer applies. 


\section{References}

Acaravci, A. and Ozturk, I., 2010. On the relationship between energy consumption, $\mathrm{CO}_{2}$ emissions and economic growth in Europe. Energy 35(12), 5412 - 5420.

Adetutu, M. O., Glass, A. J., Weyman-Jones, T. G., 2016. Economy-wide Estimates of Rebound Effects: Evidence from Panel Data. Energy J. 37(3), 251-269.

Adeyemi, O. I., Hunt, L. C., 2007. Modelling OECD industrial energy demand: Asymmetric price responses and energy-saving technical change. Energy Econ. 29, 693-709.

Adeyemi, O. I., Broadstock, D. C., Chitnis, M., Hunt, L. C., Judge, G., 2010. Asymmetric price responses and the underlying energy demand trend: Are they substitutes or complements? Evidence from modelling OECD aggregate energy demand. Energy Econ. 32(5), 1157-1164.

Amarawickrama, H. A., Hunt, L. C., 2008. Electricity demand in Sri Lanka: a time series analysis. Energy 33, 724-739.

Anderson, T. W., Hsiao, C., 1982. Formulation and estimation of dynamics models using panel data. J. Econ. 18(1), 47-82.

Ang, J. B., 2007. $\mathrm{CO}_{2}$ emissions, energy consumption, and output in France. Energy Policy 35(10), 4772- 4778 .

Ang, B.W., 2004. Decomposition analysis for policymaking in energy: which is the preferred method? Energy Policy 32(9), 1131-1139.

Antweiler, W., Copeland, B.R., Taylor, S.M., 2001. Is Free Trade Good for the Environment? Am. Econ. Rev. 91(4), 877-908.

Apergis, N., Payne, J.E., 2010. The emissions, energy consumption, and growth nexus: Evidence from the commonwealth of independent states. Energy Policy 38(1), 650 655.

Arellano, M., Bond, S., 1991. Some tests of specification for panel data: Monte Carlo evidence and an application to employment equations. Rev. Econ. Stud. 58(2), 277-297.

Arellano, M., Bover, O., 1995. Another look at the instrumental variable estimation or errorcomponents models. J. Econ. 68(1), 29-51.

Baltagi, B., 2008. Econometric analysis of panel data. John Wiley \& Sons. New York.

Blundell, R., Bond, S., 1998. Initial conditions and moment restrictions in dynamic panel data models. J. Econ. 87(1), 115-143.

Boyd, G.A., Roop, J.R., 2004. A Note on the Fisher Ideal Index Decomposition for Structural Change in Energy Intensity. Energy J. 25(1), 87-101.

Boyd, G. A., McDonald, J. F., Ross, M., Hanson, D., 1987. Separating the Changing Composition of U.S Manufacturing Production from Energy Efficiency Improvements: A Divisia Index Approach. Energy J. 8(2), 77-96.

Broadstock, D.C., Hunt, L.C., 2010. Quantifying the impact of exogenous non-economic factors on UK transport oil demand. Energy Policy 38, 1559-1565.

Chitnis, M., Hunt, L.C., 2012. What drives the change in UK household energy expenditure and associated $\mathrm{CO}_{2}$ emissions? Implication and forecast to 2020. Appl. Energy 94, 202214.

Choi, K-H., Ang, B., 2003. Decomposition of aggregate energy intensity changes in two measures: ratio and difference. Energy Econ. 25(6), 615-624. 
Diakoulaki, D., Mavrotas, G., Orkopoulos, D., Papayannakis, L., 2006. A bottom-up decomposition analysis of energy-related $\mathrm{CO}_{2}$ emissions in Greece. Energy, 31, 26382651.

Diewert, W.E, 2001. The Consumer Price Index and Index Number Theory: A Survey. Discussion paper, no. 0102, Vancouver, Department of Economic, University of British Columbia, 1-104.

Dinda, S., 2004. Environmental Kuznets curve hypothesis: A survey. Ecol. Econ. 49(4), 431455.

Driscoll, J., Kraay, A.C., 1998. Consistent covariance matrix estimation with spatially dependant data. Rev. Econ. Stat. 80: 549-560.

Expert Group on Energy Efficiency, 2007. Realizing the Potential of Energy Efficiency: Targets, Policies and Measures for G8 Countries. United Nation Foundation, Washington DC, 72pp.

Filippini, M., 2011. Short and long run time-of-use price elasticities in Swiss residential electricity demand. Energy policy, 39: 5811-5817.

Fisher, I., 1921. The Best Form of Index Number. Q. Pub. Am. Stat. Assoc. 17(133), 533-537.

Griffin, J. M., Schulman, C.T., 2005. Price Asymmetry in Energy Demand Models: A proxy for Energy-Saving Technical Change? Energy J. 26(2), 1-21.

Grossman, G. M., Krueger, A. B., 1991. Environmental impact of a North American free trade agreement. National Bureau of Economic Research Working Paper, No. 3194, NBER, Cambridge.

Harvey, A.C., 1989. Forecasting Structural Time Series Models and Kalman Filter. Cambridge University Press, Cambridge UK.

Harvey, A.C., Koopman, S. J., 1992. Diagnostic checking of unobserved components time series models. J. Bus. Econ. Stat. 10, 377-389.

Hatzigeorgiou, E., Polatidis, H., Haralambopoulos, D., 2008. $\mathrm{CO}_{2}$ emissions in Greece for 1990-1992: A decomposition analysis and comparison of results using the Arithmetic Mean Divisia Index and Logarithmic Mean Divisia Index techniques. Energy, 33, 492499.

Hatzigeorgiou, E., Polatidis, H., Haralambopoulos, D., 2011. $\mathrm{CO}_{2}$ emissions, GDP and Energy intensity: A multivariate cointegration and causality analysis for Greece, 19772007. Appl. Energy 88(4), 1377-1385.

Hoekstra, R.A, Van der Bergh. J.C.J.M., 2003. Comparing Structural and Index Decomposition Analysis. Energy Econ. 26, 39-64.

Hunt, L. C., Judge, G., Ninomiya, Y., 2003. Underlying trends and seasonality in UK energy demand: a sectoral analysis. Energy Econ. 25(1), 93-118.

Inglesi-Lotz, R., Pouris, A., 2012. Energy efficiency in South Africa: A decomposition exercise. Energy 42, 113-120.

International Energy Agency, 2015: World Energy Balances (Edition: 2015). UK Data Service. http://dx.doi.org/10.5257/iea/web/2015

Iwata, H., Okada, K., Samreth, S., 2010. Empirical study on the Environmental Kuznets Curve for $\mathrm{CO}_{2}$ in France: The role of nuclear energy. Energy Policy 38(8), 4057 - 4063.

Judson, R.A, Owen, A.L., 1999. Estimating dynamic panel data models: a guide for macroeconomists. Econ. Lett. 65, 9-15. 
Kiviet, J .F., 1995. On bias, inconsistency, and efficiency of various estimators in dynamic panel data models. J. Econ. 68, 53-78.

Koopman, S. J., Harvey, A. C., Doornik, J. A., Shephard, N., 2009. Structural Time Series Analyser, Modeller and Predictor: STAMP 8.2, Timberlake Consultants Press, London

Liu, N., Ang, B. W., 2007. Factors shaping aggregate energy intensity trend for industry: Energy intensity versus product mix. Energy Econ. 29(4), 609-635.

Martiskainen, M., 2008. Household energy consumption and behavioural change - the UK perspective. In: Geer Kan, T., Tukker, A., Vezzoli, C. and Ceschin, F. (Ed.), $2^{\text {nd }}$ Conference of the sustainable consumption research exchange (SCORE!) network: sustainable consumption and production: framework for action. Brussels, Belgium,73-90.

Metcalf, G.E., 2008. An empirical analysis of energy intensity and its determinants at the state level. Energy J. 29 (3), 1-26.

Moshiri, S., Duah, N., 2016. Changes in Energy Intensity in Canada. Energy J. 37(4), 315342.

Mulder, P., 2015. International specialization, sector structure and the evolution of manufacturing energy intensity in OECD countries. Energy J. 36(3),111-136.

Nickell, S., 1981. Biases in dynamic models with fixed effects. Econometrica 1417-1426.

Oseni, M.O., 2011. Analysis of energy intensity and its determinants in 16 OECD Countries. J. Energy Dev. 35 (1), 101-140.

Pao, H.T., Tsai, C.M., 2011. Modeling and forecasting the $\mathrm{CO}^{2}$ emissions, energy consumption and economic growth in Brazil. Energy, 36(5):2450 - 2458.

Pesaran, M.H., 2004. General Diagnostic Tests for Cross Section Dependence in Panels. CESifo Working Paper Series No. 1229; IZA Discussion Paper No. 1240. Available at SSRN: https://ssrn.com/abstract $=572504$

Roodman, D., 2009. How to do xtabond2: An introduction to difference and system GMM in Stata. Stata Journal, StataCorp LP, 9(1), 86-136.

Saboori, B., Sulaiman, J., 2013. $\mathrm{CO}_{2}$ emissions, energy consumption and economic growth in the association of Southeast Asian nations ASEAN countries: A cointegration approach. Energy 55(0), 813 - 822.

Sari, R., Soytas, U. , 2009. Are global warming and economic growth compatible? Evidence from five OPEC countries? Appl. Energy 86(10), 1887-1893.

Soytas, U., Sari, R. and Ewing, B. T. (2007). Energy consumption, Income, and carbon emissions in the United States. Ecol. Econ. 62, 482-482

Stern, D. I., 2004. The rise and fall of the environmental Kuznets curve. World Dev. 32(8), 1419-1439.

World Bank, 2016. World Development Indicators 2016. Washington, DC: World Bank. doi:10.1596/978-1-4648-0683-4

Zhao, X., Chunbo, M., Dongyue, H., 2010. Why did China's energy intensity increase during 1998-2006: Decomposition and policy analysis. Energy Policy, 38(3), 1379-1388. 


\section{Appendix}

Table A.1: Descriptive statistics of variables for energy intensity decomposition

\begin{tabular}{|c|c|c|c|c|c|c|c|c|c|c|}
\hline I. & \multirow{2}{*}{$\begin{array}{l}\text { Economic } \\
\text { activity }\end{array}$} & & \multicolumn{4}{|c|}{$\begin{array}{c}\text { Measure: } \\
\text { Constant } 2005 \text { prices, billion US\$ }\end{array}$} & \multicolumn{4}{|c|}{$\begin{array}{c}\text { Measure: } \\
\% \text { share of total GDP }\end{array}$} \\
\hline Sector: & & & Mean & SD & Min. & Max. & Mean & SD & Min. & Max. \\
\hline Mining & Value added & $Y_{1}$ & 40.74 & 84.51 & 0.10 & 645.40 & 5.20 & 4.74 & 0.91 & 29.28 \\
\hline Manufacturing & Value added & $Y_{2}$ & 140.66 & 269.78 & 0.66 & 1846.26 & 14.87 & 3.77 & 4.34 & 29.65 \\
\hline Construction & Value added & $Y_{3}$ & 57.64 & 106.72 & 0.63 & 654.10 & 6.53 & 2.14 & 2.99 & 16.10 \\
\hline Transport & Value added & $Y_{4}$ & 76.45 & 173.19 & 0.30 & 1573.16 & 7.82 & 1.94 & 3.00 & 14.56 \\
\hline Agriculture & Value added & $Y_{5}$ & 15.72 & 21.34 & 0.09 & 148.11 & 3.08 & 2.95 & 0.20 & 25.17 \\
\hline Commercial & Value added & $Y_{6}$ & 557.69 & 1282.87 & 2.07 & 9908.33 & 54.17 & 7.16 & 34.64 & 77.25 \\
\hline Residential & $\mathrm{HCE}$ & $Y_{7}$ & 553.56 & 1232.03 & 2.97 & 10343.50 & 56.47 & 7.35 & 34.03 & 86.02 \\
\hline Total & GDP & $Y$ & 922.52 & 1893.75 & 4.90 & 15083.40 & 100.0 & 0.00 & 100.0 & 100.0 \\
\hline II. & Energy & & \multicolumn{4}{|c|}{$\begin{array}{l}\text { Measure: } \\
\text { onne of oil equivalent }\end{array}$} & \multicolumn{4}{|c|}{ Measure: } \\
\hline Sector: & consumption & & Mean & SD & Min. & Max. & Mean & SD & Min. & Max. \\
\hline Mining & Energy use & $E_{1}$ & 14.56 & 34.40 & 0.03 & 224.22 & 11.49 & 4.51 & 1.57 & 28.52 \\
\hline Manufacturing & Energy use & $E_{2}$ & 33.58 & 69.51 & 0.20 & 449.06 & 30.47 & 8.30 & 12.37 & 68.88 \\
\hline Construction & Energy use & $E_{3}$ & 0.55 & 1.42 & 0.00 & 16.70 & 0.65 & 0.61 & 0.00 & 3.97 \\
\hline Transport & Energy use & $E_{4}$ & 32.58 & 93.02 & 0.10 & 633.71 & 23.71 & 7.68 & 7.02 & 58.25 \\
\hline Agriculture & Energy use & $E_{5}$ & 2.02 & 3.27 & 0.00 & 25.61 & 2.99 & 2.82 & 0.00 & 20.00 \\
\hline Commercial & Energy use & $E_{6}$ & 13.67 & 34.45 & 0.03 & 228.59 & 9.88 & 5.00 & 0.81 & 42.21 \\
\hline Residential & Energy use & $E_{7}$ & 20.96 & 43.71 & 0.15 & 277.66 & 20.82 & 7.42 & 4.18 & 52.75 \\
\hline Total & Energy use & $E$ & 117.92 & 275.68 & 0.87 & 1729.98 & 100.0 & 0.00 & 100.0 & 100.0 \\
\hline
\end{tabular}


Table A.2: Descriptive statistics for the drivers of changes in $\mathrm{CO}_{2}$ emissions, 1971-2015

\begin{tabular}{|c|c|c|c|c|c|c|c|c|c|c|c|c|}
\hline \multirow{2}{*}{$\begin{array}{l}\text { Variable: } \\
\text { Statistics: }\end{array}$} & \multicolumn{2}{|c|}{$\begin{array}{c}C O 2: \\
\text { co2 emissions } \\
\text { (tonne per capita) }\end{array}$} & \multicolumn{2}{|c|}{$\begin{array}{l}Y: \text { income (GDP } \\
\text { constant } 2005 \text { prices, } \\
\text { US\$ per capita) }\end{array}$} & \multicolumn{2}{|c|}{$\begin{array}{c}E F F: \\
\text { energy efficiency } \\
\text { index }(1971=1)\end{array}$} & \multicolumn{2}{|c|}{$\begin{array}{c}A C T: \\
\text { structural shift } \\
\text { index }(1971=1)\end{array}$} & \multicolumn{2}{|c|}{$\begin{array}{l}\text { TO: trade openness } \\
\text { (import + export } \\
\% \text { of GDP) }\end{array}$} & \multicolumn{2}{|c|}{$\begin{array}{l}\text { CES: cleaner energy } \\
\text { substitution (alternative } \\
\& \text { energy \% of total } \\
\text { energy use) }\end{array}$} \\
\hline & Mean & SD & Mean & SD & Mean & $\mathrm{SD}$ & Mean & SD & Mean & SD & Mean & SD \\
\hline Australia & 15.317 & 2.124 & 29859.760 & 7237.357 & 0.863 & 0.122 & 1.055 & 0.023 & 31.355 & 10.726 & 1.653 & 0.299 \\
\hline Austria & 7.438 & 0.719 & 30664.320 & 7607.216 & 0.793 & 0.097 & 1.055 & 0.022 & 69.470 & 21.916 & 10.991 & 1.520 \\
\hline Belgium & 10.825 & 1.450 & 29596.740 & 6689.389 & 0.717 & 0.132 & 1.054 & 0.020 & 112.263 & 31.866 & 16.651 & 7.791 \\
\hline Canada & 15.949 & 0.736 & 29442.830 & 5841.763 & 0.793 & 0.114 & 0.966 & 0.031 & 52.618 & 14.695 & 19.673 & 3.590 \\
\hline Chile & 2.701 & 0.961 & 5487.411 & 2374.319 & 0.897 & 0.118 & 1.036 & 0.021 & 51.212 & 18.005 & 7.243 & 1.524 \\
\hline Denmark & 10.259 & 1.718 & 39272.240 & 8280.936 & 0.668 & 0.177 & 1.041 & 0.040 & 67.663 & 23.181 & 1.559 & 2.101 \\
\hline Finland & 10.520 & 1.263 & 29350.310 & 8056.110 & 0.700 & 0.163 & 1.057 & 0.050 & 55.887 & 18.448 & 18.144 & 6.498 \\
\hline France & 6.366 & 1.240 & 28684.550 & 5756.529 & 0.647 & 0.170 & 1.078 & 0.047 & 39.075 & 13.422 & 33.166 & 16.187 \\
\hline Germany & 11.247 & 1.577 & 29500.330 & 6711.361 & 0.689 & 0.189 & 0.967 & 0.022 & 48.942 & 21.714 & 9.826 & 4.399 \\
\hline Greece & 6.317 & 1.707 & 17304.310 & 3297.284 & 0.985 & 0.068 & 1.309 & 0.149 & 36.264 & 15.674 & 2.121 & 1.193 \\
\hline Hungary & 6.032 & 1.135 & 8711.735 & 1963.642 & 0.774 & 0.163 & 1.041 & 0.031 & 77.460 & 62.185 & 9.908 & 6.937 \\
\hline Iceland & 7.378 & 0.838 & 43069.840 & 10901.750 & 0.959 & 0.080 & 0.913 & 0.063 & 62.479 & 5.590 & 71.060 & 12.158 \\
\hline Ireland & 8.490 & 1.319 & 30694.270 & 15136.680 & 0.672 & 0.201 & 0.933 & 0.029 & 104.887 & 51.608 & 1.210 & 1.027 \\
\hline Israel & 7.021 & 1.654 & 17248.220 & 4331.599 & 1.048 & 0.126 & 0.871 & 0.047 & 65.860 & 11.385 & 2.538 & 1.840 \\
\hline Italy & 6.550 & 0.710 & 25857.510 & 5315.414 & 0.705 & 0.120 & 1.096 & 0.042 & 38.065 & 11.395 & 5.365 & 1.185 \\
\hline Japan & 8.324 & 0.806 & 29962.100 & 7601.257 & 0.706 & 0.152 & 0.969 & 0.034 & 20.032 & 6.067 & 12.008 & 5.732 \\
\hline Korea & 6.568 & 3.334 & 11531.990 & 7507.749 & 0.717 & 0.159 & 1.225 & 0.129 & 49.202 & 24.740 & 10.950 & 6.391 \\
\hline Luxembourg & 26.131 & 8.561 & 55304.790 & 21317.650 & 0.587 & 0.241 & 0.960 & 0.078 & 247.543 & 59.819 & 0.294 & 0.149 \\
\hline Mexico & 3.168 & 0.587 & 6982.628 & 1032.792 & 0.874 & 0.122 & 1.229 & 0.112 & 33.162 & 19.907 & 4.868 & 1.531 \\
\hline Netherlands & 10.035 & 0.525 & 33275.710 & 7939.237 & 0.849 & 0.163 & 0.980 & 0.026 & 93.360 & 31.431 & 1.526 & 0.435 \\
\hline New Zealand & 6.516 & 0.949 & 23099.650 & 4084.766 & 1.111 & 0.098 & 1.055 & 0.048 & 45.002 & 11.911 & 27.150 & 3.377 \\
\hline Norway & 6.882 & 0.664 & 50328.140 & 14312.160 & 0.758 & 0.128 & 1.034 & 0.031 & 63.808 & 7.545 & 41.583 & 4.320 \\
\hline Poland & 9.189 & 1.491 & 6507.554 & 2289.039 & 0.677 & 0.275 & 1.097 & 0.116 & 44.893 & 26.406 & 0.243 & 0.227 \\
\hline Portugal & 3.782 & 1.382 & 14534.750 & 3914.853 & 1.149 & 0.116 & 1.050 & 0.044 & 47.384 & 18.306 & 6.586 & 2.584 \\
\hline Spain & 5.433 & 1.084 & 20071.410 & 5019.718 & 1.041 & 0.070 & 0.985 & 0.051 & 35.768 & 16.360 & 14.251 & 4.785 \\
\hline Sweden & 6.736 & 1.910 & 34238.260 & 7781.721 & 0.689 & 0.193 & 1.032 & 0.034 & 63.236 & 19.870 & 40.616 & 11.855 \\
\hline Switzerland & 5.824 & 0.445 & 48940.030 & 6609.728 & 0.883 & 0.106 & 1.007 & 0.016 & 80.040 & 23.149 & 35.665 & 6.456 \\
\hline Turkey & 2.527 & 0.869 & 5525.797 & 1699.889 & 0.981 & 0.081 & 1.110 & 0.055 & 28.850 & 14.767 & 4.681 & 1.887 \\
\hline UK & 9.157 & 1.234 & 31625.620 & 8071.191 & 0.671 & 0.182 & 0.967 & 0.032 & 39.702 & 11.034 & 8.402 & 2.688 \\
\hline US & 19.166 & 1.556 & 34659.460 & 8206.039 & 0.616 & 0.193 & 0.978 & 0.022 & 18.698 & 6.944 & 8.839 & 3.003 \\
\hline Panel I & 8.728 & 5.316 & 26711.080 & 15406.810 & 0.807 & 0.214 & 1.038 & 0.109 & 60.806 & 48.315 & 14.292 & 16.790 \\
\hline Panel II & 9.196 & 5.521 & 27937.620 & 16068.630 & 0.764 & 0.192 & 1.046 & 0.110 & 62.699 & 51.143 & 14.548 & 17.596 \\
\hline
\end{tabular}

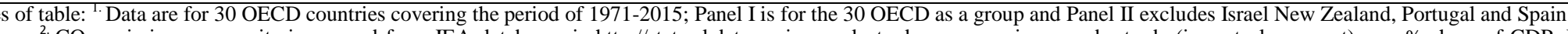

$\mathrm{CO}_{2}$ emissions per capita is sourced from IEA database via http://stats.ukdataservice.ac.uk; trade openness is proxy by trade (import plus export) as a \% share of GDP. Both total export, import and GDP data for estimating trade openness are sourced from UN statistical division database via http://data.un.org/; cleaner energy substitute is proxy by alternative indicators via http://databank worldbank.org. EFF and ACT are energy efficiency index and structural shifts index respectively derived from energy intensity decomposition 
Table A.3: Energy indices and energy (dis)saving at different time intervals for OECD country-level

\begin{tabular}{|c|c|c|c|c|c|c|c|c|c|c|c|c|c|c|c|c|c|}
\hline \multirow{3}{*}{ Cou } & \multirow{5}{*}{$\begin{array}{l}\text { Ind } \\
\text { ices }\end{array}$} & & $\begin{array}{l}\text { erag } \\
\text { (19) }\end{array}$ & $\begin{array}{l}\text { indi } \\
=1)\end{array}$ & & Char & es in & ndice & $(\%)$ & En & rgy sa & ngs (N & toe) & Con & ibuti & to sa & ngs \\
\hline & & 19 & 19 & 19 & 20 & 19 & 19 & 19 & 20 & 197 & 198 & 199 & 200 & 19 & 19 & 199 & 20 \\
\hline & & 71 & 83 & 94 & 05 & 71 & 83 & 94 & 05 & 1 & 3 & 4 & 5 & 71 & 83 & 4 & 05 \\
\hline & & 19 & 19 & 20 & 20 & 19 & 19 & 20 & 20 & 198 & 199 & 200 & 201 & 19 & 19 & 200 & 20 \\
\hline & & 82 & 93 & 04 & 15 & 82 & 93 & 04 & 15 & 2 & 3 & 4 & 5 & 82 & 93 & 4 & 15 \\
\hline & & 1. & 0 . & 0 . & 0 . & & - & - & - & - & & & & & & & \\
\hline $\begin{array}{l}\text { Aust } \\
\text { ralia }\end{array}$ & $E I$ & 07 & 95 & 86 & 73 & 0.7 & 1.2 & 1.1 & 1.1 & 3.5 & 2.57 & 12.8 & 33.8 & 1.0 & 1.0 & 1.0 & 1.0 \\
\hline & & 2 & 9 & 1 & 3 & 00 & 93 & 62 & 76 & 00 & 4 & 07 & 76 & 00 & 00 & 00 & 00 \\
\hline & $E F$ & 1. & 0 . & 0. & 0. & & - & - & - & - & & & & & & & \\
\hline & $\begin{array}{l}E F \\
F\end{array}$ & 02 & 90 & 80 & 71 & 0.2 & 1.4 & 0.9 & 0.8 & 1.1 & 6.46 & 18.5 & 37.2 & 0.4 & 3.4 & 1.5 & 1.1 \\
\hline & & 3 & 0 & 3 & 0 & 17 & 11 & 71 & 44 & 40 & 2 & 13 & 10 & 60 & 99 & 51 & 12 \\
\hline & & 1. & 1. & 1. & 1. & & & - & - & - & - & - & - & & - & - & - \\
\hline & ${ }_{T}^{A C}$ & 04 & 06 & 07 & 03 & 0.4 & 0.2 & 0.1 & 0.4 & 2.3 & 3.88 & 5.70 & 3.33 & 0.5 & 2.4 & 0.5 & 0.1 \\
\hline & & 8 & 6 & 2 & 3 & 72 & 20 & 54 & 23 & 60 & 8 & 6 & 4 & 40 & 99 & 51 & 12 \\
\hline & & 0. & 0 . & 0 . & 0 . & - & - & - & - & & & & & & & & \\
\hline $\begin{array}{l}\text { Aust } \\
\text { ria }\end{array}$ & $E I$ & 95 & 85 & 78 & 73 & 1.0 & 0.5 & 0.1 & 0.8 & 0.9 & 3.61 & 7.09 & 10.8 & 1.0 & 1.0 & 1.0 & 1.0 \\
\hline & & 5 & 7 & 5 & 2 & 82 & 98 & 71 & 83 & 90 & 4 & & 28 & 00 & 00 & 00 & 00 \\
\hline & $E F$ & 0. & 0 . & 0 . & 0. & - & - & - & - & & & & & & & & \\
\hline & $\begin{array}{l}E F \\
F\end{array}$ & 92 & 81 & 72 & 69 & 1.3 & 0.6 & 0.4 & 0.4 & 1.7 & 4.81 & 9.33 & 12.6 & 1.6 & 1.3 & 1.3 & 1.1 \\
\hline & & 3 & 4 & 8 & 3 & 93 & 82 & 47 & 77 & 37 & 6 & & 89 & 56 & 44 & 16 & 83 \\
\hline & & 1. & 1. & 1. & 1. & & & & - & - & & & - & - & - & - & - \\
\hline & ${ }_{T}^{A C}$ & 03 & 05 & 07 & 05 & 0.3 & 0.1 & 0.4 & 0.5 & 0.7 & 1.20 & 2.24 & 1.86 & 0.6 & 0.3 & 0.3 & 0.1 \\
\hline & & 6 & 3 & 9 & 6 & 68 & 45 & 17 & 33 & 47 & & 0 & 0 & 56 & 44 & 16 & 83 \\
\hline & & 0. & 0 . & 0 . & 0. & - & - & - & - & & & & & & & & \\
\hline Belg & $E I$ & 93 & 73 & 72 & 60 & 2.0 & 0.4 & 0.3 & 0.8 & 2.7 & 12.4 & 16.5 & 28.9 & 1.0 & 1.0 & 1.0 & 1.0 \\
\hline & & 7 & 4 & 5 & 5 & 86 & 79 & 73 & 81 & 40 & 68 & 46 & 18 & 00 & 00 & 00 & 00 \\
\hline & $F F$ & 0. & 0. & 0. & 0. & - & - & - & - & & & & & & & & \\
\hline & $\begin{array}{l}E F \\
F\end{array}$ & 90 & 68 & 67 & 58 & 2.4 & 0.4 & 0.3 & 0.7 & 4.1 & 15.1 & 19.9 & 31.2 & 1.5 & 1.2 & 1.2 & 1.0 \\
\hline & & 5 & 8 & 8 & 0 & 43 & 81 & 64 & 10 & 73 & 09 & 94 & 59 & 18 & 16 & 12 & 83 \\
\hline & & 1. & 1. & 1. & 1. & & & & & & - & - & - & - & - & - & - \\
\hline & $\underset{T}{A C}$ & 03 & 06 & 07 & 04 & 0.4 & 0.0 & 0.0 & 0.2 & 1.4 & 2.64 & 3.44 & 2.34 & 0.5 & 0.2 & 0.2 & 0.0 \\
\hline & $T$ & 7 & 8 & 0 & 2 & 89 & 41 & 19 & 29 & 33 & 2 & 8 & 1 & 18 & 16 & 12 & 83 \\
\hline & & 0. & 0 . & 0. & 0. & - & - & & & & & & & & & & \\
\hline can & $E I$ & 94 & 77 & 70 & 62 & 1.4 & 0.6 & 1.0 & 0.6 & 11. & 51.0 & 89.6 & 148. & 1.0 & 1.0 & 1.0 & 1.0 \\
\hline & & 5 & 6 & 9 & 3 & 64 & 15 & 31 & 75 & 013 & 85 & 95 & 897 & 00 & 00 & 00 & 00 \\
\hline & $E F$ & 0. & 0 . & 0. & 0. & - & - & - & - & & & & & - & & & \\
\hline & $F$ & 95 & 80 & 72 & 67 & 0.8 & 0.9 & 1.0 & 0.4 & 8.5 & 43.4 & 85.0 & 125. & 0.7 & 0.8 & 0.9 & 0.8 \\
\hline & & 5 & 6 & 2 & 2 & 94 & 92 & 16 & 09 & 46 & 55 & 19 & 117 & 01 & 46 & 49 & 42 \\
\hline & $A C$ & 0. & $\begin{array}{l}0 . \\
96\end{array}$ & $\begin{array}{r}0 . \\
98\end{array}$ & 92 & $0 . \overline{6}$ & 0.3 & $0 . \overline{0}$ & $0 . \overline{4}$ & 2.4 & 7.63 & 4.67 & 23.7 & 1.7 & 0.1 & 0.0 & 0.1 \\
\hline & $T$ & 8 & 2 & 2 & 7 & 32 & 88 & 62 & 41 & 67 & 0 & 6 & 81 & 01 & 54 & 51 & 58 \\
\hline & & 1. & 0 . & 0 . & 0. & - & & - & - & - & & & & & & & \\
\hline $\mathrm{e}^{-1111}$ & $E I$ & 02 & 99 & 93 & 75 & 0.2 & 0.3 & 0.2 & 2.2 & 0.1 & 0.10 & 1.44 & 8.60 & 1.0 & 1.0 & 1.0 & 1.0 \\
\hline e & & 1 & 6 & 4 & 6 & 61 & 72 & 95 & 13 & 16 & 4 & 4 & 9 & 00 & 00 & 00 & 00 \\
\hline & $E F$ & 1. & 0. & 0. & 0. & & - & $\overline{7}$ & - & & & & & & & & \\
\hline & $F$ & 00 & 97 & 88 & 72 & 0.5 & 0.1 & 0.7 & 1.9 & 0.0 & 0.38 & 2.66 & 9.85 & 0.8 & 0.2 & 2.2 & 1.1 \\
\hline & & 2 & 0 & 3 & 6 & 82 & 68 & 32 & 72 & 40 & 4 & 9 & 5 & 41 & 83 & 52 & 60 \\
\hline & $A C$ & 1. & 1. & 1. & 1. & & - & & - & - & - & - & - & & & - & - \\
\hline & $T$ & 01 & 02 & 05 & 04 & 0.3 & 0.2 & 0.5 & 0.1 & 0.1 & 0.28 & 1.22 & 1.24 & 0.1 & 0.7 & 1.2 & 0.1 \\
\hline & & 9 & 7 & 8 & 2 & 43 & 16 & 34 & 56 & 56 & 0 & 4 & 6 & 59 & 17 & 52 & 60 \\
\hline Den & & 0. & 0 . & 0. & 0. & - & - & - & - & & & & & & & & \\
\hline mar & $E I$ & 90 & 71 & 60 & 51 & 2.6 & 0.1 & 1.2 & 0.9 & 1.7 & 6.22 & 10.8 & 15.3 & 1.0 & 1.0 & 1.0 & 1.0 \\
\hline $\mathrm{k}$ & & 9 & 1 & 6 & 5 & 46 & 25 & 02 & 06 & 23 & 2 & 65 & 70 & 00 & 00 & 00 & 00 \\
\hline & & 0. & 0. & 0. & 0. & - & - & - & - & & & & & & & & \\
\hline & $\begin{array}{l}E F \\
F\end{array}$ & 91 & 69 & 56 & 48 & 2.4 & 0.5 & 1.3 & 0.7 & 1.6 & 6.62 & 12.5 & 16.9 & 0.9 & 1.0 & 1.1 & 1.1 \\
\hline & $F$ & 4 & 7 & 0 & 1 & 95 & 65 & 84 & 11 & 33 & 6 & 91 & 37 & 28 & 56 & 60 & 03 \\
\hline & & 0. & 1. & 1. & 1. & - & & & - & & & & -8 & & - & - & \\
\hline & $\begin{array}{l}A C \\
T\end{array}$ & 99 & 02 & 08 & 07 & 0.2 & 0.6 & 0.4 & 0.2 & 0.0 & 0.40 & 1.72 & 1.56 & 0.0 & 0.0 & 0.1 & 0.1 \\
\hline & & 5 & 2 & 3 & 0 & 09 & 44 & 86 & 82 & 90 & 4 & 6 & 7 & 72 & 56 & 60 & 03 \\
\hline & & 0. & 0 . & 0 . & 0. & - & - & - & - & & & & & & & & \\
\hline Finl & $E I$ & 91 & 75 & 68 & 56 & 1.8 & 0.0 & 1.5 & 0.7 & 2.0 & 7.37 & 12.4 & 21.5 & 1.0 & 1.0 & 1.0 & 1.0 \\
\hline and & & 8 & 2 & 3 & 0 & 78 & 08 & 91 & 01 & 59 & 5 & 90 & 84 & 00 & 00 & 00 & 00 \\
\hline & & 0. & 0 . & 0 . & 0 . & - & - & - & - & & & & & & & & \\
\hline & $\begin{array}{l}E F \\
F\end{array}$ & 91 & 73 & 62 & 50 & 1.8 & 0.4 & 1.7 & 0.5 & 2.0 & 7.92 & 15.6 & 25.3 & 0.9 & 1.0 & 1.2 & 1.1 \\
\hline & $F$ & 7 & 6 & 0 & 6 & 88 & 27 & 57 & 57 & 85 & 0 & 37 & 73 & 47 & 78 & 62 & 76 \\
\hline & & 1. & 1. & 1. & 1. & & & & - & - & - & - & - & & - & - & - \\
\hline & ${ }_{T}^{A C}$ & 00 & 02 & 10 & 10 & 0.0 & 0.5 & 0.5 & 0.1 & 0.0 & 0.54 & 3.14 & 3.79 & 0.0 & 0.0 & 0.2 & 0.1 \\
\hline & $T$ & 1 & 1 & 3 & 7 & 12 & 63 & 02 & 59 & 25 & 5 & 7 & 0 & 53 & 78 & 62 & 76 \\
\hline & & 0. & 0. & 0. & 0 . & - & - & - & - & & & & & & & & \\
\hline Fran & $E I$ & 89 & 70 & 62 & 51 & 2.3 & 0.5 & 0.7 & 1.1 & 20. & 65.2 & 104. & 161. & 1.0 & 1.0 & 1.0 & 1.0 \\
\hline ce & & 7 & 5 & 9 & 4 & 73 & 61 & 95 & 34 & 179 & 97 & 135 & 386 & 00 & 00 & 00 & 00 \\
\hline & & 0. & 0 . & 0 . & 0. & - & - & - & - & & & & & & & & \\
\hline & $\begin{array}{l}E F \\
F\end{array}$ & 87 & 67 & 56 & 45 & 2.6 & 0.6 & 1.0 & 1.0 & 24. & 74.8 & 127. & 191. & 1.2 & 1.1 & 1.2 & 1.1 \\
\hline & $F$ & 7 & 0 & 8 & 3 & 16 & 96 & 79 & 00 & 433 & 88 & 250 & 539 & 38 & 45 & 18 & 88 \\
\hline & & 1. & 1. & 1. & 1. & & & & & - & - & - & - & - & - & - & - \\
\hline & $T$ & 02 & 05 & 10 & 13 & 0.3 & 0.2 & 0.6 & 0.0 & 4.2 & 9.59 & 23.1 & 30.1 & 0.2 & 0.1 & 0.2 & 0.1 \\
\hline & & 4 & 3 & 8 & 3 & 41 & 54 & 85 & 17 & 55 & 1 & 15 & 54 & 38 & 45 & 18 & 88 \\
\hline
\end{tabular}




\begin{tabular}{|c|c|c|c|c|c|c|c|c|c|c|c|c|c|c|c|c|c|}
\hline Ger & & 0. & 0. & 0. & 0. & - & - & - & - & & & & & & & & \\
\hline man & $E I$ & 92 & 72 & 54 & 45 & 1.7 & 1.8 & 0.8 & 0.8 & 24. & 105. & 209. & 290. & 1.0 & 1.0 & 1.0 & 1.0 \\
\hline $\mathrm{y}$ & & 6 & 2 & 8 & 3 & 61 & 55 & 09 & 59 & 347 & 327 & 579 & 822 & 00 & 00 & 00 & 00 \\
\hline & $E F$ & 0. & 0. & 0 . & 0. & - & - & - & - & & & & & & & & \\
\hline & $\begin{array}{l}E F \\
E\end{array}$ & 93 & 75 & 58 & 46 & 1.4 & 1.7 & 1.0 & 0.9 & 21. & 92.2 & 188. & 281. & 0.9 & 0.8 & 0.8 & 0.9 \\
\hline & & 4 & 2 & 3 & 6 & 79 & 42 & 56 & 62 & 627 & 42 & 584 & 295 & 58 & 67 & 97 & 66 \\
\hline & & 0. & 0. & 0. & 0. & - & - & & & & & & & & & & \\
\hline & ${ }_{T}^{A C}$ & 99 & 95 & 94 & 97 & 0.3 & 0.2 & 0.3 & 0.1 & 2.7 & 13.0 & 20.9 & 9.52 & 0.0 & 0.1 & 0.1 & 0.0 \\
\hline & & 1 & 9 & 1 & 4 & 36 & 73 & 33 & 73 & 20 & 85 & 95 & 7 & 42 & 33 & 03 & 34 \\
\hline & & 1. & 1. & 1. & 1. & & & - & & - & - & - & - & & & & \\
\hline Gree & $E I$ & 08 & 32 & 43 & 31 & 1.3 & 2.4 & 0.9 & 0.2 & 0.8 & 3.55 & 5.92 & 5.00 & 1.0 & 1.0 & 1.0 & 1.0 \\
\hline & & 5 & 7 & 3 & 2 & 73 & 95 & 00 & 92 & 84 & 7 & 4 & 5 & 00 & 00 & 00 & 00 \\
\hline & & 0. & 1. & 1. & 0. & - & & - & & & - & - & & - & & & - \\
\hline & $E F$ & 99 & 02 & 02 & 89 & 0.4 & 0.9 & 1.4 & 0.4 & 0.1 & 0.32 & 0.29 & 2.01 & 0.0 & 0.0 & 0.0 & 0.4 \\
\hline & & 0 & 4 & 5 & 9 & 50 & 58 & 22 & 84 & 38 & 0 & 0 & 0 & 38 & 42 & 49 & 08 \\
\hline & & 1. & 1. & 1. & 1. & & & & - & - & - & - & - & & & & \\
\hline & $A C$ & 09 & 29 & 40 & 46 & 1.9 & 1.2 & 1.1 & 0.4 & 1.0 & 3.23 & 5.63 & 7.01 & 1.0 & 0.9 & 0.9 & 1.4 \\
\hline & & 8 & 5 & 0 & 0 & 18 & 64 & 33 & 44 & 22 & 7 & 4 & & 38 & 58 & 51 & 08 \\
\hline & & 0. & 0. & 0. & 0. & - & - & - & - & & & & & & & & \\
\hline & $E I$ & 96 & 88 & 74 & 59 & 0.7 & 0.5 & 1.9 & 0.7 & 0.8 & 2.79 & 6.91 & 13.9 & 1.0 & 1.0 & 1.0 & 1.0 \\
\hline gary & & 3 & 9 & 7 & 3 & 80 & 31 & 23 & 68 & 77 & 5 & 9 & 54 & 00 & 00 & 00 & 00 \\
\hline & & 0. & 0. & 0. & 0 . & - & - & - & - & & & 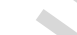 & & & & & \\
\hline & $\begin{array}{l}E F \\
F\end{array}$ & 95 & 86 & 70 & 55 & 1.0 & 0.4 & 2.1 & 0.6 & 1.0 & 3.45 & 8.33 & 15.7 & 1.1 & 1.2 & 1.2 & 1.1 \\
\hline & & 6 & 5 & 4 & 5 & 83 & 48 & 54 & 32 & 98 & 7 & 9 & 14 & 69 & 55 & 05 & 28 \\
\hline & & 1. & 1. & 1. & 1. & & - & & - & - & - & - & - & - & - & - & - \\
\hline & AC & 00 & 02 & 06 & 06 & 0.3 & 0.0 & 0.4 & 0.1 & 0.2 & 0.66 & 1.42 & 1.76 & 0.1 & 0.2 & 0.2 & 0.1 \\
\hline & & 9 & 8 & 3 & 8 & 44 & 80 & 93 & 59 & 21 & 2 & 0 & 0 & 69 & 55 & 05 & 28 \\
\hline Icela & & 0. & 0. & 0. & 0. & - & - & - & & & & & & & & & \\
\hline nd & $E I$ & 99 & 89 & 78 & 80 & 0.3 & 1.1 & 0.8 & 1.1 & 0.0 & 0.19 & 0.48 & 0.61 & 1.0 & 1.0 & 1.0 & 1.0 \\
\hline & & 9 & 6 & 7 & 9 & 43 & 87 & 86 & 72 & 06 & & 9 & 6 & 00 & 00 & 00 & 00 \\
\hline & $E F$ & 1. & 0. & 0. & 0. & & - & - & & & & & & & & & - \\
\hline & $F$ & 01 & 95 & 88 & 97 & 0.0 & 0.8 & 0.5 & 1.1 & 0.0 & 0.09 & 0.25 & 0.05 & 0.3 & 2.5 & 0.5 & 0.0 \\
\hline & $\Gamma$ & 7 & 2 & 1 & 9 & 56 & 53 & 11 & 89 & & 0 & 9 & 9 & 87 & 61 & 31 & 07 \\
\hline & $A C$ & 0. & 0. & 0. & 0. & - & - & - & & & & & & & - & & \\
\hline & $T$ & 98 & 94 & 89 & 82 & 0.3 & 0.4 & 0.4 & 0.1 & 0.0 & 0.09 & 0.23 & 0.55 & 0.6 & 1.5 & 0.4 & 1.0 \\
\hline & & 2 & 1 & 4 & 7 & 96 & 07 & 90 & 55 & 26 & 9 & 0 & 7 & 13 & 61 & 69 & 07 \\
\hline Irela & & 0. & 0. & 0. & 0. & - & - & - & & & & & & & & & \\
\hline nd & $E I$ & 87 & 72 & 52 & 37 & 2.0 & 1.0 & 2.0 & 1.4 & 1.0 & 2.79 & 10.0 & 19.7 & 1.0 & 1.0 & 1.0 & 1.0 \\
\hline & & 2 & 8 & 1 & 8 & 15 & 93 & 84 & 76 & 03 & 2 & 39 & 29 & 00 & 00 & 00 & 00 \\
\hline & $F F$ & 0. & 0. & 0. & 0. & - & - & - & & & & & & & & & \\
\hline & $F$ & 90 & 78 & 56 & 41 & 1.2 & 1.4 & 1.9 & 1.8 & 0.7 & 2.20 & 8.85 & 17.8 & 0.7 & 0.7 & 0.8 & 0.9 \\
\hline & $\Gamma$ & 6 & 1 & 2 & 6 & 83 & 16 & 55 & 38 & 17 & 3 & 7 & 37 & 45 & 69 & 82 & 01 \\
\hline & & 0. & 0. & 0. & 0. & - & & - & & & & & & & & & \\
\hline & $T$ & 96 & 93 & 92 & 91 & 0.8 & 0.2 & 0.5 & 0.4 & 0.2 & 0.58 & 1.18 & 1.89 & 0.2 & 0.2 & 0.1 & 0.0 \\
\hline & & 1 & 3 & 6 & 0 & 53 & 70 & 21 & 86 & 86 & 9 & 1 & 2 & 55 & 31 & 18 & 99 \\
\hline Israe & $F I$ & 0. & 0. & 0. & 0. & & & $=$ & - & 0 & 0 & $0=2$ & 11 & & & & \\
\hline & & 91 & 91 & 90 & 19 & 0.9 & 0.9 & 0.5 & 2.3 & 0.4 & 0.19 & 0.53 & 4.11 & 1.0 & 1.0 & 1.0 & 1.0 \\
\hline & & 1 & 1 & 1 & $0^{1}$ & & 10 & 49 & & 49 & $J$ & 2 & 0 & 00 & & 00 & 00 \\
\hline & $E F$ & 00 & 13 & 15 & 89 & 0.1 & 2.1 & $1 \overline{3}$ & 29 & 00 & 0.94 & $17 \overline{3}$ & 2.01 & 00 & 56 & 11 & 04 \\
\hline & $F$ & 9 & 1 & 9 & 5 & 56 & 38 & 80 & 32 & 50 & 5 & 6 & 4 & 99 & 14 & 955 & 30 \\
\hline & $A C$ & 0. & 0. & 0 . & 0. & & $\overline{7}$ & & & & & & & & & & \\
\hline & $T$ & 90 & 86 & 83 & 88 & 1.1 & 0.7 & 0.5 & 0.1 & 0.4 & 1.14 & 2.26 & 2.10 & 1.0 & 6.6 & 12. & 0.5 \\
\hline & & 0 & 0 & 0 & $0^{3}$ & 25 & 21 & 00 & 03 & 99 & 0 & 1 & 2 & 99 & 14 & 955 & 10 \\
\hline Italy & $E I$ & 91 & 74 & 71 & 68 & 1.9 & 0.4 & 0.1 & 0.6 & 11. & 40.1 & 55.6 & 64.5 & 1.0 & 1.0 & 1.0 & 1.0 \\
\hline & & 6 & 7 & 2 & 6 & 99 & 00 & 25 & 94 & 822 & 27 & 14 & 11 & 00 & 00 & 00 & 00 \\
\hline & & 0. & 0 & 0. & 0 . & - & - & - & - & & & & & & & & \\
\hline & $\begin{array}{l}E F \\
F\end{array}$ & 87 & 69 & 62 & 60 & 2.3 & 0.5 & 0.3 & 0.5 & 17. & 50.6 & 76.6 & 85.3 & 0.8 & 1.2 & 1.3 & 1.3 \\
\hline & $F$ & 8 & 3 & 7 & 7 & 89 & 64 & 70 & 06 & 326 & 76 & 14 & 94 & 93 & 58 & 77 & 27 \\
\hline & $A C$ & 1. & 1. & 1. & 1. & & & & & & & - & & & - & & \\
\hline & $T$ & 04 & 07 & 13 & 12 & 0.5 & 0.2 & 0.4 & 0.2 & 5.5 & 10.5 & 21.0 & 20.8 & 0.1 & 0.2 & 0.3 & 0.3 \\
\hline & & 5 & 9 & 7 & 9 & 29 & 92 & 39 & 02 & 04 & 49 & 00 & 83 & 07 & 58 & 77 & 27 \\
\hline
\end{tabular}

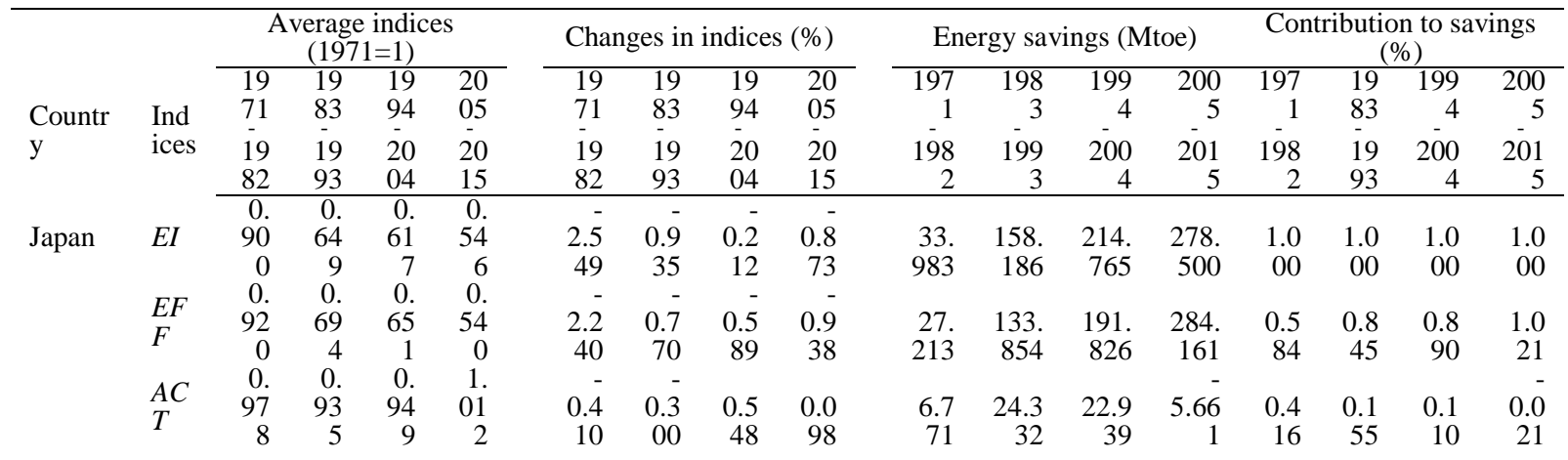


$\begin{array}{lrrrr} & & 1 . & 0 . & 0 . \\ \text { Korea } & E I & 00 & 85 & 87\end{array}$ $\begin{array}{llrrrr} & & 0 & 5 & 1 & 0 . \\ & E F & 0 . & 0 . & 0 . & 0 \\ & F & 4 & 74 & 69 & 49 \\ & & 4 & 6 & 3 & \\ & A C & 09 & 1 . & 1 . & \\ & T & 6 & 6 & 26 & 41 \\ & & 0 . & 0 . & 0 . & 0 \\ \text { Luxem } & E I & 91 & 57 & 40 & 3 \\ \text { bourg } & & 2 & 9 & 6 & \\ & E F & 0 . & 0 . & 0 . & 0 \\ & F & 94 & 60 & 38 & 38 \\ & 4 & 0 & 9 & \\ & A C & 0 . & 0 . & 1 . & 0 \\ & 96 & 96 & 04 & 86 \\ & T & 4 & 7 & 6 & \\ & & 1 . & 1 . & 1 . & 0\end{array}$

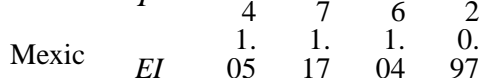

$\begin{array}{lrrrrr}\text { o } & E I & 05 & 17 & 04 & 97 \\ & & 0 & 6 & 8 & 7\end{array}$

$\begin{array}{rrrrr} & 0 . & 0 . & 8 & 0 \\ F & 96 & 99 & 81 & 71\end{array}$

$\begin{array}{rrrrr}F & 96 & 99 & 81 & 71\end{array}$

$\begin{array}{rrrrr}A C & 1 . & 1 . & 1 . & 1 .\end{array}$

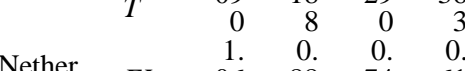

$\begin{array}{lrrrrr}\text { lands } & E I & 06 & 88 & 74 & 61 \\ & & 9 & 7 & 6 & 8\end{array}$

$\begin{array}{lrrrr}E F & 1 . & 0 . & 0 . & 0 \\ F & 05 & 90 & 76 & 65\end{array}$

$\begin{array}{rrrrr} & 6 & 4 & 4 & 1 \\ & 1 . & 0 . & 0 . & 0 . \\ T & 01 & 98 & 97 & 94\end{array}$

$\begin{array}{lrrrr} & 2 & 1 & 6 & 9 \\ \text { New } & 1 . & 1 . & 1 . & 1 .\end{array}$

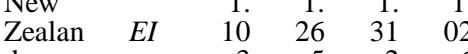

$\begin{array}{lrrrr} & 3 & 5 & 2 & 6 \\ E F & 1 . & 1 . & 1 . & 0 . \\ F & 09 & 17 & 18 & 98\end{array}$

$\begin{array}{rrrrr}F & 7 & 17 & 18 & 98 \\ & 7 & 1 & 9 & 9\end{array}$

$\begin{array}{lrrrr}A C & 1 . & 1 . & 1 . & 1 . \\ T & 00 & 07 & 10 & 03 \\ & 5 & 9 & 3 & 8\end{array}$

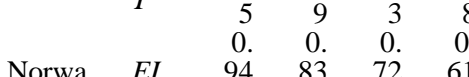

$\begin{array}{lrrrrr}\text { y } & E I & 94 & 83 & 72 & 61 \\ & & 3 & 8 & 2 & 6\end{array}$

$\begin{array}{lrrrr} & 0 . & 0 . & 0 . & 0 \\ F & 92 & 81 & 67 & 60\end{array}$

$\begin{array}{lrrrr}A C & 1 . & 1 . & 1 . & 1 . \\ T & 02 & 03 & 06 & 01 \\ & 5 & 5 & 3 & 4\end{array}$

Poland

$\begin{array}{rrrrr} & 0 . & 0 . & 0 . & 0 . \\ \text { EI } & 95 & 88 & 60 & 40\end{array}$

$\begin{array}{rrrr}5 & 9 & 2 & 0\end{array}$

$\begin{array}{lrrrr}E F & 0 . & 0 . & 0 . & 0 . \\ F & 95 & 89 & 49 & 34\end{array}$

$\begin{array}{llll}6 & 3 & 3 & 3\end{array}$

$\begin{array}{lrrrr}A C & 0 . & 1 . & 1 . & 1 . \\ T & 99 & 01 & 21 & 16\end{array}$

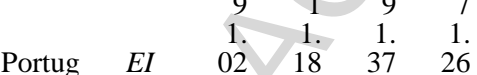

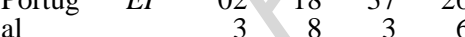

$\begin{array}{lrrrr}E F & 1 . & 1 . & 1 . & 1 . \\ F & 01 & 16 & 29 & 14\end{array}$

$\begin{array}{rrrrr}A C & 1 . & 1 . & 1 . & 1 . \\ T & 00 & 02 & 06 & 10\end{array}$

$\begin{array}{rrrrr}T & 6 & 4 & 5 & 9\end{array}$

Spain $\begin{array}{lllll}E I & 03 & 01 & 08 & 96\end{array}$

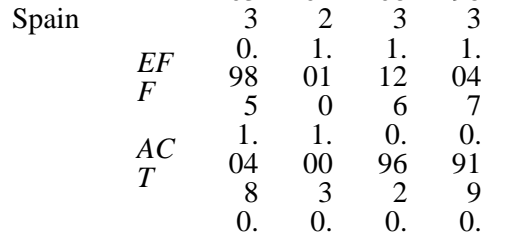

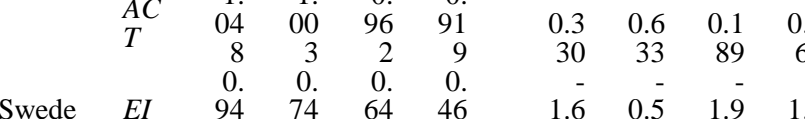

$\begin{array}{lrrrrrrrrr}\text { Swede } & E I & 94 & 74 & 64 & 46 & 1 . \overline{6} & 0 . \overline{5} & 1 . \overline{9} & 1.2 \\ \mathrm{n} & & 3 & 5 & 9 & 5 & 79 & 16 & 73 & 02\end{array}$ $\begin{array}{rrrrrrrrrrrr}0 . \overline{5} & 0.1 & 1 . \overline{6} & 0 . \overline{8} & 0.0 & 9.54 & 20.6 & 72.8 & 1.0 & 1.0 & 1.0 & 1.0\end{array}$ $\begin{array}{rrrrrrrrrrrr}- & - & 28 & 81 & & 0.0 & 9.54 & 20.6 & 72.8 & 1.0 & 1.0 & 1.0\end{array}$ $\begin{array}{rrrrrrrrrrrr}1.4 & 0.3 & 2.0 & 0.9 & 2.7 & 18.6 & 53.5 & 142 . & 10 . & 2.1 & 2.8 & 1.9 \\ 98 & 53 & 25 & 69 & 57 & 85 & 31 & 806 & 409 & 22 & 83 & 65\end{array}$ $\begin{array}{lllllllllllll}1.0 & 0.6 & 1.3 & 0.9 & 2 . \overline{7} & 9.1 \overline{4} & 32 . \overline{8} & 70 . \overline{0} & 9 . \overline{4} & 1 . \overline{1} & 1 . \overline{8} & 0 . \overline{9}\end{array}$ $\begin{array}{llllllllllll}78 & 72 & 71 & 02 & 93 & 0 & 85 & 03 & 09 & 22 & 83 & 65\end{array}$

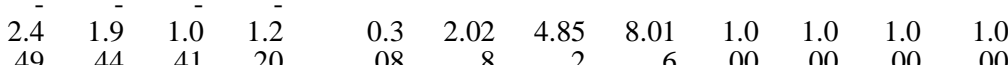
$\begin{array}{rrrrrrrrrrrr}1 . \overline{9} & 2 . \overline{3} & 1 . \overline{3} & 0 . \overline{5} & 0.1 & 1.91 & 5.09 & 6.91 & 0.3 & 0.9 & 1.0 & 0.8\end{array}$

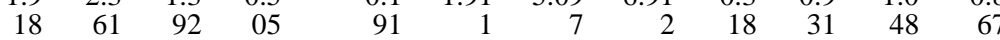
$\begin{array}{llllllllllll}0 . \overline{6} & 0.4 & 0.8 & 2 . \overline{1} & 0.1 & 0.11 & 0.24 & 1.10 & 0.6 & 0.0 & 0.0 & 0.1\end{array}$ $\begin{array}{llllllllllll}1.3 & 0 . \overline{2} & 0 . \overline{8} & 1 . \overline{2} & 3 . \overline{5} & 14 . \overline{0} & 4.6 \overline{0} & 3.82 & 1.0 & 1.0 & 1.0 & 1.0\end{array}$ $\begin{array}{llllllllllll}33 & 27 & 98 & 95 & 87 & 06 & 1 & 2 & 00 & 00 & 00 & 00\end{array}$ $\begin{array}{llllllllllll}0 . \overline{0} & 0 . \overline{5} & 1 . \overline{5} & 1 . \overline{0} & 2.5 & 1.15 & 24.0 & 48.5 & 4 . \overline{8} & 0 . \overline{1} & 9 . \overline{1} & 6 . \overline{2}\end{array}$ $\begin{array}{llllllllllll}65 & 92 & 47 & 57 & 51 & 3 & 48 & 25 & 08 & 19 & 66 & 07\end{array}$ $\begin{array}{rrrrrrrrrrrr}1.4 & 0.4 & 1.2 & 0.2 & 6.1 & 15.1 & 28 . \overline{6} & 44 . \overline{7} & 5.8 & 1.1 & 10 . & 7.2 \\ 08 & 92 & 83 & 07 & 37 & 59 & 50 & 03 & 08 & 19 & 166 & 07\end{array}$ \begin{tabular}{llllllllllll}
\hline$\overline{7}$ & $0 . \overline{5}$ & $1 . \overline{3}$ & $1 . \overline{3}$ & $3 . \overline{7}$ & 7.45 & 23.2 & 41.6 & 1.0 & 1.0 & 1.0 & 1.0
\end{tabular}

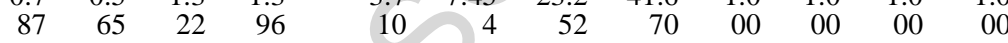
$\begin{array}{lllllllllllll}0 . \overline{6} & 0 . \overline{4} & 1 . \overline{5} & 1 . \overline{0} & 3.0 & 6.23 & 21.3 & 37.1 & 0.8 & 0.7 & 0.9 & 0.8\end{array}$ $\begin{array}{rrrrrrrrrrrr}- & - & & - & 5 & & & & & & & \\ 0.1 & 0.1 & 0.2 & 0.5 & 0.6 & 1.22 & 1.86 & 4.49 & 0.1 & 0.2 & 0.0 & 0.1\end{array}$

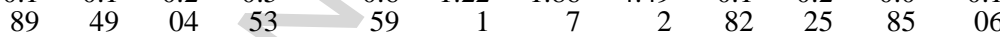

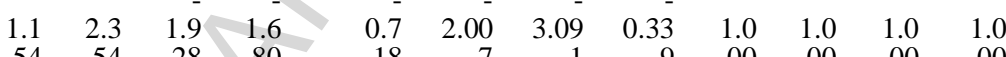

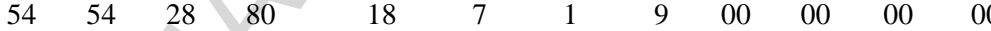
$\begin{array}{llllllllllll}0.8 & 1.4 & 1 . \overline{6} & 0 . \overline{6} & 0 . \overline{6} & 1.3 \overline{5} & 1.9 \overline{6} & 0.15 & 1.2 & 0.6 & 0.6 & 23 .\end{array}$ $\begin{array}{llllllllllll}65 & 14 & 30 & 62 & 76 & 6 & 2 & 1 & 40 & 51 & 21 & 411\end{array}$ $\begin{array}{rrrrrrrrrrrr}0.2 & 0.7 & 0.1 & 0 . \overline{9} & 0 . \overline{0} & 0.6 \overline{5} & 1.12 & 0.4 \overline{9} & 0 . \overline{2} & 0.3 & 0.3 & 24 . \\ 64 & 18 & 14 & 56 & 42 & 0 & 9 & 0 & 40 & 49 & 79 & 411\end{array}$ $\begin{array}{rrrrrrrrrrrr}1.1 & 0.3 & 1.5 & 0.6 & 1.1 & 4.03 & 9.84 & 16.6 & 1.0 & 1.0 & 1.0 & 1.0\end{array}$ $\begin{array}{rrrrrrrrrrrr}\overline{1} & 0 . \overline{8} & 1 . \overline{0} & 0 . \overline{5} & 1.5 & 4.82 & 11.6 & 17.1 & 1.4 & 1.1 & 1.2 & 1.0\end{array}$

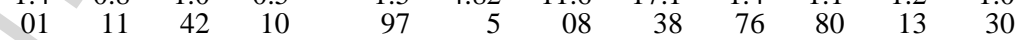
$\begin{array}{rrrrrrrrrrrr}0.2 & 0.5 & 0 . \overline{5} & 0 . \overline{2} & 0 . \overline{4} & 0.7 \overline{9} & 1.7 \overline{6} & 0.4 \overline{8} & 0 . \overline{4} & 0 . \overline{1} & 0 . \overline{2} & 0 . \overline{0} \\ \overline{78} & 92 & 84 & 00 & 70 & 1 & 1 & 7 & 76 & 80 & 13 & 30\end{array}$ $\begin{array}{llllllllllll}0.3 & 1.8 & 3 . \overline{2} & 1 . \overline{2} & 4.3 & 9.95 & 49.4 & 112 . & 1.0 & 1.0 & 1.0 & 1.0\end{array}$ $\begin{array}{llllllllllll}21 & 29 & 27 & 81 & 68 & 2 & 68 & 841 & 00 & 00 & 00 & 00\end{array}$ $\begin{array}{rrrrrrrrrrrr}0.4 & 3 . \overline{3} & 2 . \overline{5} & 0 . \overline{8} & 4.3 & 10.2 & 67.7 & 131 . & 1.0 & 0.9 & 1.4 & 1.1\end{array}$ $\begin{array}{rrrrrrrrrrrr}0 . \overline{1} & 2.2 & 0 . \overline{1} & 0 . \overline{6} & 0.0 & 0.3 \overline{1} & 18 . \overline{3} & 18 . \overline{6} & 0 . \overline{0} & 0.0 & 0 . \overline{4} & 0.1\end{array}$

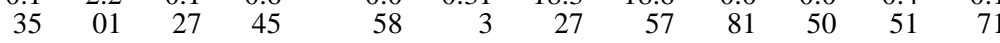
$\begin{array}{llllllllllll}0.9 & 1.8 & 0.9 & 2 . \overline{0} & 0 . \overline{2} & 1.9 \overline{7} & 5.25 & 4.1 \overline{7} & 1.0 & 1.0 & 1.0 & 1.0\end{array}$ $\begin{array}{llllllllllll}03 & 01 & 88 & 88 & 10 & 9 & 1 & 9 & 00 & 00 & 00 & 00\end{array}$ $\begin{array}{rrrrrrrrrrrr}0.9 & 1.3 & 0.2 & 2 . \overline{1} & 0 . \overline{1} & 1.7 \overline{1} & 4.20 & 2.3 \overline{6} & 1.2 & 0.8 & 0.8 & 0.5\end{array}$ $\begin{array}{rrrrrrrrrrrr}0 . \overline{0} & 0.3 & 0.5 & 0.2 & 0 . \overline{0} & 0.26 & 1.04 & 1.8 \overline{1} & 0 . \overline{2} & 0.1 & 0.1 & 0.4\end{array}$ $\begin{array}{llllllllllll}0.0 & 0.2 & 0.6 & 2 . & - & - & - & - & - & & & \\ 67 & 02 & 93 & 53 & 1.7 & 0.83 & 6.90 & 3.86 & 1.0 & 1.0 & 1.0 & 1.0\end{array}$ $\begin{array}{rrrrrrrrrrrr}0.0 & 0.2 & 0.6 & 2.1 & 1.7 & 0.83 & 6.90 & 3.86 & 1.0 & 1.0 & 1.0 & 1.0 \\ 67 & 02 & 93 & 53 & 17 & 7 & 8 & 2 & 00 & 00 & 00 & 00\end{array}$ $\begin{array}{llllllllllll}0 . \overline{2} & 0.8 & 0.9 & 2 . \overline{1} & 0.7 & 0.80 & 10 . \overline{2} & 4.8 \overline{1} & 2 . \overline{3} & 0 . \overline{4} & 1.4 & 0.2\end{array}$

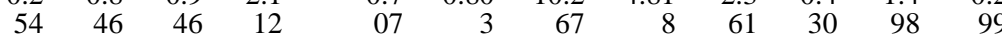
$\begin{array}{llllllllllll}0.3 & 0 . \overline{6} & 0 . \overline{1} & 0 . \overline{1} & 2 . \overline{4} & 0.0 \overline{3} & 3.35 & 8.68 & 3.3 & 1.4 & 0 . \overline{4} & 0.7\end{array}$

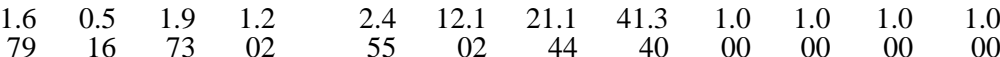




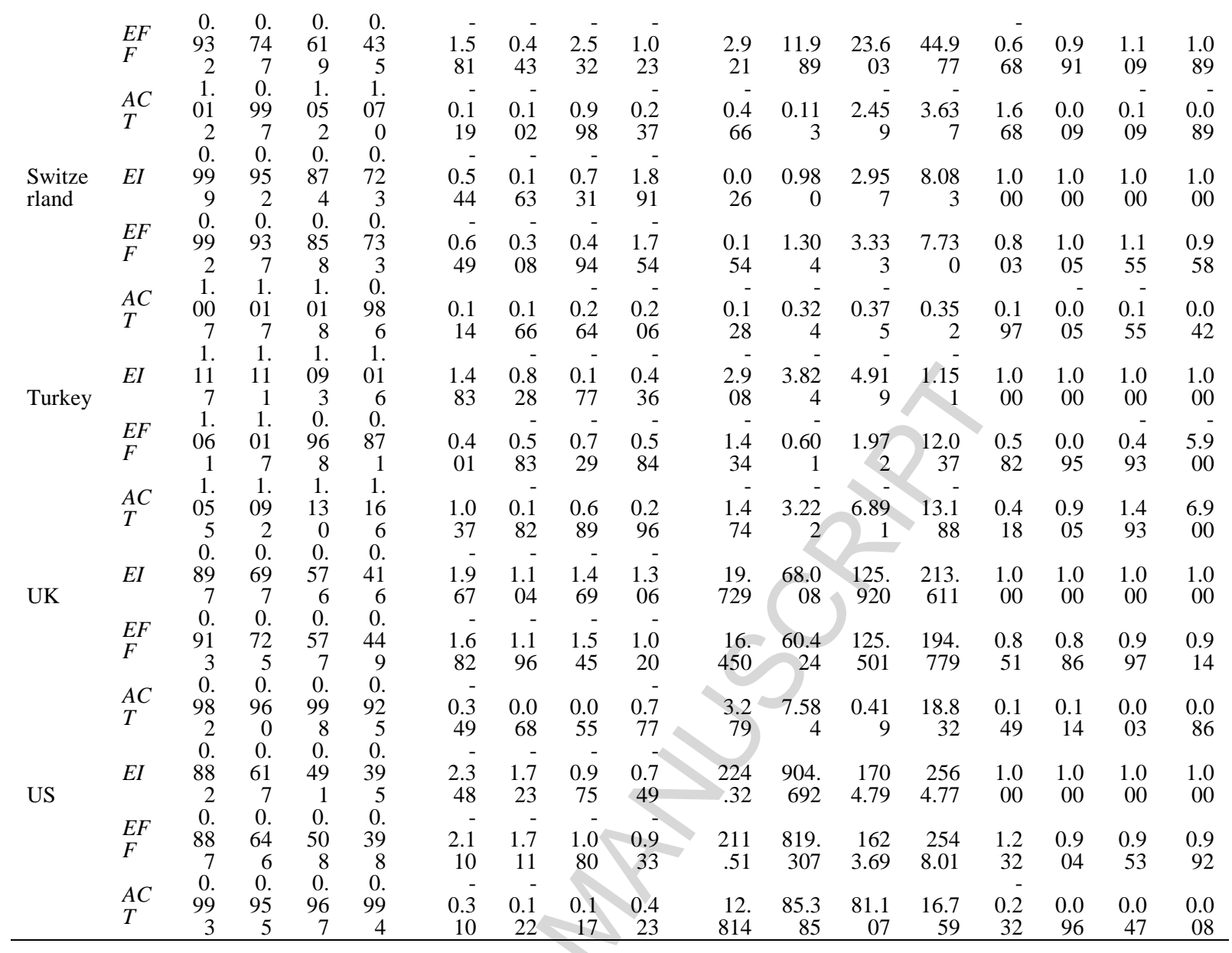




\section{Highlights}

-We use index decomposition analysis to derive the true energy efficiency level

-We use econometric models to examine the impact of energy efficiency on $\mathrm{CO}_{2}$ emissions

- We account for both economic and noneconomic factors such as lifestyle and behaviour

- Energy efficiency makes a relative bigger contribution to driving down $\mathrm{CO}_{2}$ emissions

- Noneconomic factors also exert a non-trivial influence on $\mathrm{CO}_{2}$ emissions 